\title{
Winter mixed-layer development in the central Irminger Sea: The effect of strong, intermittent wind events
}

\author{
by \\ Kjetil Văge \\ B.S. Physics (2003) \\ University of New Brunswick, Canada \\ Submitted in partial fulfillment of the requirements for the degree of \\ MASTER OF SCIENCE \\ at the \\ MASSACHUSETTS INSTITUTE OF TECHNOLOGY \\ and the \\ WOODS HOLE OCEANOGRAPHIC INSTITUTION
}

September 2006

(C) Kjetil Våge, 2006. All rights reserved.

The author hereby grants to MIT and WHOI permission to reproduce and distribute publicly paper and electronic copies of this thesis document in whole or in part.

Author

MIT/WHOI Joint Program in Physical Oceanography

August 11, 2006

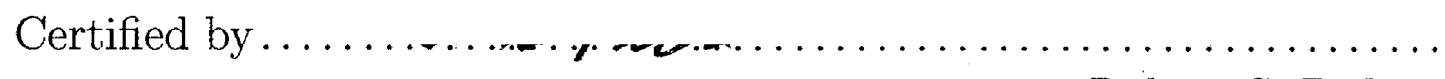

Robert S. Pickart

Senior Scientist, Woods Hole Oceanographic Institution

Thesis Supervisor

Accepted by

Joseph Pedlosky

Chairman, Joint Committee for Physical Oceanography 


\title{
Winter mixed-layer development in the central Irminger Sea: \\ The effect of strong, intermittent wind events
}

\author{
by \\ Kjetil Våge \\ Submitted to the Massachusetts Institute of Technology \\ and the Woods Hole Oceanographic Institution \\ in partial fulfillment of the requirements for the degree of \\ Master of Science
}

\begin{abstract}
The impact of the Greenland tip jet on the wintertime mixed-layer of the southwest Irminger Sea is investigated using in-situ moored profiler data and a variety of atmospheric data sets. The mixed-layer was observed to reach $400 \mathrm{~m}$ in the spring of 2003, and $300 \mathrm{~m}$ in the spring of 2004. Both of these winters were mild and characterized by a low North Atlantic Oscillation (NAO) index. All of the storms that were advected through the region were tracked, and the tip jet events that occurred throughout the two winters were identified. Composite images of the tip jets elucidated the conditions during which tip jets were likely to take place, which led to an objective method of determining tip jet occurrences by taking into account the large-scale pressure gradients. Output from a trajectory model indicates that the air parcels entering a tip jet accelerate and descend as they are deflected around southern Greenland.

A heat flux timeseries for the mooring site was constructed that includes the enhancing influence of the tip jet events. This was used to drive a one-dimensional mixed-layer model, which was able to reproduce the observed mixed-layer deepening in both winters. All of the highest heat flux events took place during tip jets, and removal of the tip jets from the heat flux timeseries demonstrated their importance in driving convection east of Greenland. The deeper mixed-layer of the first winter was in large part due to a higher number of robust tip jet events, which in turn was caused by a greater number of storms passing northeast of southern Greenland. This interannual change in storm tracks was attributable to a difference in upper level steering currents. Application of the mixed-layer model to the winter of 1994-1995, during a period characterized by a high NAO index, resulted in convection reaching $1600 \mathrm{~m}$. This prediction is consistent with concurrent hydrographic data, supporting the notion that deep convection can occur in the Irminger Sea during strong winters.
\end{abstract}

Thesis Supervisor: Robert S. Pickart

Title: Senior Scientist, Woods Hole Oceanographic Institution 


\section{Acknowledgments}

Firstly I would like to thank my advisor, Dr. Bob Pickart, for providing access to a phenomenal data set, excellent guidance during the development of the ideas in this thesis and for numerous helpful comments that greatly improved this manuscript. I am very grateful for the opportunity to work with such a fine scientist and person, and for the numerous ski trips and runs.

I wish to thank John Toole, Paula Fratantoni and Anna Nikolopoulos for very helpful discussions regarding the processing and calibration of the moored profiler instruments. A conversation with Kent Moore led to improvements of the atmospheric chapters of this thesis. Remaining errors are my own.

The Matlab version of the PWP model was kindly provided by Tom Farrar, along with valuable suggestions and answers to my questions. Thanks to Terry McKee for providing computer support.

The main part of the thesis work was done at the University of Alaska, Fairbanks, where my advisor generously invited me along during his sabbatical. It is a pleasure to thank the people at the School of Fisheries and Ocean Sciences for their hospitality, and for making my stay there a very pleasant one. Thanks also to my peers in the Physical Oceanography department at the Woods Hole Oceanographic Institute for a very friendly and stimulating learning environment.

I would like to thank my parents, Kari and Sigbjørn, and my brothers, Stian and Vidar, for their support and encouragement throughout the period of this work. Special thanks and appreciation to my fiancée, Selina, for her invaluable and boundless love, care and understanding.

I acknowledge the NOAA Climate Diagnostics Center for the NCEP re-analysis data (www.cdc.noaa.gov). QuikSCAT data are produced by Remote Sensing Systems and sponsored by the NASA Ocean Vector Winds Science Team (www.remss.com). The BADC trajectory model was supplied by the UK Met Office (www.badc.rl.ac.uk).

Financial support for this work was provided by National Science Foundation grant OCE-0450658. 


\section{Contents}

1 Introduction $\quad 6$

2 Calibration of the moored profiler data 13

2.1 CTD calibration . . . . . . . . . . . . . . . . . 14

2.2 ACM calibration . . . . . . . . . . . . . . . 17

3 Properties of the mixed-layer $\quad 22$

3.1 Mixed-layer evolution . . . . . . . . . . . . . . . . 23

$3.2 \theta$ - S properties . . . . . . . . . . . . . . . . . 29

4 Air-sea interaction and the effect of the Greenland tip jet 31

4.1 Storm tracks . . . . . . . . . . . . . . . . . . . . . . . 31

4.2 Signature of tip jet events $\ldots \ldots \ldots \ldots \ldots \ldots$

4.3 Air parcel trajectories $\ldots \ldots \ldots \ldots \ldots$

4.3.1 5 December 2002 case study . . . . . . . . . . . . . . . 42

4.3 .2 All robust tip jets . . . . . . . . . . . . . . . . 44

4.4 Objective detection of tip jets $\ldots \ldots \ldots \ldots \ldots \ldots$

5 Heat fluxes $\quad 51$

5.1 Latent heat flux . . . . . . . . . . . . . . . . 53

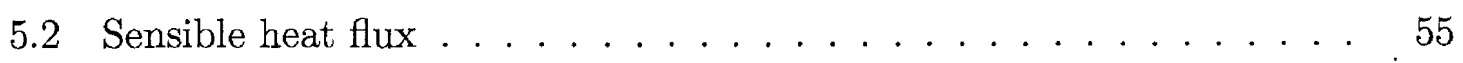

5.3 Total heat flux $\ldots \ldots \ldots \ldots \ldots \ldots \ldots \ldots$ 
$6 \quad 1 D$ mixed-layer model $\quad 59$

6.1 Winter $0203 \ldots \ldots \ldots$. . . . . . . . . . . . . . . . . .

6.2 Winter $0304 \ldots \ldots \ldots \ldots$. . . . . . . . . . . . . 63

6.3 Winter $9495 \ldots \ldots \ldots \ldots \ldots$

6.4 Sensitivity studies . . . . . . . . . . . . . . . . . 68

6.4.1 Momentum flux . . . . . . . . . . . . . . 68

6.4 .2 Heat flux ...................... 69

6.4 .3 Fresh water flux . . . . . . . . . . . . . . 69

$\begin{array}{lll}7 & \text { Discussion and conclusions } & 70\end{array}$ 


\section{Chapter 1}

\section{Introduction}

Deep convection in the open ocean occurs when a set of oceanic and atmospheric conditions are satisfied, allowing the deepening winter mixed-layer to penetrate the thermocline and reach great depths. The required conditions are (i) strong atmo-

spheric forcing that removes buoyancy from the surface waters, (ii) a preconditioned water column containing weakly stratified water and (iii) a cyclonic circulation that isolates the water subjected to the forcing and causes the isopycnal surfaces to dome, bringing the weakly stratified water close to the surface (Marshall and Schott, 1999). Only a limited number of locations in the World Ocean are known in which these requirements are satisfied and deep convection has been observed, namely the Greenland, Labrador, Mediterranean and Weddell Seas (Marshall and Schott, 1999).

Low-pressure systems following the North Atlantic winter storm track advect cold, dry continental air from the Canadian land mass over the southwestern Labrador Sea (Fig. 1-1), where deep convection has been observed (Clarke and Gascard, 1983; Lilly et al., 1999; Pickart et al., 2002). Large heat fluxes result when the air reaches the icefree ocean (LabSea Group, 1998). The retention of water from the previous winters' deep convection provides a preconditioned state (Marshall and Schott, 1999; Lazier et al., 2002), and a localized cyclonic recirculation gyre in the western Labrador Sea (Lavender et al., 2000) isolates the water resulting in exposure to the atmospheric cooling for an extended period of time. The bottom water found in the Labrador Sea is a mixture of overflow water from the Nordic Seas and its entrained products, and 
presents a well stratified barrier near $2500 \mathrm{~m}$ through which it is very difficult for convection to penetrate (Lilly et al., 1999). The resulting intermediate water mass formed by convection is known as Labrador Sea Water (LSW), and is characterized by low salinity and a lower potential vorticity $(\mathrm{PV})^{1}$ than any other water mass in the North Atlantic (Talley and McCartney, 1982). Sub-basin scale cyclonic flow in the southeastern Labrador Sea was also observed using autonomous profiling floats (Fig. 1-1). Despite the weaker atmospheric forcing on that side of the basin, there is a tendency for deep mixed-layers to be found in this area (Lavender et al., 2002), possibly due to the localized wind patterns associated with the orography of Greenland (Martin and Moore, 2006).

The production and characteristics of LSW exhibit significant interannual variability (Talley and McCartney, 1982; Lazier et al., 2002), which is correlated with the North Atlantic Oscillation (NAO, Dickson et al., 1996). The NAO is the dominant mode of atmospheric variability over the North Atlantic (Rogers, 1990), and is described by an index based on the difference in sea level pressure between Lisbon, Portugal and Stykkisholmur, Iceland. A positive value means that the Icelandic Low is deeper than the mean, and is associated with a northeastward shift of the winter storm track (Rogers, 1990), an increased occurrence of cyclones in the North Atlantic (Serreze et al., 1997) and a greater probability of deep convection in the Labrador Sea (Dickson et al., 1996). During the high-NAO period in the early 1990s, intense convection and mixed-layers reaching depths of $2300 \mathrm{~m}$ were observed, while during the latter part of the decade, coinciding with a lower NAO index, convection extended to less than than $\sim 1000 m$ (Lazier et al., 2002; Fig. 1-2).

There is an increasing body of evidence that LSW is not formed exclusively in the Labrador Sea and that deep convection occurs in the southwest Irminger Sea as well (e.g. Pickart et al., 2003a; Straneo et al., 2003; Bacon et al., 2003; Centurioni and Gould, 2004). One of the pieces of evidence supporting this involves the distribution of tracers. A lateral map of the mid-depth distribution of PV from data collected

\footnotetext{
${ }^{1}$ Planetary potential vorticity is defined as $P V=\frac{f}{\rho} \frac{\partial \rho}{\partial z}$, where $\mathrm{f}$ is the Coriolis parameter, $\rho$ is density and $\mathrm{z}$ is depth, and is obtained from a scaling of Ertel's potential vorticity (Pedlosky, 1987).
} 


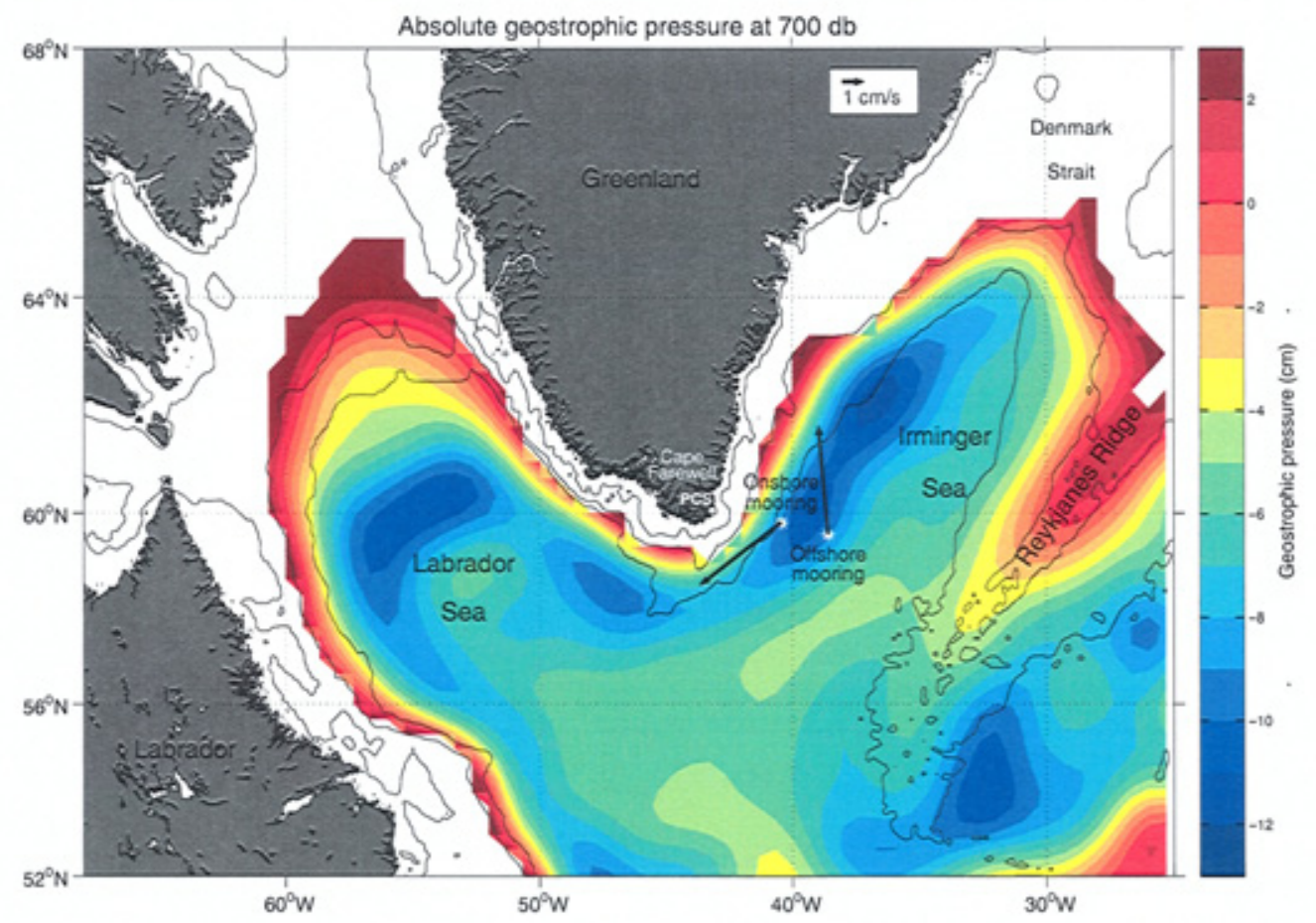

Figure 1-1: Objectively mapped absolute geostrophic pressure at $700 \mathrm{db}$, from Lavender et al. (2000). A series of cyclonic recirculations (associated with low geostrophic pressure) are located in the Irminger and Labrador Seas. The mooring positions are indicated by the white stars, and the mean current vectors at $700 d b$ for 2002-3 (onshore mooring) and 2002-3 and 2003-4 (offshore mooring) are shown. The isobaths (gray lines) are 200, 1500 and $2500 \mathrm{~m}$. The location of the Prins Christian Sund coastal meteorological station is indicated by PCS.

during the high-NAO period of the early 1990s shows a second, isolated minimum in the Irminger Sea (Pickart et al., 2003a). Spreading of LSW was investigated with an advective-diffusive model, and the results imply that the Irminger Sea is associated with a local source of low-PV water. Pickart et al. (2003a) showed that, similar to the Labrador Sea case, the conditions for deep convection described above are satisfied in the Irminger Sea, except for the atmospheric forcing. The heat flux associated with passage of synoptic scale low-pressure systems is up to $30 \%$ smaller, since Greenland represents a smaller reservoir of cold, dry continental air than Canada and most of the air reaching the Irminger Sea has already been modified by the Labrador Sea.

The analysis carried out by Pickart et al. (2003a) was based on the relatively low 


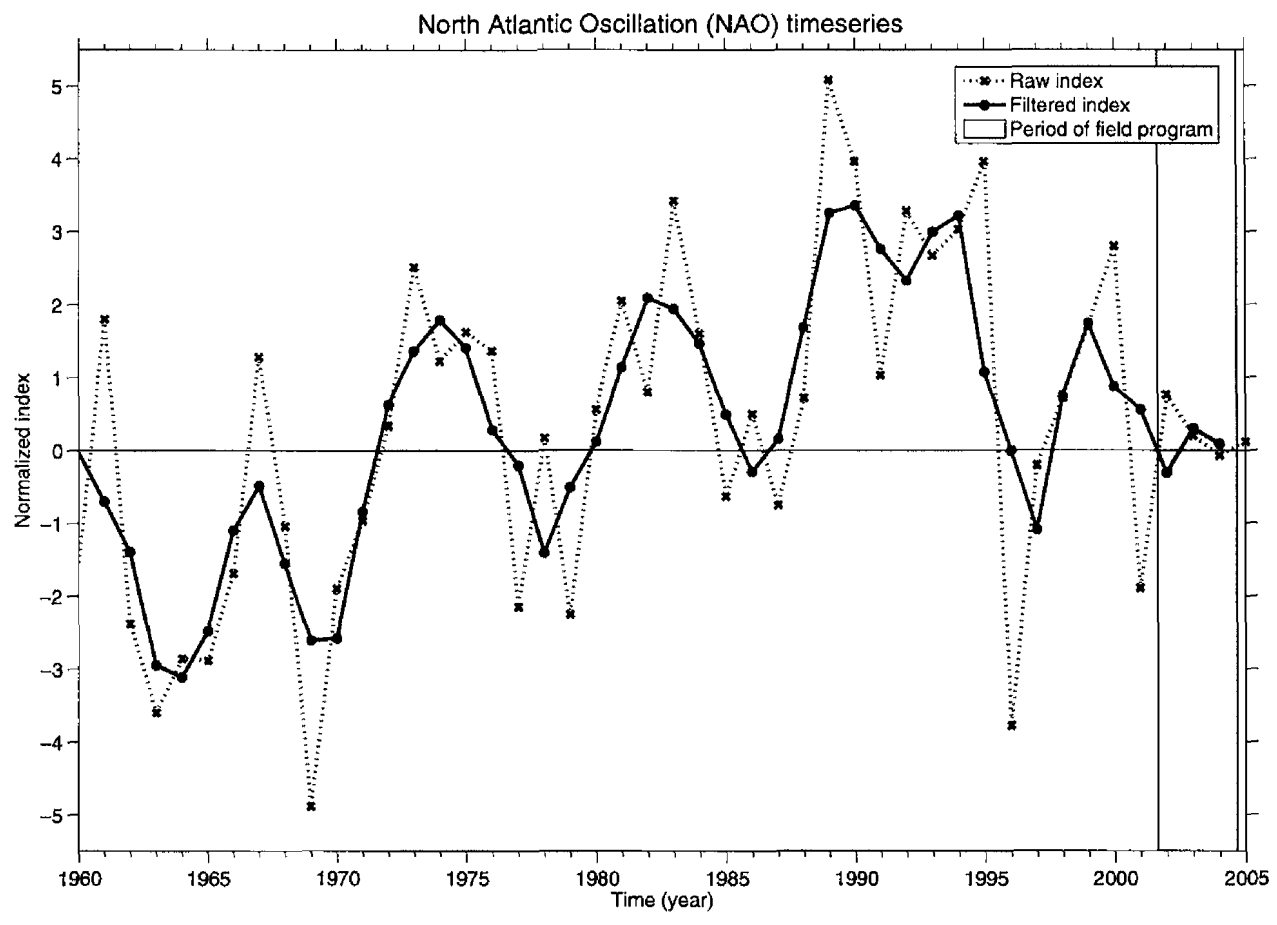

Figure 1-2: Timeseries of the December-March North Atlantic Oscillation (NAO) index from J. Hurrell, http://www.cgd.ucar.edu/cas/jhurrell/nao.stat.winter.html. Yearly values (dashed line), a 3-year running mean (solid blue line) and the time period of the Irminger Sea field program (shaded) are plotted.

spatial resolution National Centers for Environmental Prediction (NCEP) reanalysis fields (Kalnay et al., 1996). A mechanism capable of enhancing the heat fluxes over the southern Irminger Sea exists in the form of a strong, narrow, intermittent wind pattern called the Greenland tip jet (Doyle and Shapiro, 1999; Pickart et al., 2003b), which is not properly resolved by NCEP. Tip jets are predominantly a wintertime phenomenon formed in the lee (eastern) side of Cape Farewell, and it is presently unknown whether the air parcels forming the tip jet descend directly from the altitude of the Greenland plateau, governed by conservation of the Bernoulli function (Doyle and Shapiro, 1999), or if the tip jet is formed through an acceleration of air parcels as they are deflected around the southern tip of Greenland (Moore and Renfrew, 2005). Figure 1-3 shows a typical tip jet as it appears in the high-resolution data from the SeaWinds microwave scatterometer on the QuikBird satellite (QuikSCAT). 
The maximum wind speed during this event was $50 \mathrm{~m} / \mathrm{s}$, while the greatest registered NCEP wind speed was $24 \mathrm{~m} / \mathrm{s}$, less than half the QuikSCAT value. The high wind speeds, low temperature and relatively low humidities characteristic of tip jet events are readily detected using data from a meteorological station situated adjacent to Prins Christian Sund (PCS) near Cape Farewell (Pickart et al., 2003b).

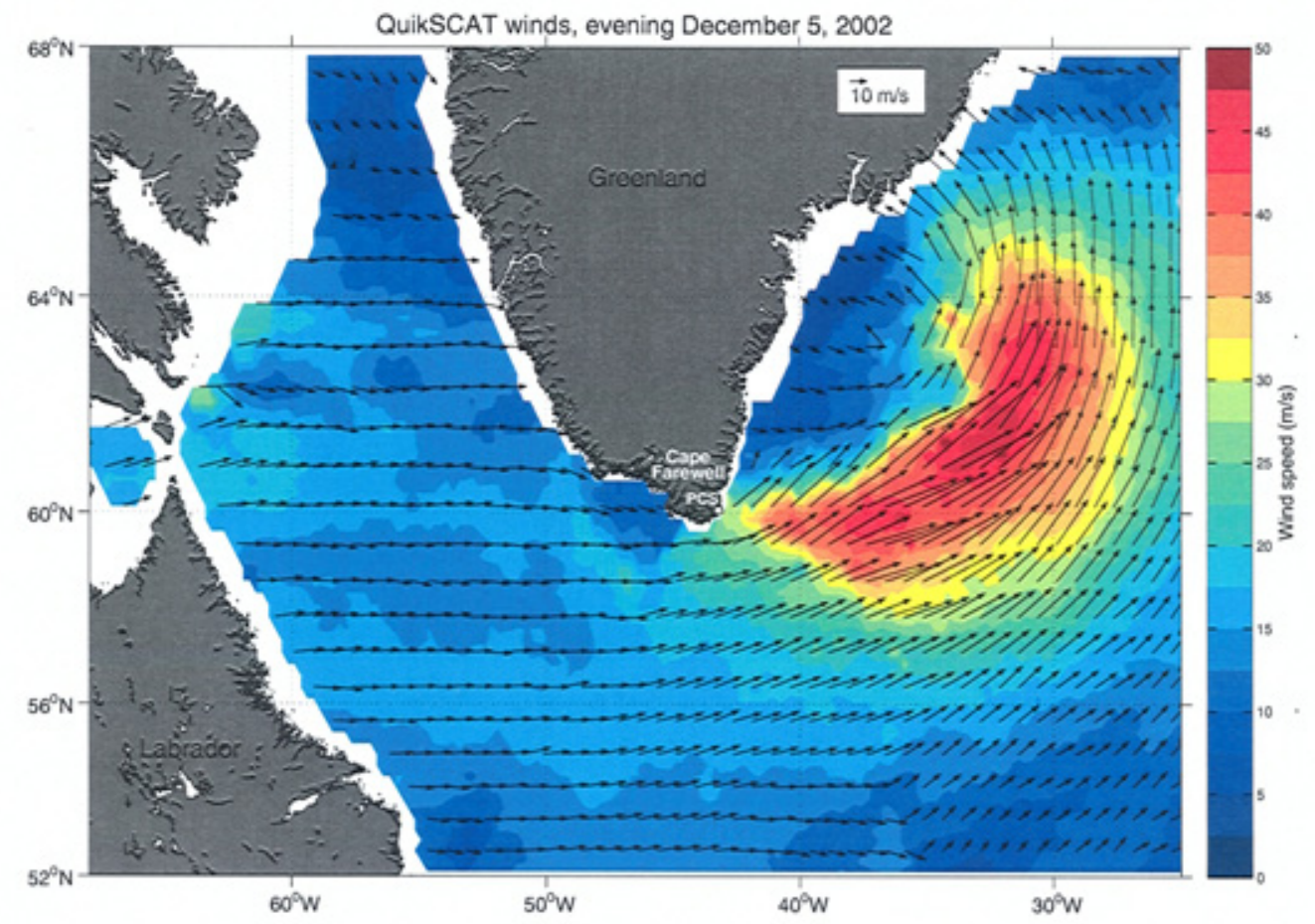

Figure 1-3: The QuikSCAT wind speed (color) and vectors (every $9^{\text {th }}$ point) showing a tip jet on 5 December, 2002. The wind speed at the mooring site during this event was $37 \mathrm{~m} / \mathrm{s}$.

Tip jet events are triggered by low-pressure systems that generally follow the mean storm track and enter the region northeast of Cape Farewell, and occur more often during high-NAO winters (Moore, 2003). Recently it has been argued that meridional shifts of the center of the Icelandic Low are more strongly related to the occurrence of tip jet events than the sea level pressure signal of the NAO (Bakalian et al., 2006). Even though the events are intermittent and seasonal, their signature is evident in a 4year average of wind stress curl (Chelton et al., 2004). This positive curl is important for the regional circulation and possible deep convection in the Irminger Sea (Spall 
and Pickart, 2003; Pickart et al., 2003b).

Although these recent studies have led to renewed interest in the Irminger Sea as a possible site of deep convection, this is, in fact, an old idea. Almost a century ago Nansen (1912) postulated the Irminger Sea as a location where deep convection could take place. His hypothesis was built on a very limited amount of data, and subsequent winter expeditions to the Irminger Sea were partially motivated by a desire to verify the hypothesis (Defant, 1936). Evidence of deep convection was found (Wattenberg, 1938; Sverdrup et al., 1942; Wüst, 1943), but the idea was essentially forgotten by the oceanographic community largely because the discovery of deep convection in the Labrador Sea put an increased emphasis on that basin. However, recent observations from autonomous profiling floats (Centurioni and Gould, 2004) and from a combination of float and hydrographic data (Bacon et al., 2003) have revealed mixedlayer depths in excess of $800 \mathrm{~m}$ southeast of Cape Farewell. This suggests that the Irminger Sea is capable of sustaining deep convection, consistent with the enhariced atmospheric forcing of the Greenland tip jet. The fact that the recent measurements were made during a relatively weak NAO period, and that sparsely distributed profiling floats have a low probability of observing localized convective events, suggests that mixed layers can reach much greater depths in the Irminger Sea under more favorable conditions.

Formation of LSW through deep convection has important consequences for the North Atlantic meridional overturning circulation (Schmitz and McCartney, 1993), for the global heat budget (Talley, 2003), for the modification of the dense overflow waters from the Nordic Seas and subsequent entrainment into the Deep Western Boundary Current (Dickson and Brown, 1994) and for the stratification and ventilation of the interior North Atlantic (Pickart et al., 2002). Another sub-polar area of LSW formation would affect all of these, and also have great importance for the biological productivity in the region (Sverdrup et al., 1942) as well as for understanding the spreading of LSW into the North Atlantic (Sy et al., 1997).

In 2001 a field program was initiated to obtain direct winter season observations of the water column in the southwest Irminger Sea using two moored profiling in- 
struments (Doherty et al., 1999) in order to test the hypothesis that deep convection occurs there. In this study, data from the offshore site is considered, along with a variety of atmospheric data sets, to investigate the coupling between the atmosphere and the ocean that might lead to overturning east of Greenland. The mooring was positioned to be in the center of the region of PV minimum east of Cape Farewell under the expected path of the Greenland tip jet (Fig. 1-1). The moored profiler was programmed to obtain twice daily profiles of temperature, salinity and current vectors between 60 and $1800 \mathrm{~m}$. The specific goals of the present study are to examine the development of the winter mixed layer, assess the importance of the Greenland tip jet in driving convection and investigate the atmospheric conditions that lead to tip jet events. A description of the calibration procedure of the data set and properties of the mixed-layer are presented first, followed by an investigation of the wintertime atmospheric conditions over the southwest Irminger Sea in general, and during tip jet events in particular. These results are then used to develop an improved estimate of the heat flux timeseries at the mooring site, which in turn is used to force a one-dimensional mixed-layer model of the overturning. 


\section{Chapter 2}

\section{Calibration of the moored profiler}

\section{data}

The two moorings in the field program were equipped with a McLane moored profiler (MP), a motorized vehicle able to propel itself vertically along the mooring wire at a nominal speed of $0.3 \mathrm{~m} / \mathrm{s}$ over a distance of 1 million meters (Doherty et al., 1999). The field program lasted for 3 years, with mooring turnarounds every summer. Only data from the offshore mooring (Fig. 1-1) will be considered in this study. The MP failed shortly after the first deployment, but the second deployment returned 582 profiles between early August 2002 and early June 2003 and the third deployment resulted in 471 profiles between early August 2003 and late March 2004. During the remainder of this study, the 2002-2003 (0203) and 2003-2004 (0304) deployments will be referred to as the first and second deployments respectively. Ascending profiles started at 0 GMT and descending profiles started at 6 GMT. Each profile took about 2 hours. In between profiles, the MP rested in stand-by mode at the top and bottom of the profiling range.

Among the advantages of the MP compared to a mooring containing discrete instruments are: Its ability to obtain near full water column observations at high vertical resolution, which makes it ideal for studies of the mixed-layer evolution;

its ability to carry a diverse package of instruments; and a reduced uncertainty as only one set of instruments requires calibration (Doherty et al., 1999). The main 
disadvantage associated with the MP is a limited temporal resolution of measurements at each depth. During the course of the Irminger Sea deployments, the profiler started drifting slowly while in stand-by mode towards its neutrally buoyant position at mid-depth. This behavior became more pronounced with time, yielding as a result essentially only one full profile per day towards the end of the period. A limited number of profiles were not recorded, either because the pressure data was not written to memory or due to the MP being stuck along the mooring wire. This affected 11 profiles during the first deployment, of which 6 were sequential and left a 3-day gap in the record, and none in the second deployment.

The MPs carried a conductivity, temperature and pressure (CTD) sensor with nominal accuracies of $\pm 0.0005 \mathrm{~S} / \mathrm{m}, \pm 0.005{ }^{\circ} \mathrm{C}$ and $\pm 0.03 \%$ of full scale pressure respectively, and an acoustic current meter (ACM) with a nominal accuracy of \pm 2 $\mathrm{cm} / \mathrm{s}$ in speed and $\pm 2^{\circ}$ in direction. The raw CTD and ACM data were low-pass filtered (with a $1^{\text {st }}$ order digital Butterworth filter at $0.23 \mathrm{~Hz}$ (sample rate of $1.8 \mathrm{~Hz}$ ) for the CTD data and with an $8^{\text {th }}$ order digital Butterworth filter at $0.08 \mathrm{~Hz}$ (sample rate of $2 \mathrm{~Hz}$ ) for the ACM data), de-spiked and averaged into $2 \mathrm{db}$ pressure bins (see Toole et al., 1999). The mooring was also equipped with a vector averaging current meter (VACM) and a temperature sensor located below the bottom stop of the MP, near $1840 \mathrm{~m}$. The nominal accuracies of these instruments are $\pm 1 \mathrm{~cm} / \mathrm{s}$ in speed, $\pm 5^{\circ}$ in direction and $\pm 0.05^{\circ} \mathrm{C}$ in temperature.

\subsection{CTD calibration}

Shipboard CTD casts at the mooring site prior to deployment and after recovery of the mooring were carried out for calibration purposes. The CTD cast prior to deployment was given the most weight because of the premature termination of the deployments. Conductivity drift and offset were determined by requiring the mean potential conductivity ${ }^{1}$ ratio of the MP and shipboard conductivities to be unity in

\footnotetext{
${ }^{1}$ Potential conductivity is the conductivity calculated from the equation of state using the observed salinity and potential temperature with a reference pressure of zero (John Toole, personal communication, 2005).
} 
the depth interval where the potential temperature $(\theta)$ - salinity $(\mathrm{S})$ relation was most stable. These regions were found between $1100 \mathrm{db}$ and $1170 \mathrm{db}$ for the first deployment and between $1140 \mathrm{db}$ and $1170 \mathrm{db}$ for the second deployment, in the region of Labrador Sea Water formed in previous years. There was no obvious instrument drift for either deployment, and the MP salinity agreed well with the salinity from the shipboard CTD cast during the second deployment. A salinity offset of 0.022 was corrected for in the second deployment. The temperature timeseries at the bottom of the mooring agreed well with the VACMs' thermistors for both deployments.

Each profile was searched for density inversions (a stable stratification below the mixed layer was assumed), and inversions exceeding $0.005 \mathrm{~kg} / \mathrm{m}^{3}$ were interpolated over. This threshold was determined from a consideration of the range of density variability in the above mentioned range of stable $\theta-\mathrm{S}$ characteristics, and corresponds to changes of approximately \pm 0.006 in salinity. Less than $30 \%$ of the profiles in each deployment contained inversions, and most were caused by outliers missed by the de-spiking routine. A small number of profiles (7 in the first deployment and 3 in the second) contained enough inversions to warrant a partial flagging of the salinity data rather than interpolation. See Fratantoni et al. (2006) for more details on the CTD calibration process.

The temperature and pressure sensors are expected to perform at their nominal accuracy level of $\pm 0.005{ }^{\circ} \mathrm{C}$ and $\pm 0.03 \%$ of full scale pressure respectively. The final accuracy of the conductivity sensor was estimated from a consideration of the salinity timeseries at the $3.16{ }^{\circ} \mathrm{C}$ potential temperature isotherm (Fig. 2-1). The characteristic bend near $\left(34.84,3.4^{\circ} \mathrm{C}\right)$ is a signature of LSW. The width of the salinity envelope at the $3.16{ }^{\circ} \mathrm{C}$ isotherm was approximately 0.03 . It was assumed that variability at this potential temperature took place on timescales greater than the time difference between ascending and descending profiles, i.e. less than about 8 hours. Thus the salinity at this isotherm measured by the ascending profiler should agree with the measurement of the descending profiler within the range given by the error bars for each pair of profiles. The assumption is not perfect, but we believe that it is reasonable based on the stable nature of that part of the water column. With 

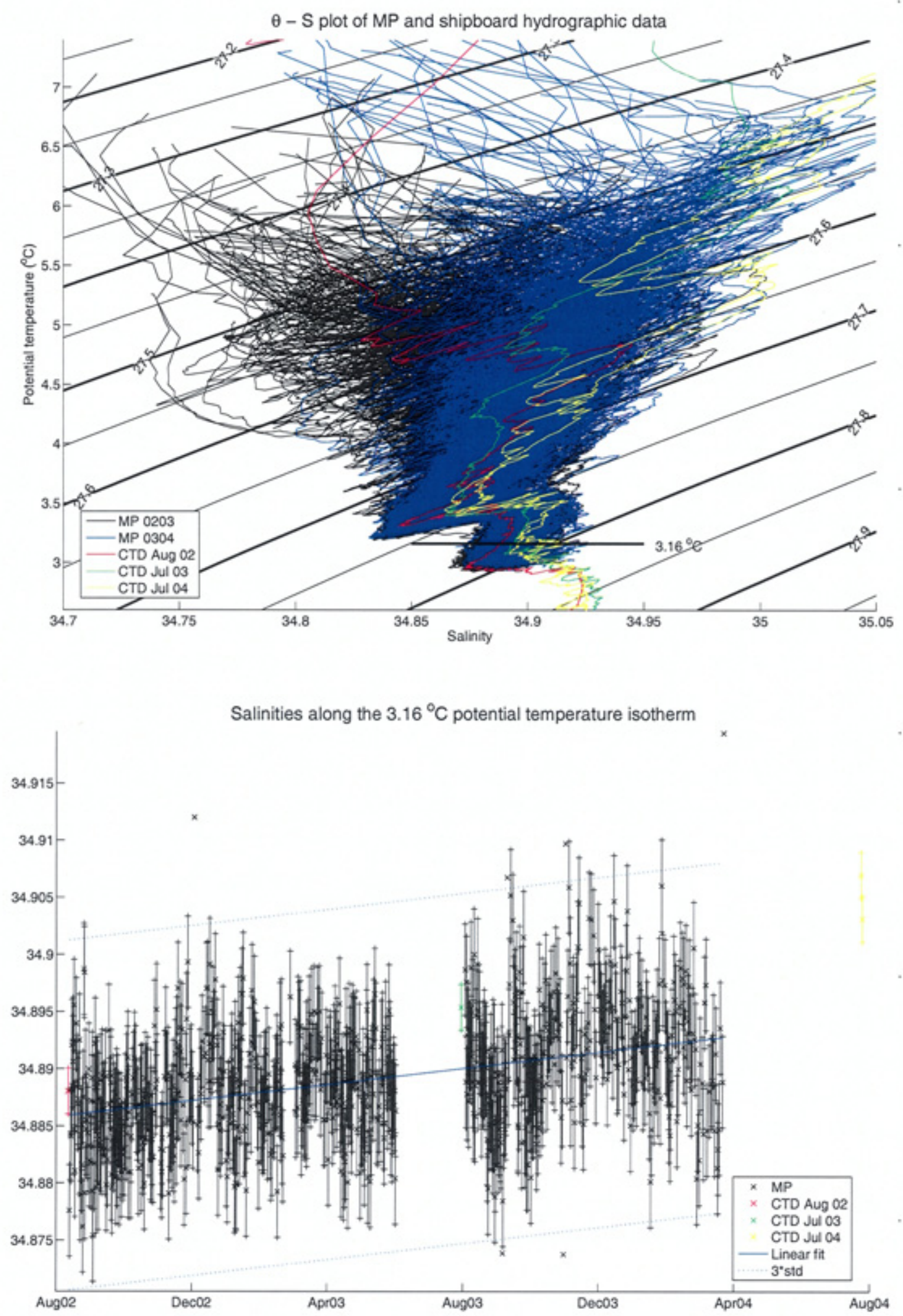

Figure 2-1: Top: $\theta-\mathrm{S}$ plot of MP and shipboard CTD data; bottom: Salinities along the indicated $3.16{ }^{\circ} \mathrm{C}$ isotherm with uncertainty estimate (black lines) along with the best linear fit (solid blue line) and \pm 3 times standard deviation (dotted blue lines) for both deployments. 
an uncertainty of 0.004 , this is true for $95 \%$ of the measurements, and it is thus our estimate of the final accuracy of the salinity data. Data points outside the 3 times standard deviation envelope were excluded. The results did not differ significantly when the two deployments were considered separately. The trend of increasing salinity at the $3.16{ }^{\circ} \mathrm{C}$ potential temperature isotherm is considered real, as it is reflected also in the shipboard CTD measurements, which have an accuracy of 0.002 .

\subsection{ACM calibration}

The ACM employed two horizontal and two vertical acoustic paths, a magnetic compass and a tilt sensor to reconstruct the 3D flow field (Toole at al., 1999). Only the horizontal velocities will be considered here. The speed of sound in the ocean varies with temperature and pressure, and the initial computation of the path velocities had only taken the effect of a changing temperature into account. The pressure effect was corrected for by multiplying the ACM velocities with a depth dependent factor obtained from dividing the square of the true speed of sound with the square of the speed of sound at surface pressure. The depth dependent speed of sound was computed using the MP CTD data, which introduced an error, as the temperature used by the ACM to compute the initial sound speed was lagged by an unknown factor due to the thermal mass of the ACM pressure housing and the water trapped inside the MP housing (these temperatures were unfortunately not recorded). The magnitude of the scale factor increased from 1 at the surface to 1.04 at the bottom of the MP's range.

The raw ACM path velocities require a bias correction. A depth independent bias was derived from tank tests of the sensors and hardwired into the instrument. Indications of a depth dependent bias have also been found. The cause of the bias is related to a change in impedance of the circuit connecting the acoustic transducers to the current meter electronics with pressure and temperature (John Toole, personal

communication, 2005). The pressure effect was found to be dominant (the lack of influence of thermal inertia made estimates of the ascending and descending bias 
profiles nearly identical). As pressure does not change with time, a steady bias profile can be assumed. For a sufficiently long record in an area where the amplitude of the current variability is greater than the mean, it was also assumed that the velocity became vanishingly small at every depth at some point during the record. This assumption provided an opportunity to compute the depth dependent bias profile from the raw path velocities. The raw velocity data at each pressure bin was sorted, and the maximum of the $2.5 \%$ lowest velocities in each bin was recorded (the minimum velocity at each depth would have produced a very noisy profile). This bias profile was subsequently de-spiked and low-pass filtered before the estimate of the velocity bias was removed from the raw data. New pressure gridded files were created from the edited raw data.

As the ACM was situated on a moving platform whose ability to orient itself in the direction of the ambient current was unclear, particularly since the mean current was relatively weak (the mean current velocity for both deployments was $11 \mathrm{~cm} / \mathrm{s}$ as recorded by the VACM), the VACM record was deemed more accurate. For comparison, timeseries of speed and direction were computed by extrapolation of the bottom $150 m$ of the MP profiles to the depth of the VACM, and the VACM record was interpolated in time to match the ACM record. The two timeseries are plotted in Figures 2-2 and 2-3. The correlations between the ACM and VACM speeds were 0.81 for both deployments. For the directions, the correlations were 0.94 and 0.90 for the first and second deployments respectively, with the periodic nature of the directional data taken into account. A velocity scale factor and a directional offset were computed by minimizing the root mean square (rms) difference between each of the VACM and ACM data points in speed and direction. The resulting scale factors and offsets were 0.89 and $24^{\circ}$ for the first deployment and 1.31 and $35^{\circ}$ for the second deployment respectively. These are consistent with those applied to previous MP deployments (John Toole, personal communication, 2005).

In addition to the scale factor, a velocity offset was required for the second deployment (i.e. a correction to the bias computed above). A higher scale factor would have increased the mean extrapolated ACM velocities to the same level as the VACM 

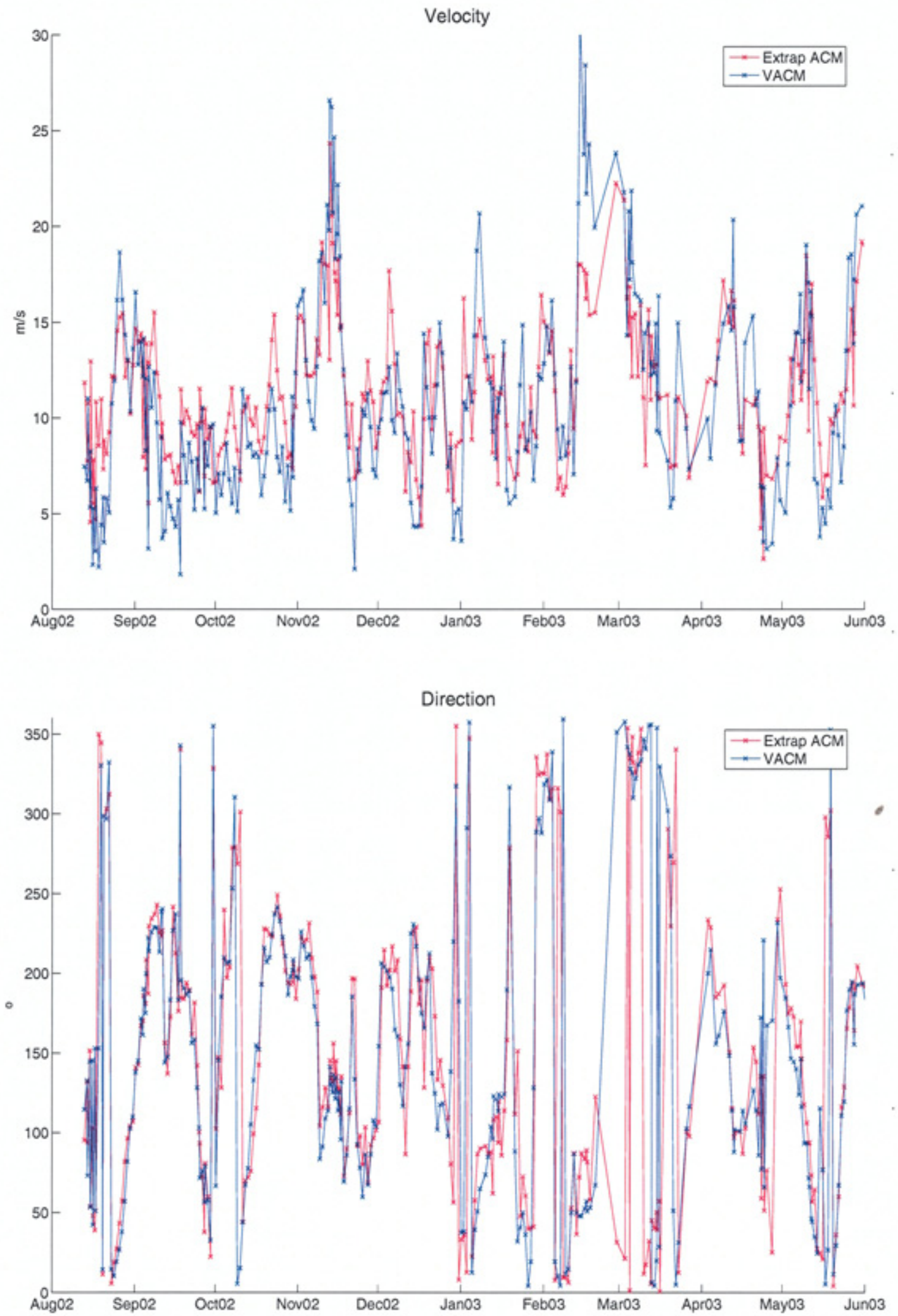

Figure 2-2: Comparison of extrapolated ACM (red) and VACM (blue) velocities (top) and directions (bottom) for the winter of 0203 . 

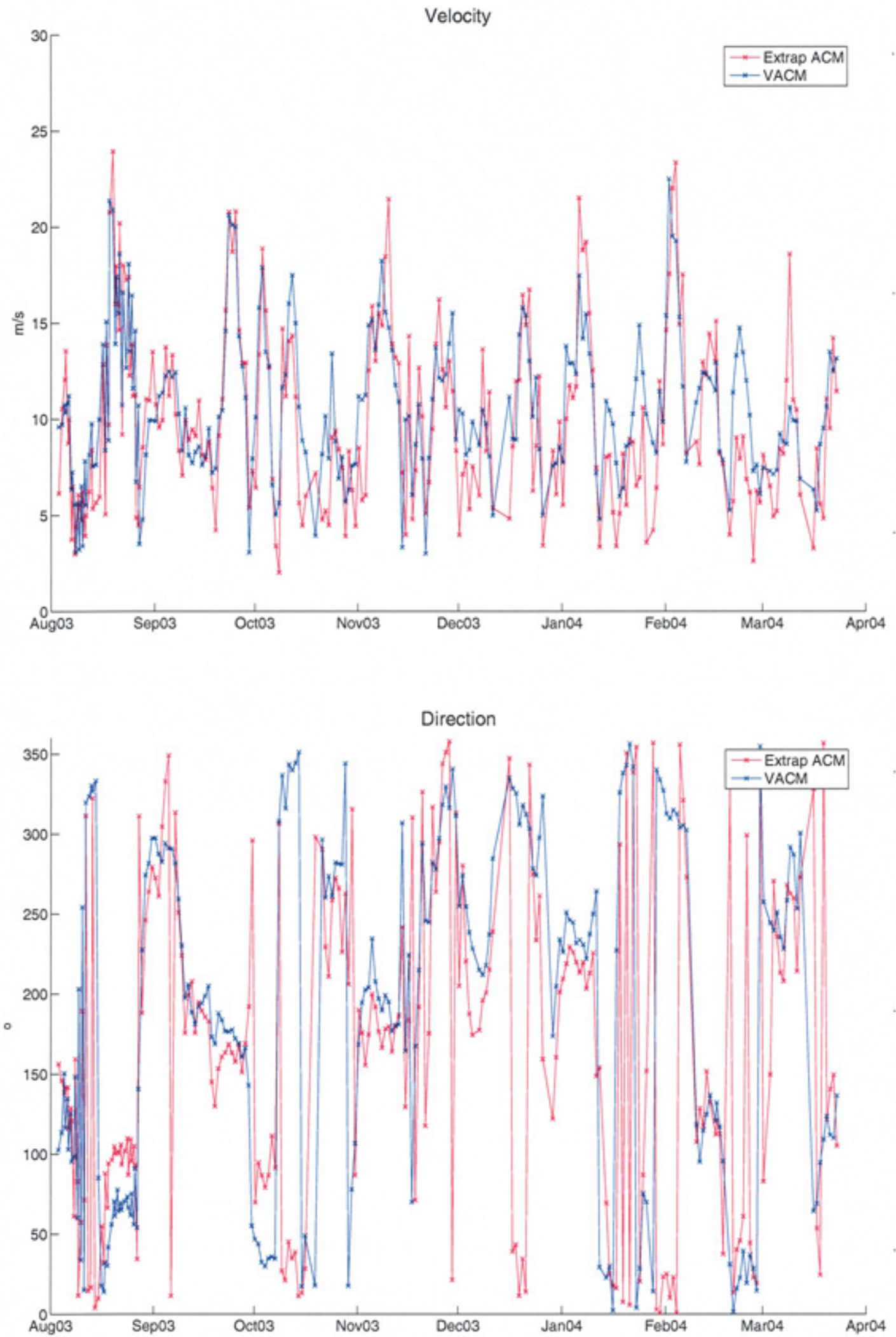

Figure 2-3: As Figure 2-2, but for the winter of 0304. 
velocities, but would have made the variance of the ACM velocities unrealistically large. This velocity offset was chosen subjectively, taking into consideration both the mean and variance of the two timeseries as well as the rms difference between the timeseries. A shift of $2.5 \mathrm{~cm} / \mathrm{s}$ was applied to the ACM velocities before multiplication with the scale factor, in effect adding a depth independent bias to each profile of the second deployment. One weakness of this approach is the tendency for the VACM to stall in currents under $2 \mathrm{~cm} / \mathrm{s}$, but this is difficult to assess.

The accuracy of the ACM was estimated directly from the rms difference between the ACM and the VACM records. For the first deployment, the rms differences were $3.1 \mathrm{~cm} / \mathrm{s}$ in velocity and $35^{\circ}$ in direction, and for the second deployment, the rms differences were $2.8 \mathrm{~cm} / \mathrm{s}$ in velocity and $50^{\circ}$ in direction. With a $\pm 1 \mathrm{~cm} / \mathrm{s}$ accuracy of the VACM velocities, the uncertainty of the ACM velocities for both years is estimated to about $\pm 2 \mathrm{~cm} / \mathrm{s}$. Toole et al. (1999) estimated the accuracy of their absolute velocity data to be $\pm 1 \mathrm{~cm} / \mathrm{s}$. Our estimate is conservative in comparison. Despite the high correlation between the ACM and VACM directions, the rms differences are significant. We believe that this is mainly because of the low current velocities typical of the Irminger Sea gyre (Lavender et al., 2000; Fratantoni, 2001; Lavender et al., 2005), which prevents the MP from orienting itself properly with the direction of the current. This is also true to a lesser extent for the VACM. The velocity offset applied to the second deployment also contributed to the greater rms difference in direction. With an accuracy of $\pm 5^{\circ}$ for the VACM, the uncertainties in direction are thus estimated to $\pm 30^{\circ}$ for the first deployment and $\pm 45^{\circ}$ for the second deployment. 


\section{Chapter 3}

\section{Properties of the mixed-layer}

The calibrated data from the MP CTD were used to derive the potential temperature $(\theta)$, potential density $\left(\sigma_{\theta}\right)^{1}$ and buoyancy frequency $(N)$. The measured and derived quantities were smoothed and uniformly regridded (10 $\mathrm{m}$ in depth and $12 \mathrm{hr}$ in time) to make property-time plots. The results are displayed in Figures 3-1 and 3-2. Among the most noticeable features is the signature of the deepening mixed-layer in the salinity and buoyancy frequency plots. The enhancement of the buoyancy frequency at the base of the mixed-layer is caused by the large vertical density gradient where the mixed-layer density profile joins the underlying part of the profile. As winter progresses and the mixed-layer deepens, the gradient at the base of the mixed-layer decreases because of the less abrupt transition to the remainder of the profile; hence this feature of the buoyancy frequency becomes less effective as an indicator of mixedlayer depth in late winter (Fig. 3-3). The mixed-layer will be the focus of attention in the remainder of this chapter. The ambient LSW layer is well recognizable by the salinity minimum and the local minimum in buoyancy frequency, which like PV indicates weak stratification, around $800 \mathrm{~m}$. It is immediately clear that the mixedlayer did not reach this depth through the duration of the field program, and the observed LSW layer was probably an older vintage. This is discussed further below. The vertical displacements of the mid-depth isotherms and isohalines were likely caused by mesoscale variability. They were mutually compensating, and thus little

\footnotetext{
${ }^{1}$ Potential temperature and potential density are referenced to the sea surface.
} 
evidence is seen in potential density. Surface drifter and satellite altimetry studies show that the interior Irminger Sea in general is a region of relatively low eddy kinetic energy (Fratantoni, 2001).

\subsection{Mixed-layer evolution}

The mixed-layer depth for each profile in the MP timeseries was determined following the method of Pickart et al. (2002). The depth was first subjectively estimated by visual inspection of the potential density profile. Then the mean and standard deviation were computed for this chosen depth range. An envelope two standard deviations wide was overlaid on the potential density profile, and the final mixed-layer depth was objectively determined as the location where the profile permanently left the envelope (see Figure 3-4 for an example). In particularly noisy cases, the potential temperature and salinity profiles were also inspected, and occasionally the extent of the mixed-layer was determined subjectively using the envelope merely as a guide. The approximate bounds of the mixed-layer, however, were always unambiguous, In order to characterize the mean properties of the mixed-layer, a linear fit was made to the potential temperature, salinity and potential density profiles. The procedure was carried out for each profile in both deployments that had a mixed-layer deeper than 60 $m$ (the upper limit of the profiler). Several of the profiles contained multiple mixed layers, similar to those found by Pickart et al. (2002) in the Labrador Sea during active convection. Separate layers stacked vertically, small-scale lateral variations or slantwise convection were offered as explanations for the origin of the multiple mixed-layers.

The mixed-layer depths for each profile are plotted in Figure 3-5 overlaid on buoyancy frequency. For the winter ${ }^{2}$ of 0203 , mixed-layers were first observed at $60 \mathrm{~m}$ in the beginning of November. The tendency of the depth of the deepest mixed-layers was to increase slowly until the end of January, interrupted by some shoaling events.

\footnotetext{
${ }^{2}$ Throughout this work winter is considered as the period from November through April - the period during which mixed-layers deeper than $60 \mathrm{~m}$ in general were observed.
} 

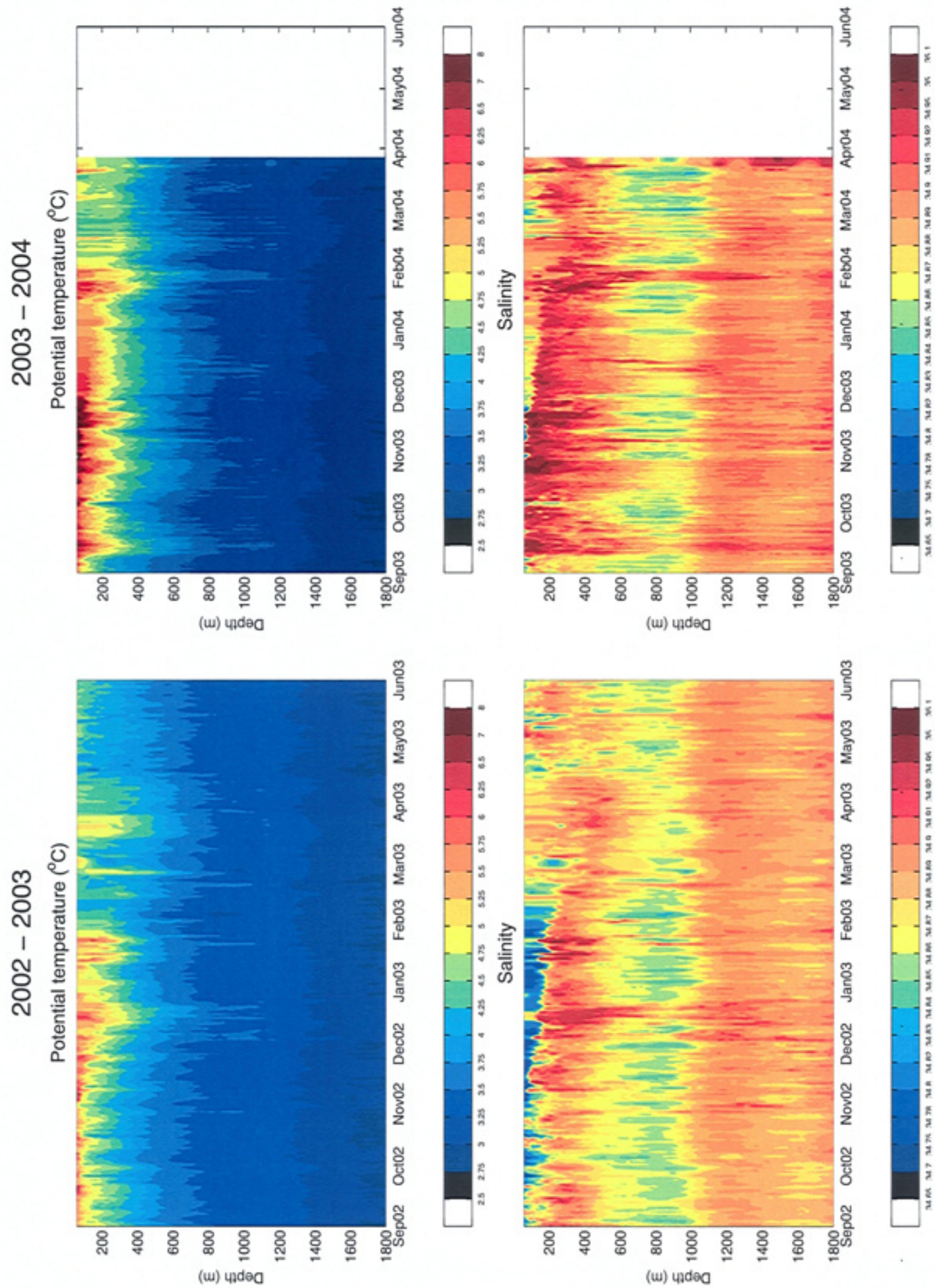

(w) पidea
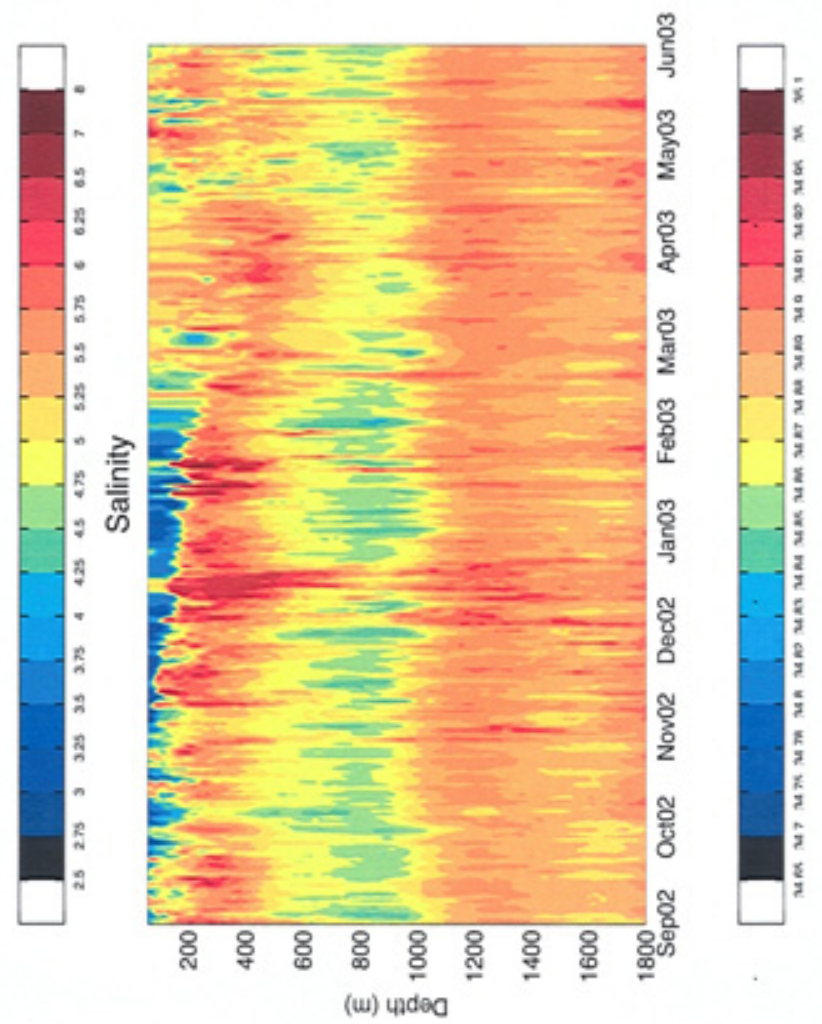

Figure 3-1: Timeseries of potential temperature and salinity from the MP CTD. The right column is for 0203 and the left is for 0304 . 

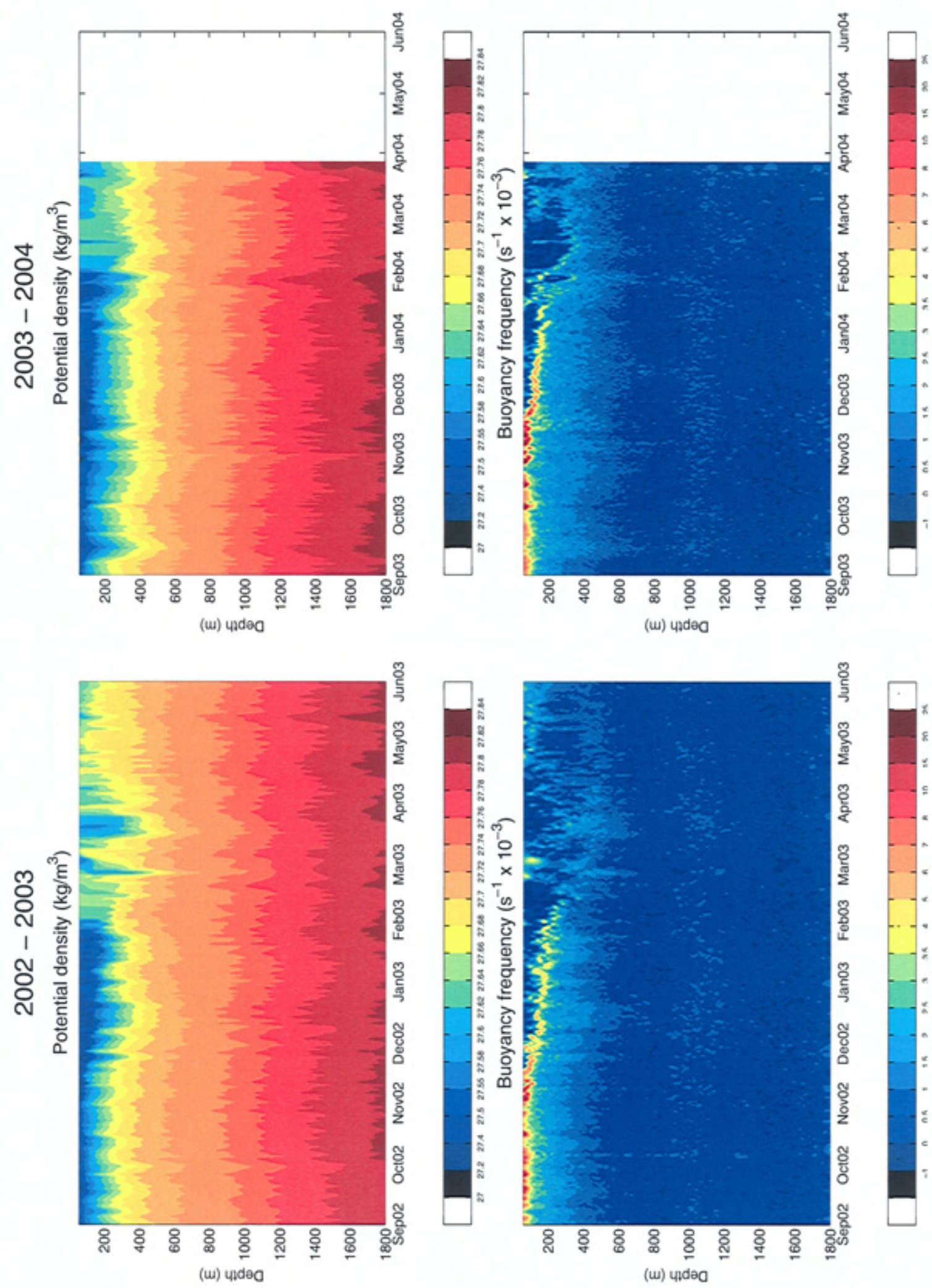

Figure 3-2: Same as Figure 3-1 for potential density and buoyancy frequency. 

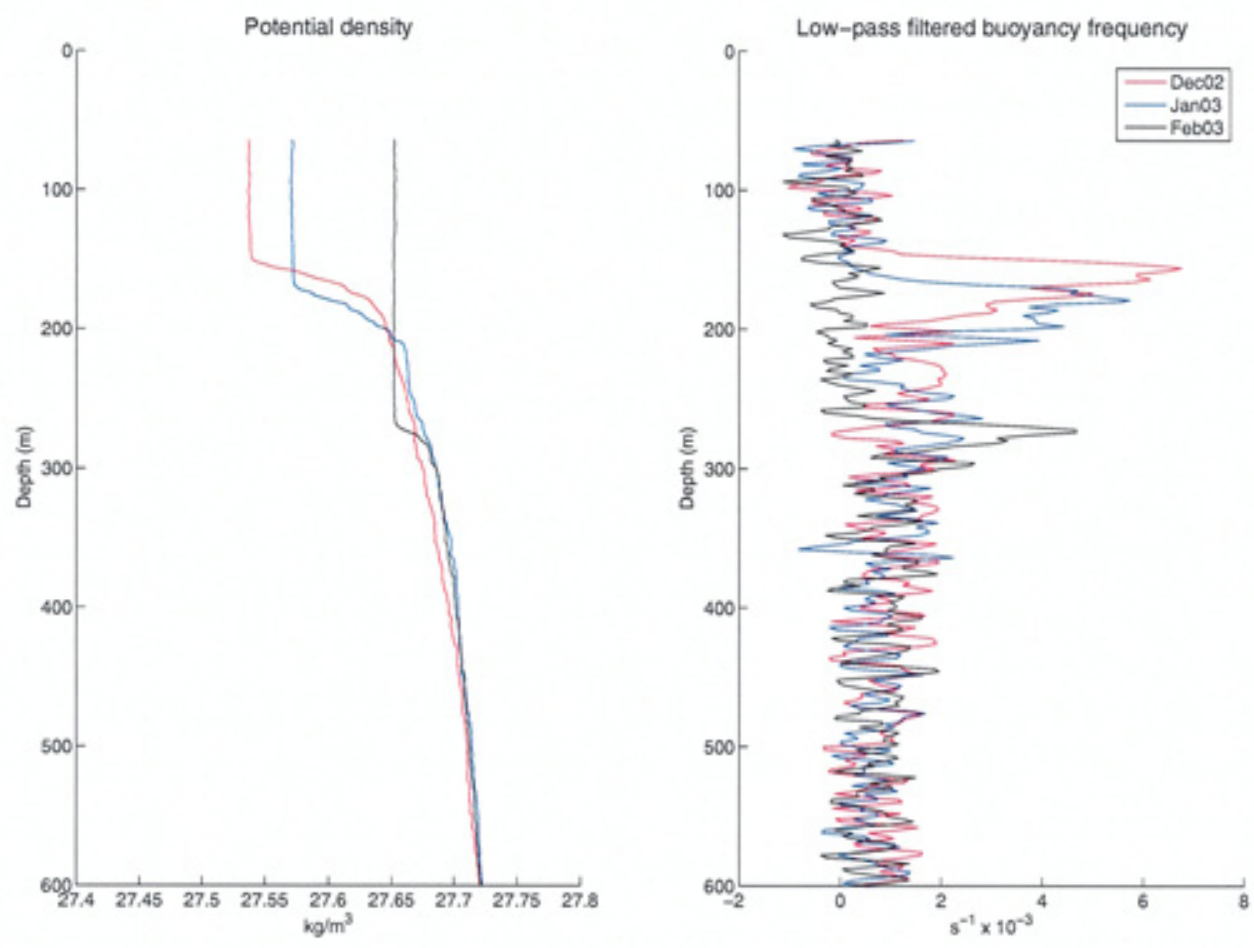

Figure 3-3: Evolution of potential density and buoyancy frequency during the winter 0203. The buoyancy frequency was low-pass filtered with a first order Butterworth filter of width 0.4 (normalized).

At the end of January, the mixed-layer depth started to increase substantially, exceeding $400 \mathrm{~m}$ by the end of the month, and the buoyancy frequency signature at the base of the mixed-layer started to fade as described above. The general depth of the mixed-layer was about $400 \mathrm{~m}$ until restratification occurred rather abruptly in the middle of April. Mixed-layers deeper than $60 \mathrm{~m}$ were, however, found until the middle of May. The mixed-layers observed between the middle of February and the middle of April exhibited considerable variability, reaching depths ranging from less than $100 \mathrm{~m}$ to almost $600 \mathrm{~m}$. Small-scale variability is a phenomenon ubiquitous during active convection. Pickart et al. (2002) observed significant differences even between downcast and upcast traces of shipboard CTD casts during active convection in the Labrador Sea. The variability in mixed-layer depth illustrates the small scales inherent in the convective process (Marshall and Schott, 1999). It should be noted that the MP has better temporal resolution than profiling floats for observing 

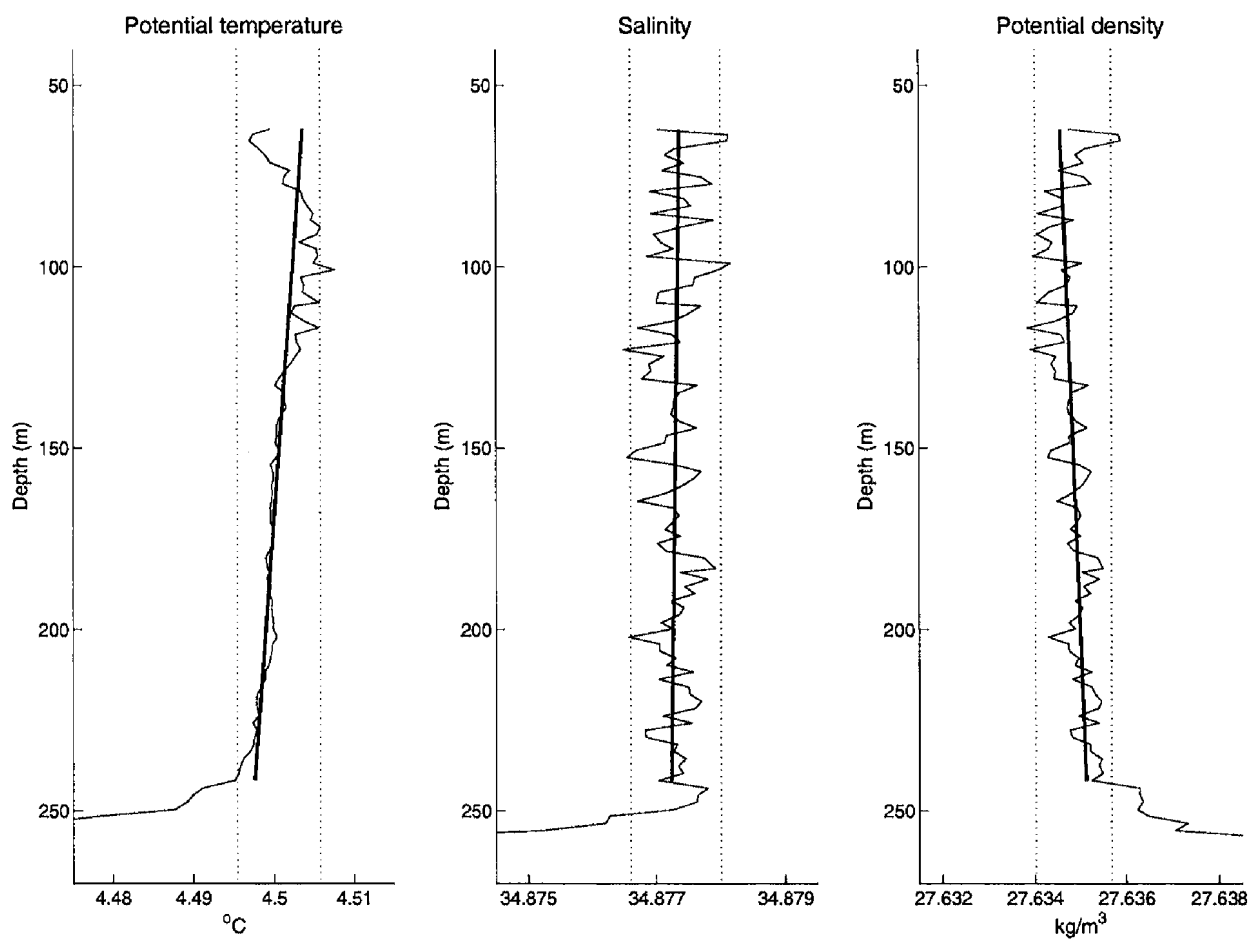

Figure 3-4: Illustration of the mixed-layer depth determination procedure showing one of the MP profiles, the double standard deviation envelope and the linear fit. The mixed-layer in this example reached $244 \mathrm{~m}$.

such highly spatially and temporally localized convective events (Bacon et al., 2003). Even though the convective plumes themselves are localized and intermittent, lateral exchange between the convected water mass and the ambient fluid facilitates spreading along the neutrally buoyant level of the convected water, and the envelope of the mixed-layer depths in Figure 3-5 is considered the overall depth of convection.

For the winter of 0304, mixed-layers were also first observed at $60 \mathrm{~m}$ in the beginning of November, and the overall mixed-layer depth developed in a similar way during the first half of the winter. It did not, however, undergo the same kind of abrupt deepening in February as the previous winter's mixed-layer did. The envelope of the mixed-layer depth reached about $300 \mathrm{~m}$ in the middle of February, and the individual mixed-layers displayed a similar kind of variability, though with a significantly smaller range. Mixed-layers deeper than $350 \mathrm{~m}$ were not observed during the winter of 0304. The MP failed before the final restratification at the end of the winter 

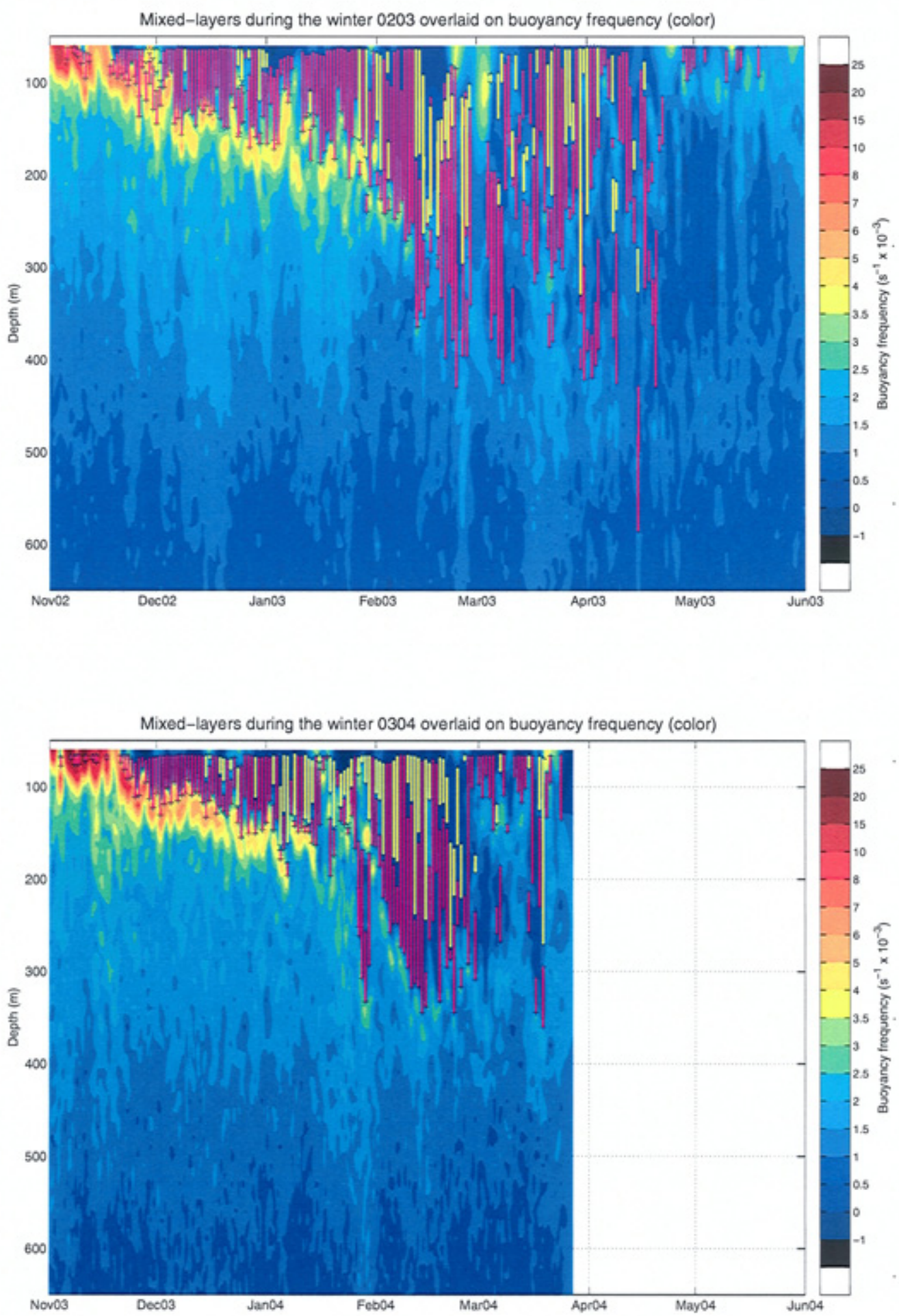

Figure 3-5: Mixed-layers (see text for method of determination) for each profile during winter 0203 (top) and winter 0304 (bottom). The primary (deepest) mixed-layers are indicated by the magenta lines and the secondary (shallower) mixed-layers by the yellow lines. 
season occurred.

The differences in mixed-layer depth between the two winters can largely be explained by the different atmospheric conditions in the western North Atlantic, in particular by the number of Greenland tip jet events, and by differences in the initial stratification (the preconditioned phase of the ocean). This is addressed in subsequent chapters.

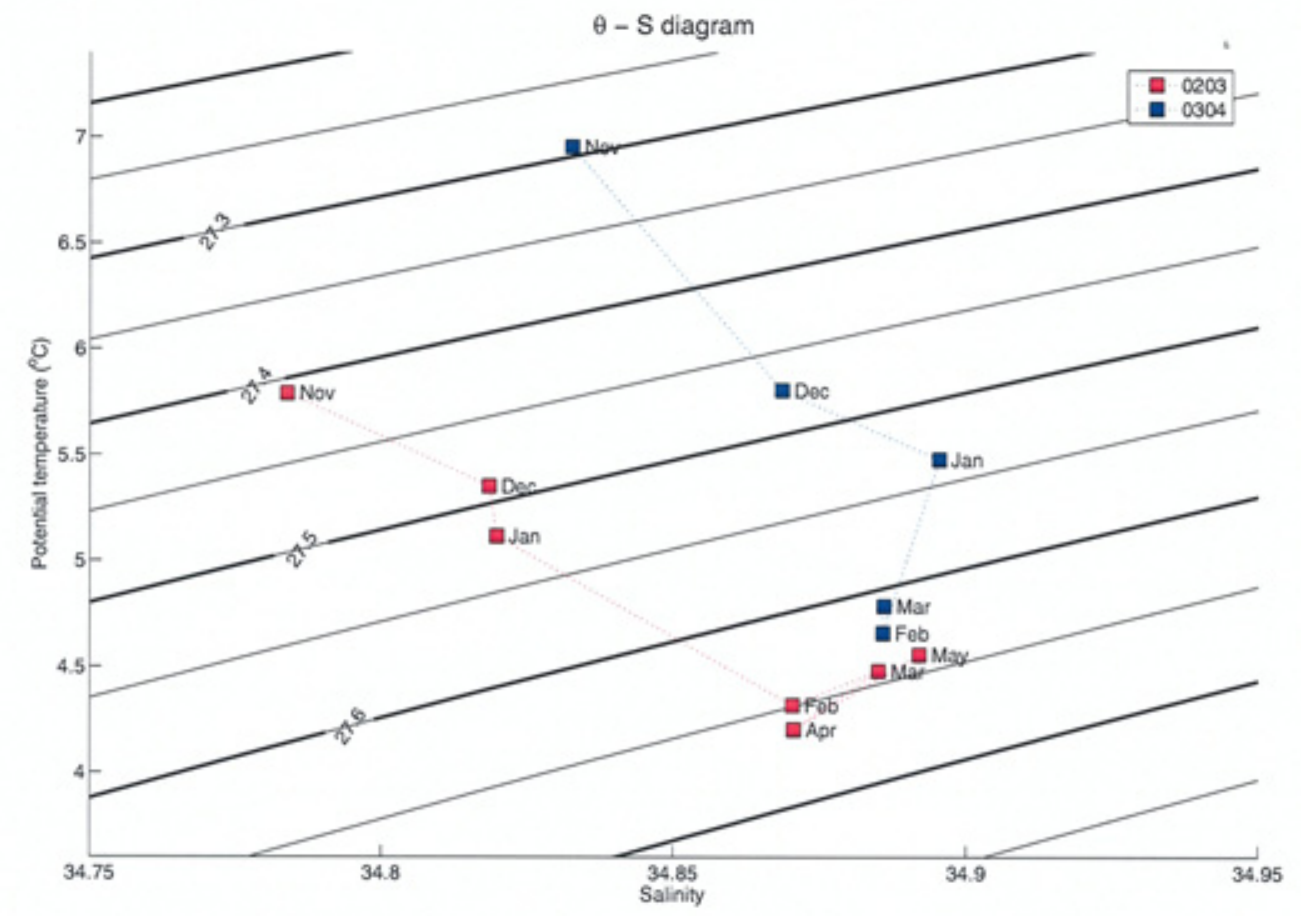

Figure 3-6: Monthly mean $\theta$ - S properties of the deepest mixed-layer for the winters 0203 and 0304 with contours of $\sigma_{\theta}\left(\mathrm{kg} / \mathrm{m}^{3}\right)$.

\section{$3.2 \quad \theta-\mathrm{S}$ properties}

The monthly mean mixed-layer potential temperatures and salinities for each of the two winters are plotted in Figure 3-6. During the first half of the winter, the mixedlayer was relatively cold and fresh in 0203 and relatively warm and salty in 0304 . Towards the second half of the winter, however, the properties for the two years converged, and from February until the end of the convective season they remained 
in the region bounded by 4.2 and $4.8^{\circ} \mathrm{C}$ and 34.87 and 34.90 . The densest monthly mean mixed-layer was observed in April 2003. It had a temperature of $4.2{ }^{\circ} \mathrm{C}$, a salinity of 34.87 and a density of $27.66 \mathrm{~kg} / \mathrm{m}^{3}$. For comparison, LSW formed in the Labrador Basin in 1997 had a potential temperature of $2.9^{\circ} \mathrm{C}$, a salinity of 34.84 and a density of $27.78 \mathrm{~kg} / \mathrm{m}^{3}$ (Pickart et al., 2002), which is much colder and slightly fresher than the water mass produced in the Irminger Sea during winter 0203. As convection reached no deeper than about $400 \mathrm{~m}$ in 0203 , this discrepancy is to be expected (deep convection in the Labrador Sea in 1997 was observed to reach nearly $1500 \mathrm{~m}$; Pickart et al., 2002). The LSW layer found centered near $800 \mathrm{~m}$ in the Irminger Sea during the field program had about the same salinity as the LSW produced in the Labrador Sea in 1997, but was about half a degree warmer, and likely belongs to a vintage formed after the high NAO period of the early 1990s, when deep convection penetrated to shallower depths (Lazier et al., 2002). 


\section{Chapter 4}

\section{Air-sea interaction and the effect of the Greenland tip jet}

In order to understand the seasonal evolution of the mixed-layer in Figure 3-5, as well as the difference in final mixed-layer depths between the two winters, the atmospheric conditions during the two winters are now investigated. The major cause of the deepening mixed-layer in the southwest Irminger Sea is the passage of winter storms, and in particular Greenland tip jet events associated with these storms.

\subsection{Storm tracks}

The 6-hourly sea level pressure (SLP) fields from the NCEP reanalysis were used to track every closed (within $4 \mathrm{mb}$ ) low-pressure system within the domain of Figure 4-1. While automated cyclone detection and tracking algorithms are available (e.g. Serreze et al., 1997), because of the high cyclone activity associated with the Icelandic Low and cyclone splitting and merging associated with the high topography of Greenland (Petersen et al., 2003; Tsukernik et al., in press), the tracking was done by hand. The resulting storm tracks for both winters are plotted in Figure 4-1. In general the storms propagated through the domain from southwest to northeast along the North Atlantic storm track (Hoskins and Hodges, 2002). During the winters 0203 and 0304, 80 and 96 storms respectively were tracked. Several instances of cyclone 
interaction were observed. Weakening low-pressure systems were often overtaken by subsequent deeper lows leading to mergers, and there were numerous cases of cyclones splitting south of Cape Farewell and continuing as two separate lows on either side of Greenland.

\subsection{Signature of tip jet events}

Due to its relatively coarse spatial resolution $\left(1.9^{\circ}\right)$, concerns about the ability of the NCEP wind field to capture small-scale phenomena such as the Greenland tip jet were raised by Pickart et al. (2003b) and Moore (2003). This motivated use of the higher-resolution $\left(1 / 4^{\circ}\right)$ QuikSCAT wind data set. At the latitudes of interest in this study, wind speed and direction data from the SeaWinds scatterometer as processed by Remote Sensing Systems, Inc. (Wentz et al., 2001) were available two times daily. The NCEP sea level pressure field has a much larger scale than the wind field, and is not significantly affected by the tip jet events. However, the configuration of the sea level pressure gradient field was found to play an important role for tip jet formation. Tip jet events were readily recognized by strong zonal (westerly) winds originating near Cape Farewell and extending into the Irminger Sea (see Fig. 1-3), following intensified pressure gradients. The same number of events (17) occurred during each winter, although there was significant variability in their strengths.

Figures 4-2 to 4-5 show composites of each winter's tip jet events, with the given number of hours being the time relative to the peak of the event. Each tip jet event was associated with a parent cyclone located in the area east of Greenland and north of Cape Farewell, whose position is marked with an L in Figure 4-2. For most of the tip jet events, the parent low was situated directly off the southeastern coast of Greenland. Some events, however, occurred when the center of the low was as distant as northeast of Iceland almost $2000 \mathrm{~km}$ away. Common for all of the tip jet events, regardless of the position of the parent low, was the pattern of sea level pressure gradients displayed in Figure 4-3. Enhanced pressure gradients along the eastern coast of Greenland curving sharply to the east near Cape Farewell over the Irminger 

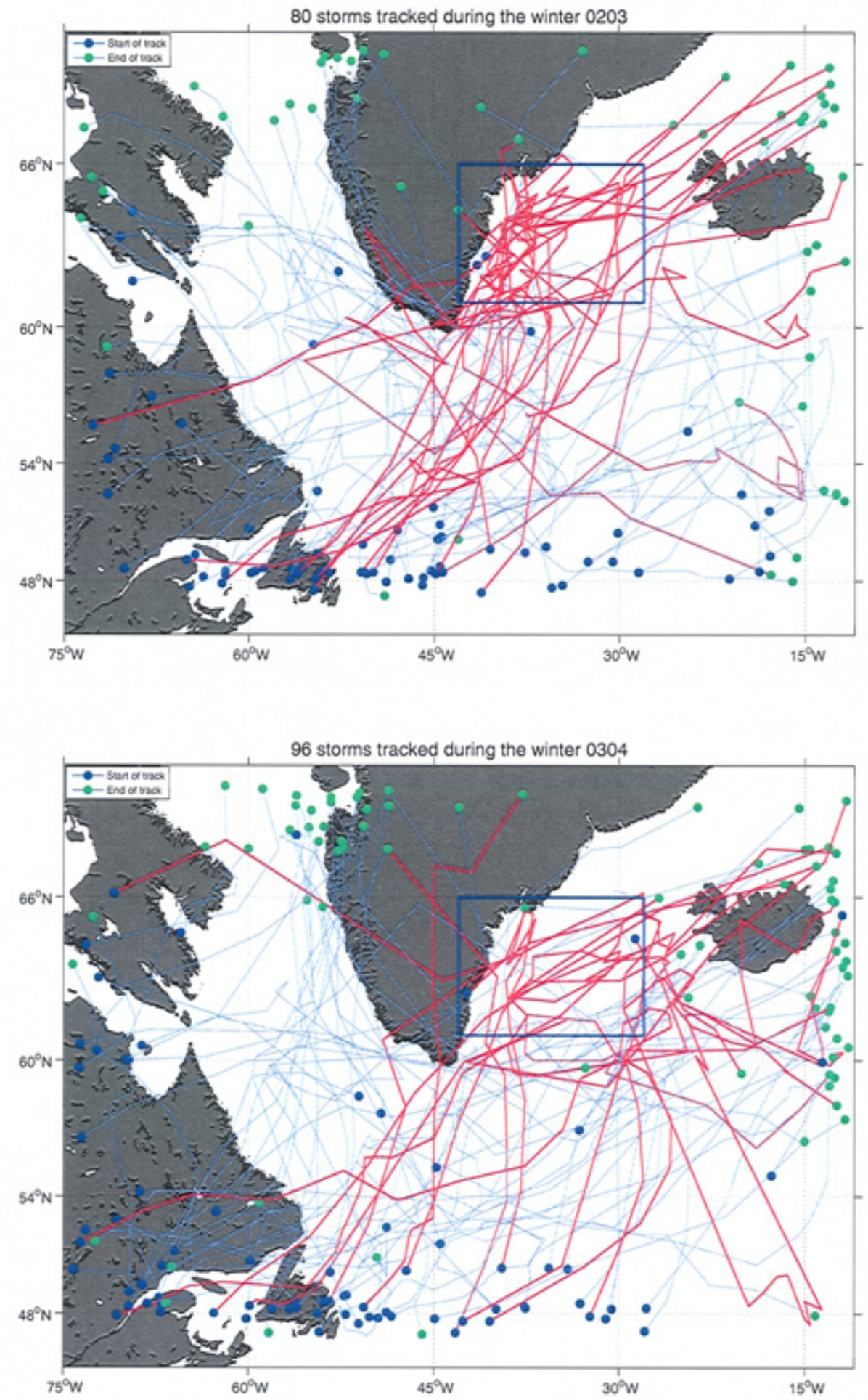

Figure 4-1: Closed low-pressure systems tracked manually using NCEP reanalysis data from entry into domain (blue dot) until departure from domain (green dot) for the winters 0203 (top) and 0304 (bottom). The "trigger box" is the area within the blue frame (see text for explanation). Storms directly responsible for causing tip jet events have red tracks. 
Sea were present during all of the events. The gradient along the coast of Greenland is due to the topographic barrier of the Greenland plateau (e.g. Moore and Renfrew, 2005). While the magnitude of this gradient of sea level pressure may be questionably represented by NCEP because of the high topography of the Greenland landmass (Moore, personal communication, 2006), the general feature is robust. Despite some variation in the path of the tip jets, the mean composite wind speed during the peak of the tip jet events exceeded 25 and $20 \mathrm{~m} / \mathrm{s}$ southeast of Cape Farewell for the first and second winters respectively (Fig. 4-4). The location of the mooring was just north of the region of maximum mean winds, and not all of the individual tip jet events occurred directly above the mooring. Strong northeasterly winds along the eastern coast of Greenland are evident in Figure 4-4 as well. These are barrier winds, and are also associated with low-pressure systems northeast of Cape Farewell (Moore and Renfrew, 2005). Figure 4-5 shows the advection of cold air over the Irminger Sea during tip jet events, which contributes to elevated air-sea heat fluxes (see next chapter). The composites indicate that the tip jet is a rather short-lived phenomenon, with peak winds generally sustained for less than one day (Fig. 4-4).

Despite the similarity in appearance and number of tip jet events in each year, there were several important differences between the two winters. Most notably, the majority of the tip jet events that took place during the winter 0304 were significantly weaker than those of the previous winter, which is reflected in overall higher sea level pressures of the storm centers (Fig. 4-2), weaker pressure gradients (Fig. 4-3) and lower wind speeds (Fig. 4-4). The tip jets of the winter 0304 generally also advected warmer air over the Irminger Sea (Fig. 4-5), which in turn results in smaller heat fluxes. A contributing factor to the higher mean tip jet sea level pressure of 0304 was the greater scatter of the parent lows (Fig. 4-2). The seasonal mean sea level pressure fields for the entire winters were also quite different (Fig. 4-6), even though the NAO index was nearly identical for the two winters (Fig. 1-2). During the winter of 0203, there were both deeper and a larger number of low-pressure systems occupying the area east of southern Greenland. During the winter of 0304, the center of the cyclonic activity associated with the Icelandic Low was shifted eastwards, but as the mean sea 

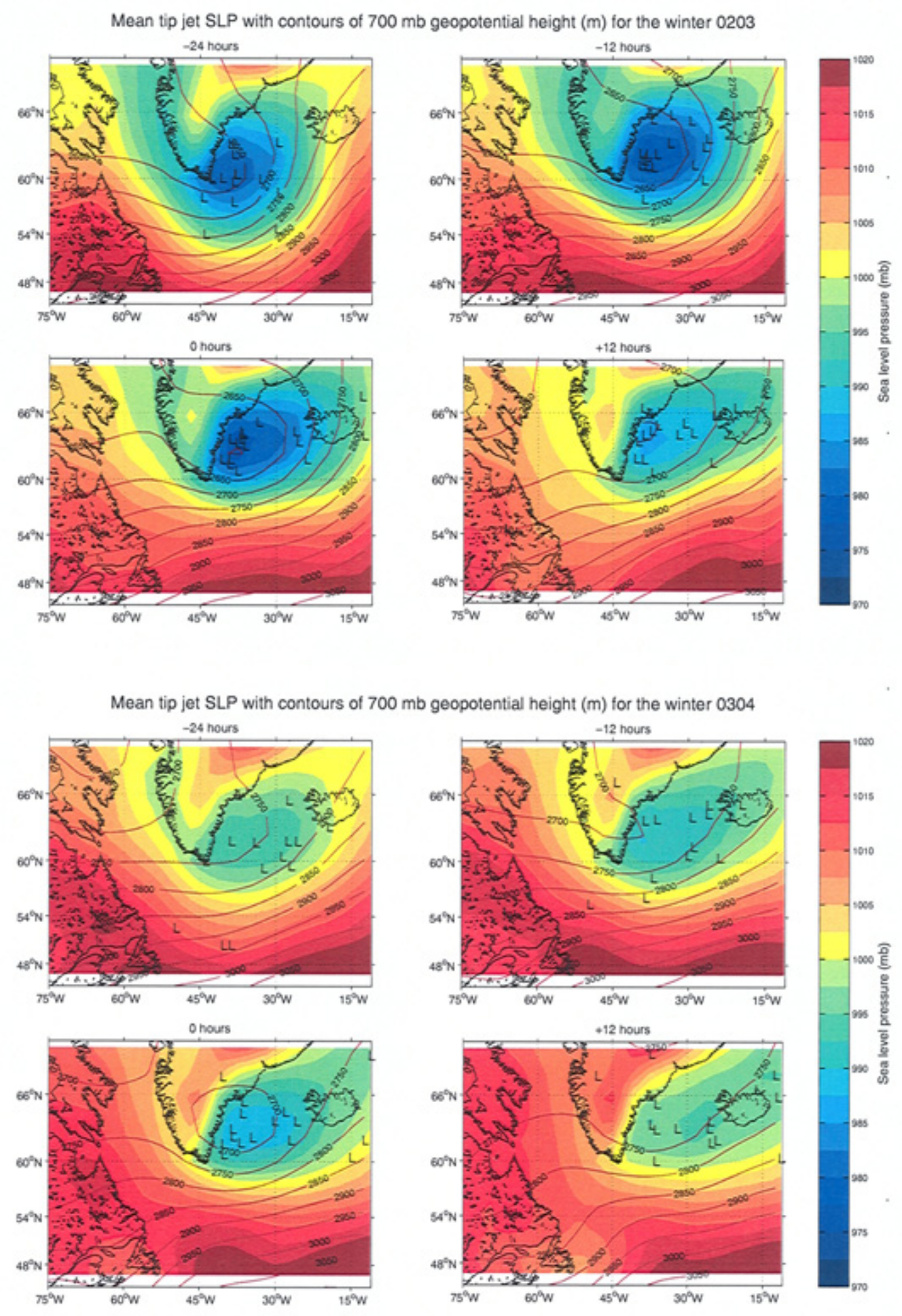

Figure 4-2: Composite of NCEP sea level pressure (color, $m b$ ) during all of the tip jet events for the winter 0203 (top) and 0304 (bottom). Overlaid on this is the height of the $700 \mathrm{mb}$ geopotential surface (contours, $\mathrm{m}$ ), which is a measure of the upper level steering currents. The given times indicate hours before and after the peak of the tip jet event, and the L marks the center of the parent low-pressure system. 

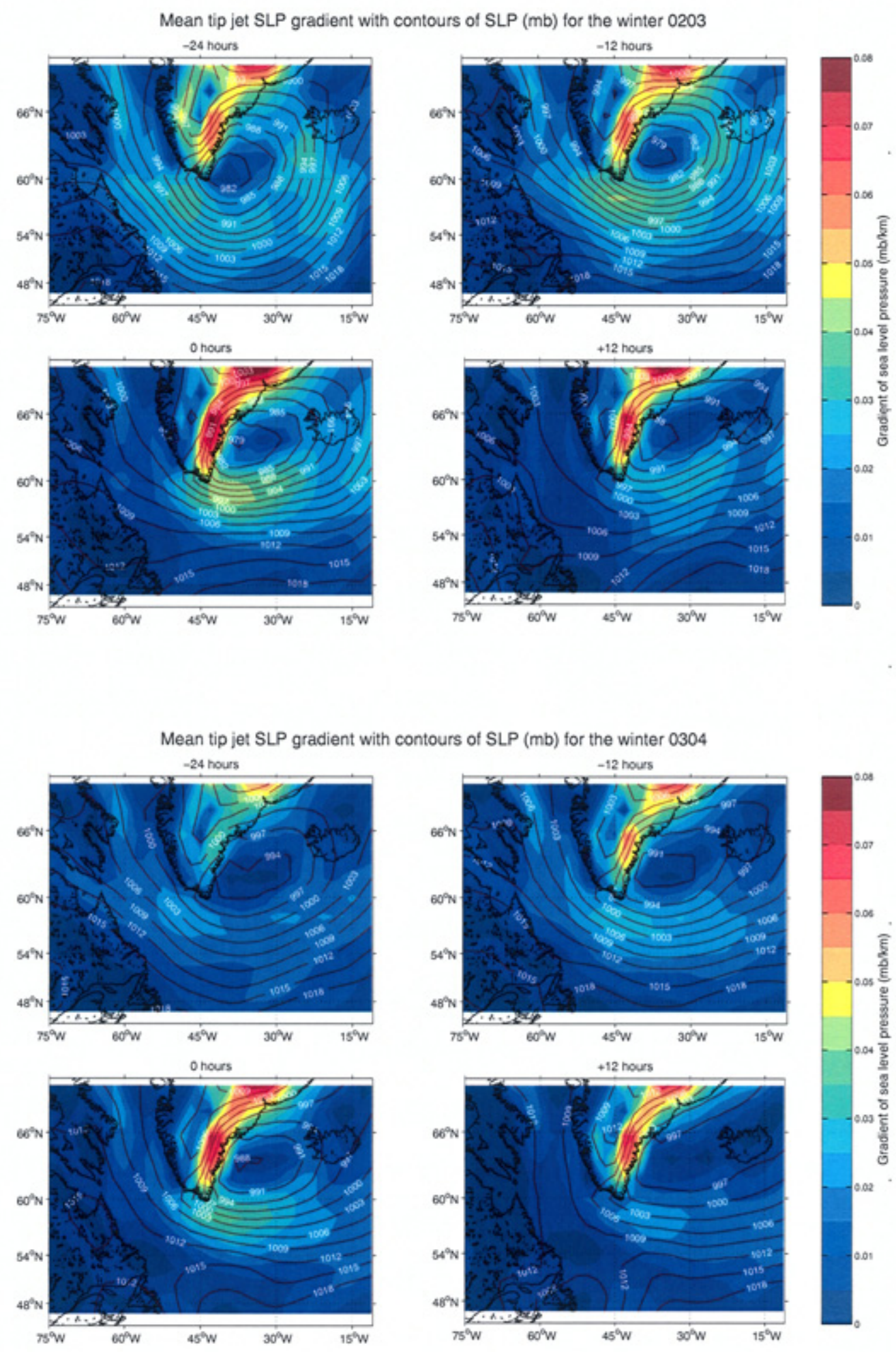

Figure 4-3: Composite of NCEP sea level pressure gradient (color, $\mathrm{mb} / \mathrm{km}$ ) during all of the tip jet events for the winter 0203 (top) and 0304 (bottom) with contours of sea level pressure $(\mathrm{mb})$ overlaid. 

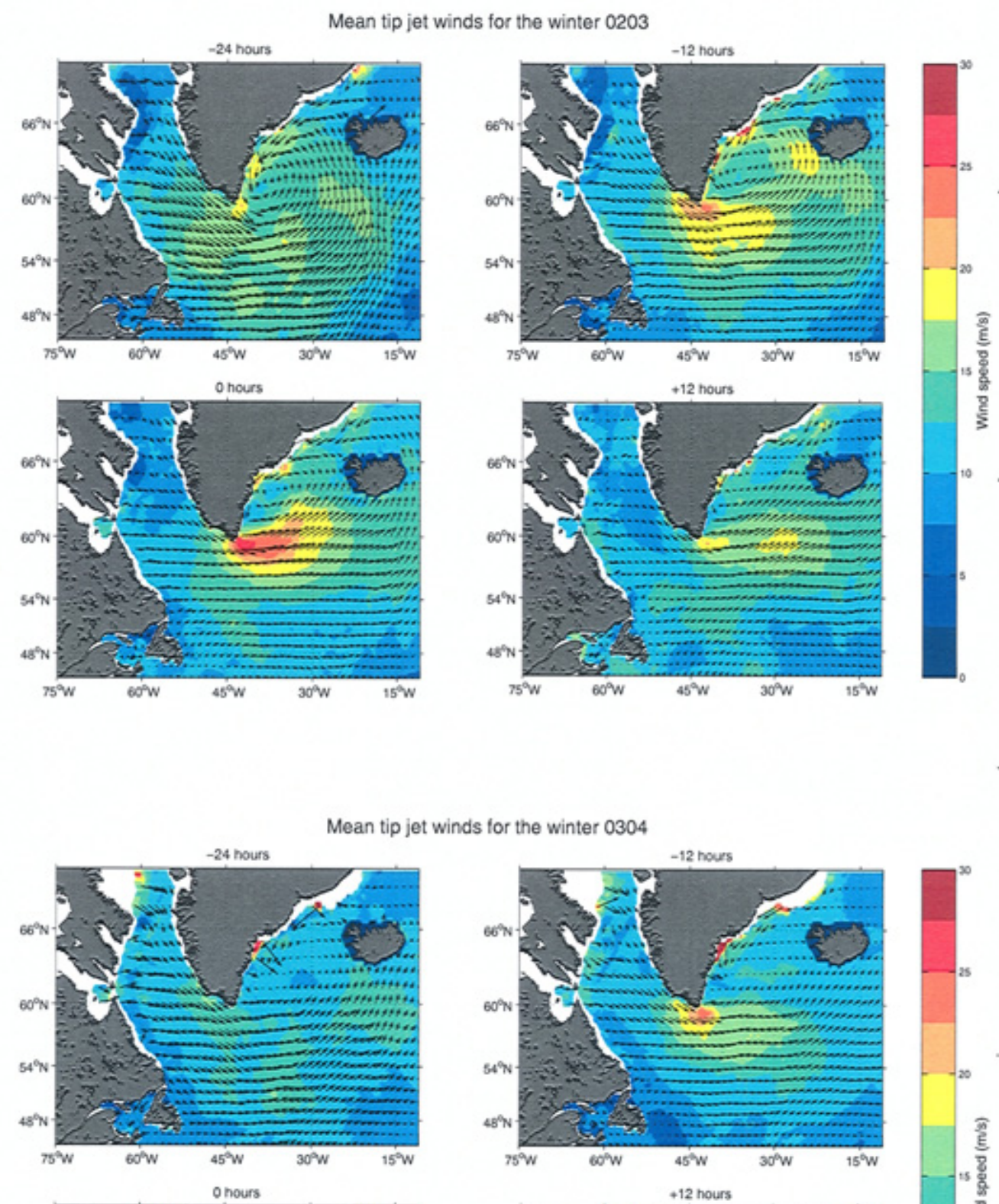

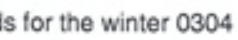

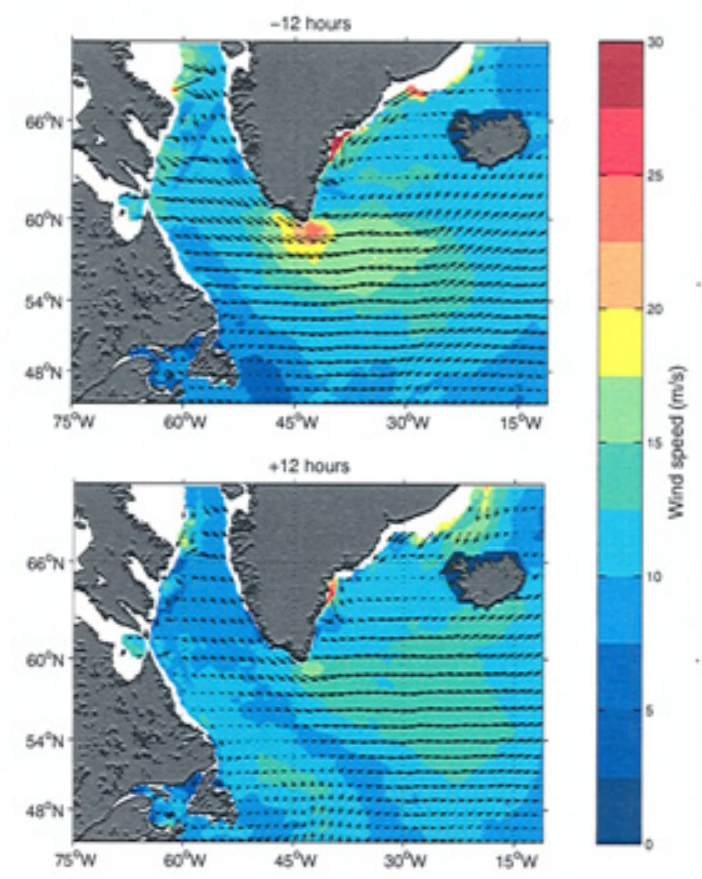

Figure 4-4: Composite of QuikSCAT $10 \mathrm{~m}$ wind speed (color, $\mathrm{m} / \mathrm{s}$ ) during all of the tip jet events for the winter 0203 (top) and 0304 (bottom). Every $25^{\text {th }}$ wind vector is plotted. 
Mean tip jet $2 \mathrm{~m}$ air temperature for the winter 0203
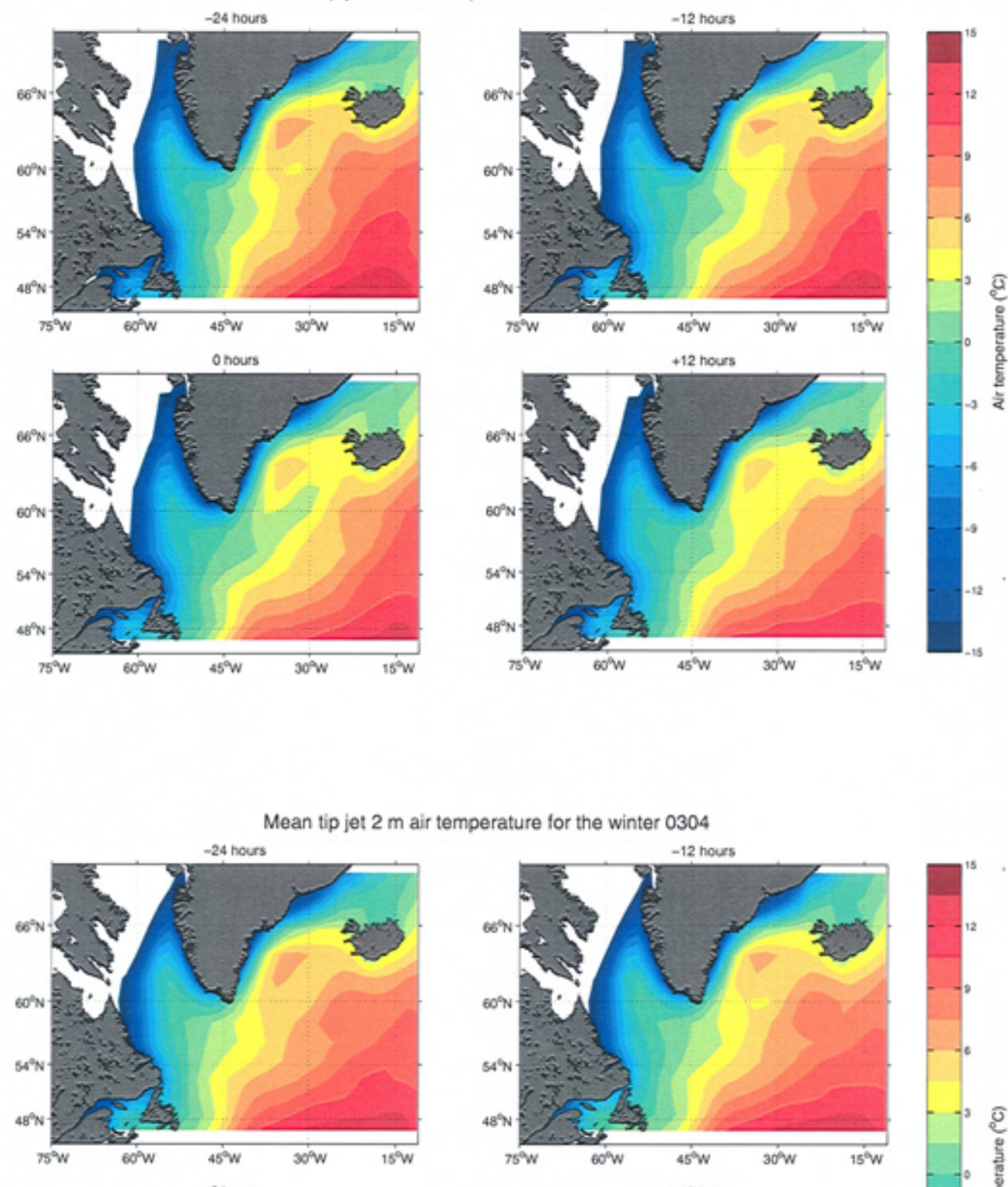

perature for the winter 0304
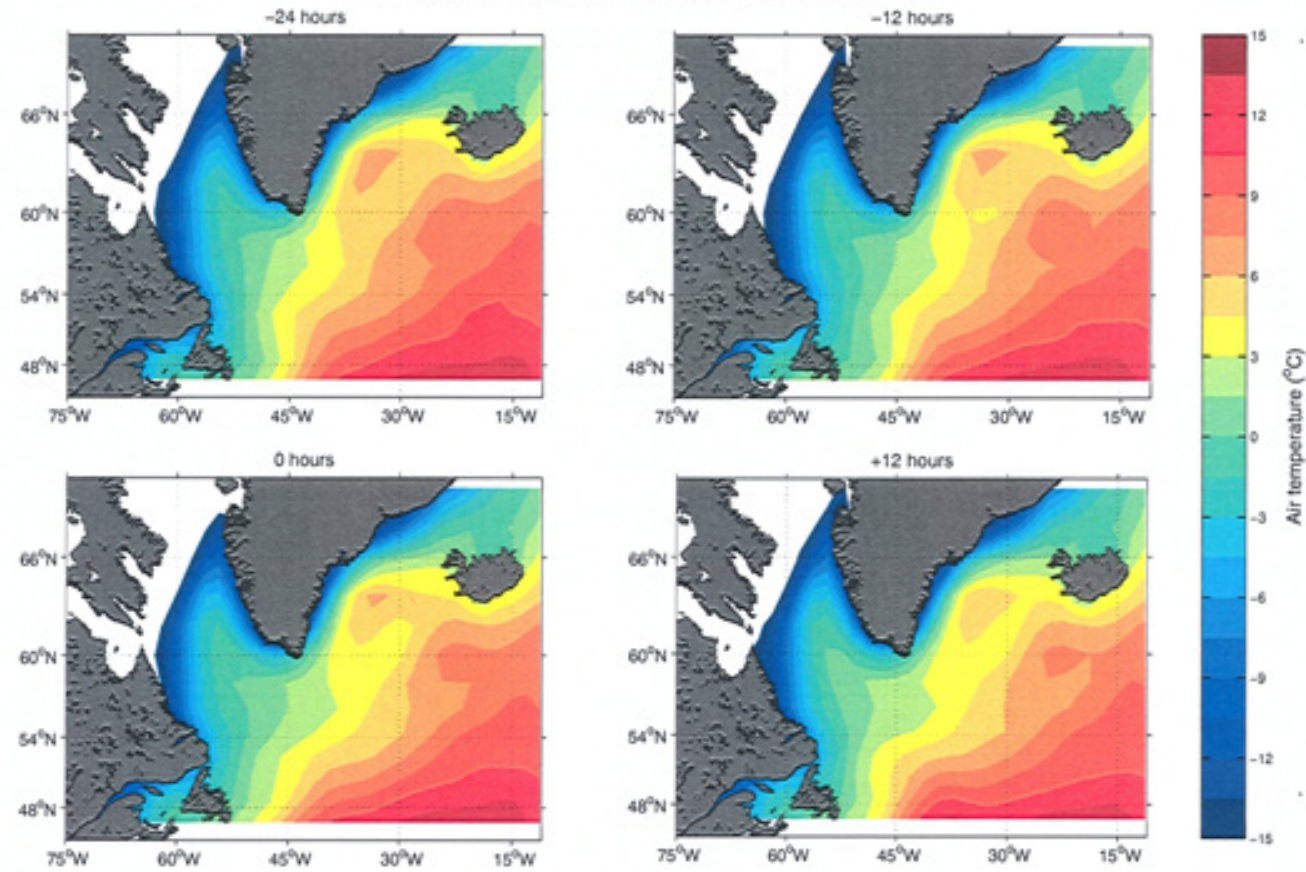

Figure 4-5: Composite of NCEP $2 \mathrm{~m}$ air temperature (color, ${ }^{\circ} \mathrm{C}$ ) during all of the tip jet events for the winter 0203 (top) and 0304 (bottom). 
level pressure near Stykkisholmur, Iceland, did not change much, this shift was not reflected in the NAO index (the winter mean sea level pressures in Lisbon, Portugal, were approximately identical for the two winters according to the World Monthly Surface Station Climatology from the National Climatic Data Center). Such lateral shifts of the center of the Icelandic Low are well-known, and meridional shifts have recently been related to the frequency of tip jet events (Bakalian et al., 2006).
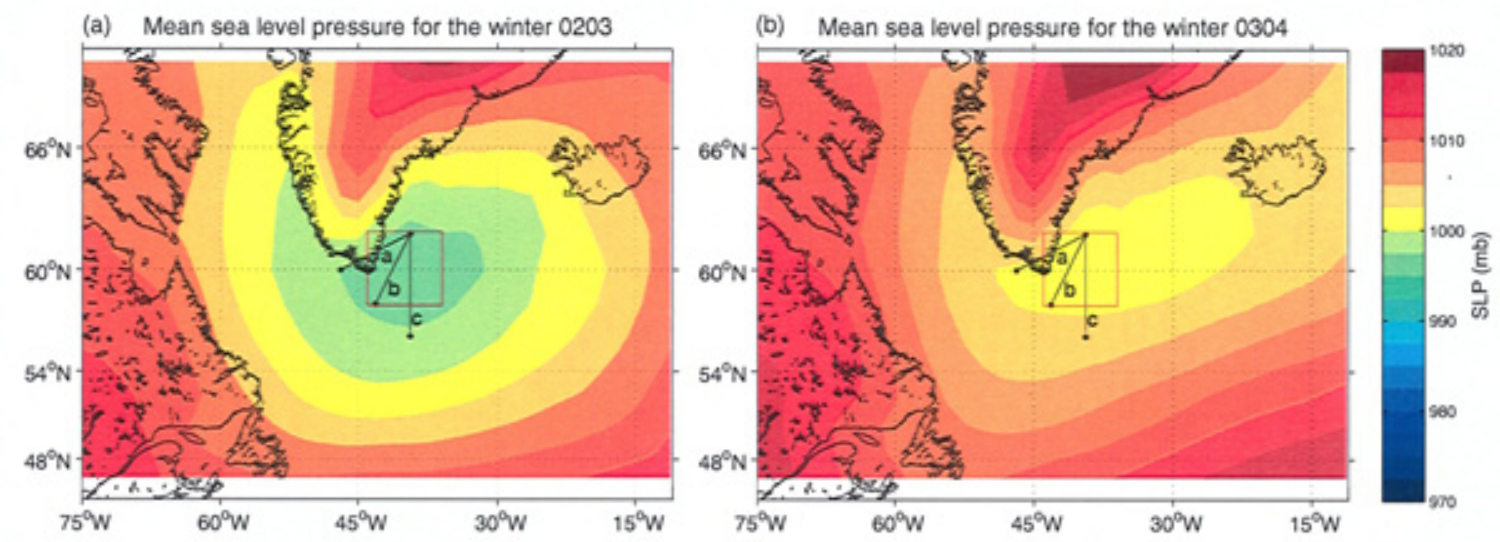

Figure 4-6: Mean NCEP sea level pressure for winters 0203 (a) and 0304 (b). See text for explanation of the box and the lines.

The tracks of the storms that led to tip jet events are plotted in red in Figure 4-1. During the winter of 0203, most of the tip jet producing storms followed a well defined path that entered the domain near Newfoundland, Canada, proceeded in a northeastward direction past Cape Farewell through the Denmark Strait, and left the domain northeast of Iceland. By contrast, the storms that caused tip jets during the second winter followed no such "highway". Instead the tracks were distributed throughout most of the western North Atlantic. The main reason for this dissimilarity is the steering currents, which are the prevailing upper-level flow patterns that govern the movement of smaller embedded low-level features. Figure 4-7 shows the mean 700 $m b$ geopotential height contours for the two winters. The contours were oriented in a more meridional direction near Cape Farewell during the first winter, causing more lows to enter the Irminger Sea and become trapped in the lee of Greenland by the steering currents (as in Figure 4-2 at 0 hours), while the more zonally oriented contours of the second winter tended to advect the low-pressure systems across the North 
Atlantic without focusing them near Greenland, which apparently is unfavorable for the generation of strong tip jets. The contours of the mean $700 \mathrm{mb}$ geopotential height during the canonical tip jet events for both winters (Fig 4-2) are more similar to the mean contours of the winter 0203 than the winter 0304 (Fig. 4-7). On a larger scale, the winter of 0203 may be classified according to Vautard (1990) as being associated with a "blocking" regime, while the conditions for the winter of 0304 were more similar to the "Atlantic ridge" regime. Although these regimes may not last for more than a couple of weeks at the time, they appear to be the dominant modes that occurred during these two winters.

Pickart et al. (2003b) found that every one of the storms between December 1992 and March 1993 passing through an area dubbed the "trigger box" (see Fig. 4-1) caused tip jet events. During the winters of 0203 and 0304 some storms did pass through this area without leading to such events. We believe that these storms failed to produce tip jets because they did not result in the pressure gradient field associated with the canonical tip jet event (Fig. 4-3), either due to interaction with another lowpressure system (Fig. 4-8) or because the pressure associated with the cyclone was not low enough relative to the ambient sea level pressure west and south of Cape Farewell. From Figures 4-2 and 4-8 it is evident that a cyclone passing in the vicinity of the "trigger box" east of Greenland will not always cause a tip jet event. Furthermore, low-pressure systems north and east of Iceland are occasionally able to produce tip jet events despite being far removed from the coast of Greenland. Examination of a greater number of tip jet events may be required to make a more conclusive statement, however.

\subsection{Air parcel trajectories}

In order to further investigate the formation of tip jets as well as the origin of the air parcels constituting the tip jet events and the observed differences between the two winters' events, the British Atmospheric Data Centre's (BADC) trajectory model was employed (http://www.badc.rl.ac.uk). This model computed back trajectories from 

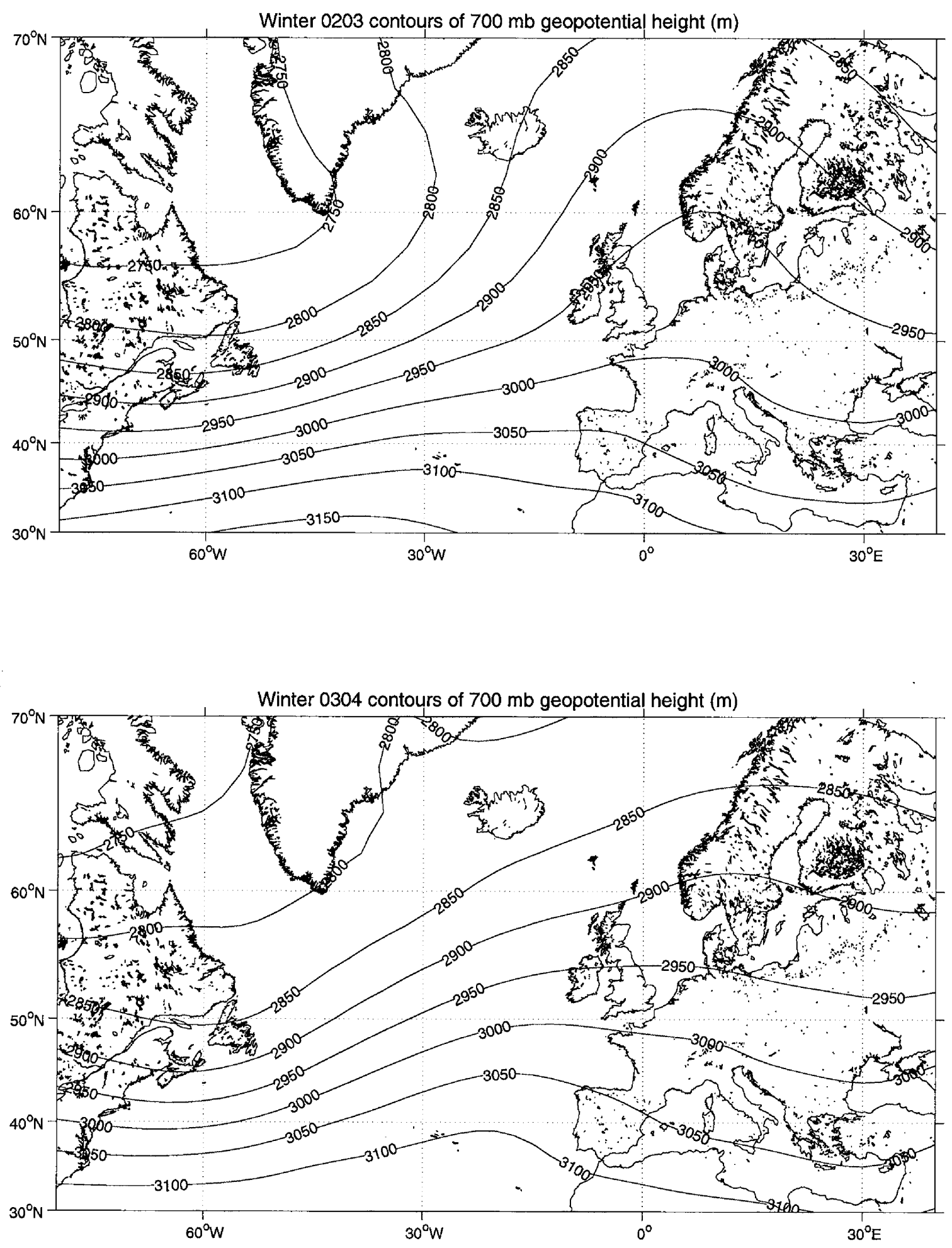

Figure 4-7: Contours of mean $700 \mathrm{mb}$ geopotential height $(\mathrm{m})$ for the entire winter of 0203 (top) and 0304 (bottom). 

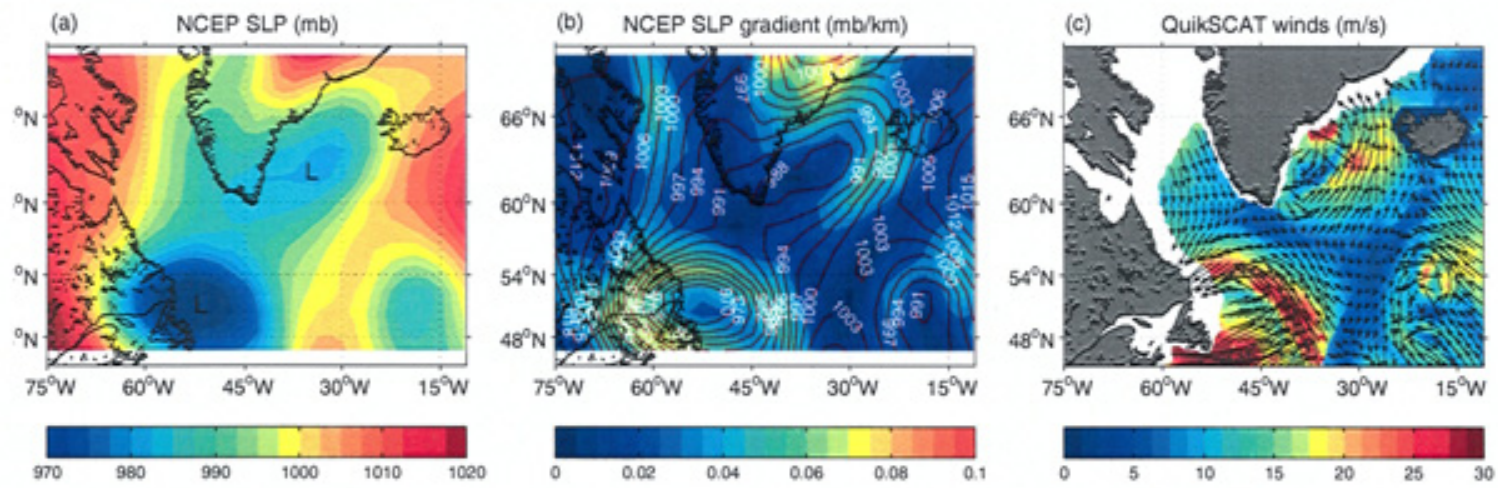

Figure 4-8: Example of a low-pressure system east of Greenland that failed to produce a tip jet due to interaction with a second low northeast of Newfoundland in (a) NCEP sea level pressure $(\mathrm{mb}),(\mathrm{b})$ NCEP sea level pressure gradient $(\mathrm{mb} / \mathrm{km})$ and (c) QuikSCAT winds $(\mathrm{m} / \mathrm{s})$.

the European Centre for Medium-Range Weather Forecasts' (ECMWF) $1.125^{\circ}$ model analysis data using 3D advection. We produced two-day long back trajectories that terminated at $900 \mathrm{mb}$ (about $700 \mathrm{~m}$ ) above the mooring site in the Irminger Sea. This pressure level was chosen to avoid air parcels intersecting the topography of Greenland. First a case study of the robust 5 December 2002 tip jet event (Fig. 1-3) is examined in detail, and then the ensemble of all the robust tip jet events for both winters is considered and the two winters are contrasted.

\subsubsection{December 2002 case study}

The history of the air parcels constituting the 5 December 2002 tip jet event are plotted in Figure 4-9. Trajectories were calculated to terminate every 3 hours, from 21 hours before the peak of the tip jet event to 12 hours after the peak, and the labels at the beginning of each trajectory in Figure 4-9 (a) correspond to the time of termination relative to the peak. As mainly QuikSCAT and NCEP fields were used to determine when the peak occurred, the exact timing is only accurate to within about 6 hours. All of the trajectories except the one ending 3 hours prior to the peak, which did intersect the topography of Greenland, are included. The blue L's indicate the position of the parent low-pressure system at each time step. The trajectories show 
(a) Backward trajectories during the 5 December 2002 tip jet event

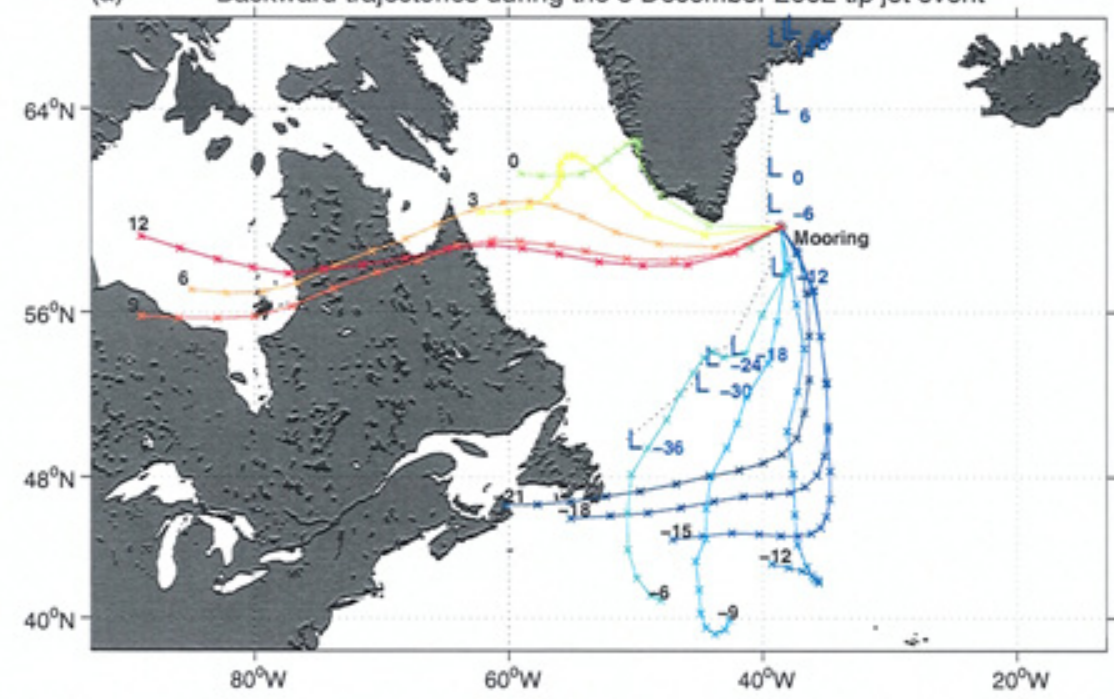

(b)

Time vs, pressure

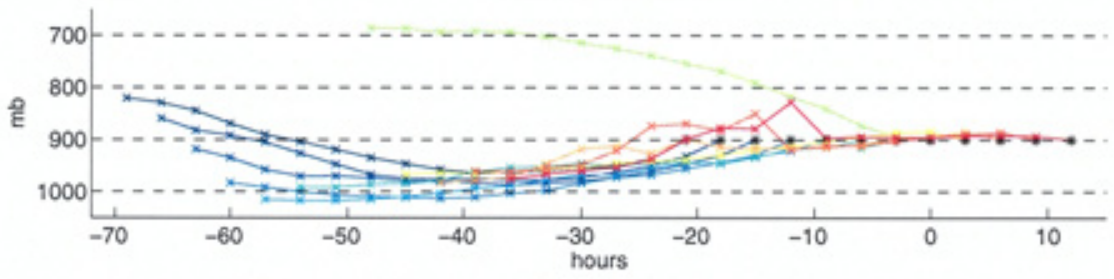

(c) NCEP fields at the mooring site during the 5 December 2002 tip jet event
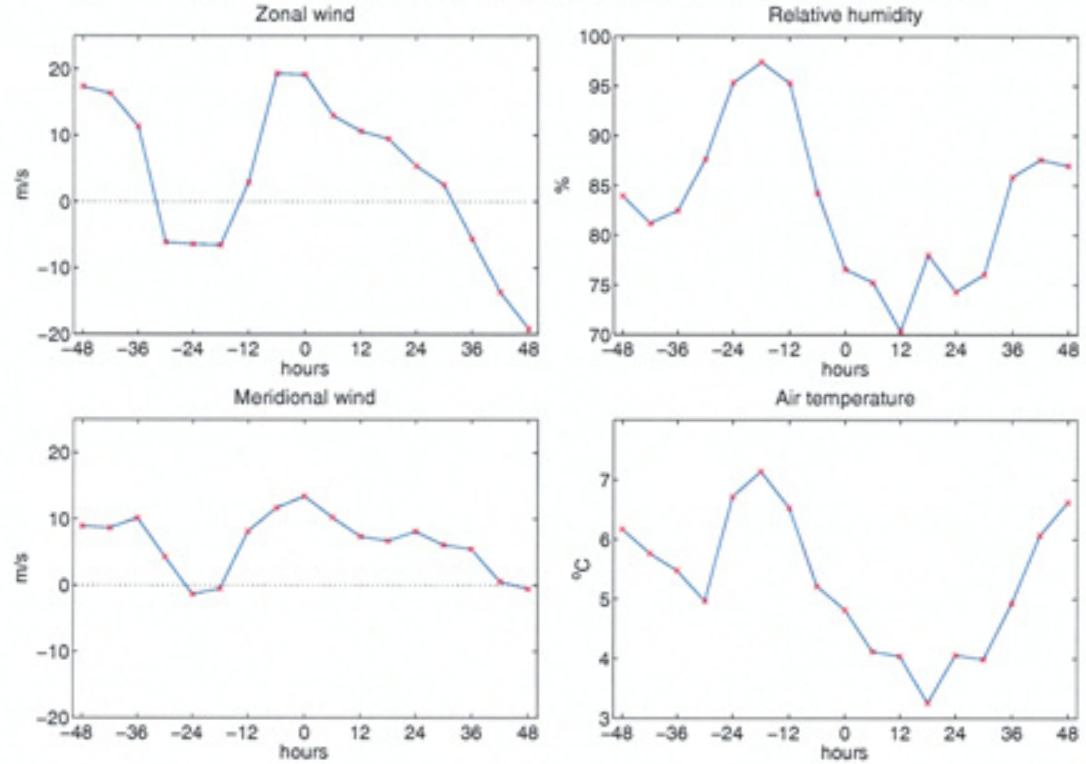

Figure 4-9: Case study of the 5 December 2002 tip jet event. Time is measured in hours before and after the peak of the event. (a) Backward trajectories and positions of the parent low, (b) pressure along the trajectories and (c) NCEP winds, relative humidity and air temperature encompassing the event. 
that as the low progressed from Newfoundland, where it entered the domain and tracking commenced, until near time 0 , when it was positioned off the east coast of Greenland, the air at the mooring site originated from the south. Some time between -6 and 0 hours the tip jet formed, and the air parcels at the mooring site then came directly from the west, from the Labrador Sea and northern Canada. The trajectories from 0 to 6 hours after the peak showed a significant acceleration before reaching the mooring (evident from the increase in distance between tick marks). The high wind speed south of Greenland was associated with the tip jet event. The air parcels were generally ascending before reaching the mooring site with the exception of the parcel following the trajectory at the peak of the event, which descended sharply prior to its termination at the mooring site (Fig. 4-9 (b)). The NCEP fields at the mooring site during the two days before and after the peak of the tip jet event are shown in Figure 4-9 (c). The zonal (westerly) wind reached almost $20 \mathrm{~m} / \mathrm{s}$ near time 0 , which is much lower than the observed $37 \mathrm{~m} / \mathrm{s}$ zonal wind by QuikSCAT (Fig. 1-3). Only a weak increase in the meridional (southerly) wind was noted. Although NCEP is not ideal for resolving tip jet events, a clear regime change from warm and moist oceanic air to colder and drier continental air was evident in the air temperature and relative humidity plots immediately preceding the peak of the tip jet event.

\subsubsection{All robust tip jets}

With the possible exception of the trajectory at -3 hours (not shown), the trajectory model indicated that the air parcels caught in the tip jet skirted around Greenland rather than descending from the Greenland plateau. Figure 4-10 shows the computed trajectories of all the robust tip jet events for both winters, for those air parcels that arrived at the mooring site during the peak of each event. Most of the air parcels found in the tip jets approached Greenland from a westerly direction (Fig. 4-10 (a)), and were then deflected by the high topography of southern Greenland resulting in acceleration before eventually reaching the mooring site. None of the air parcels reaching the mooring site at the $900 \mathrm{mb}$ pressure level came from the Greenland plateau according to the BADC trajectory model, which supports the observation of 

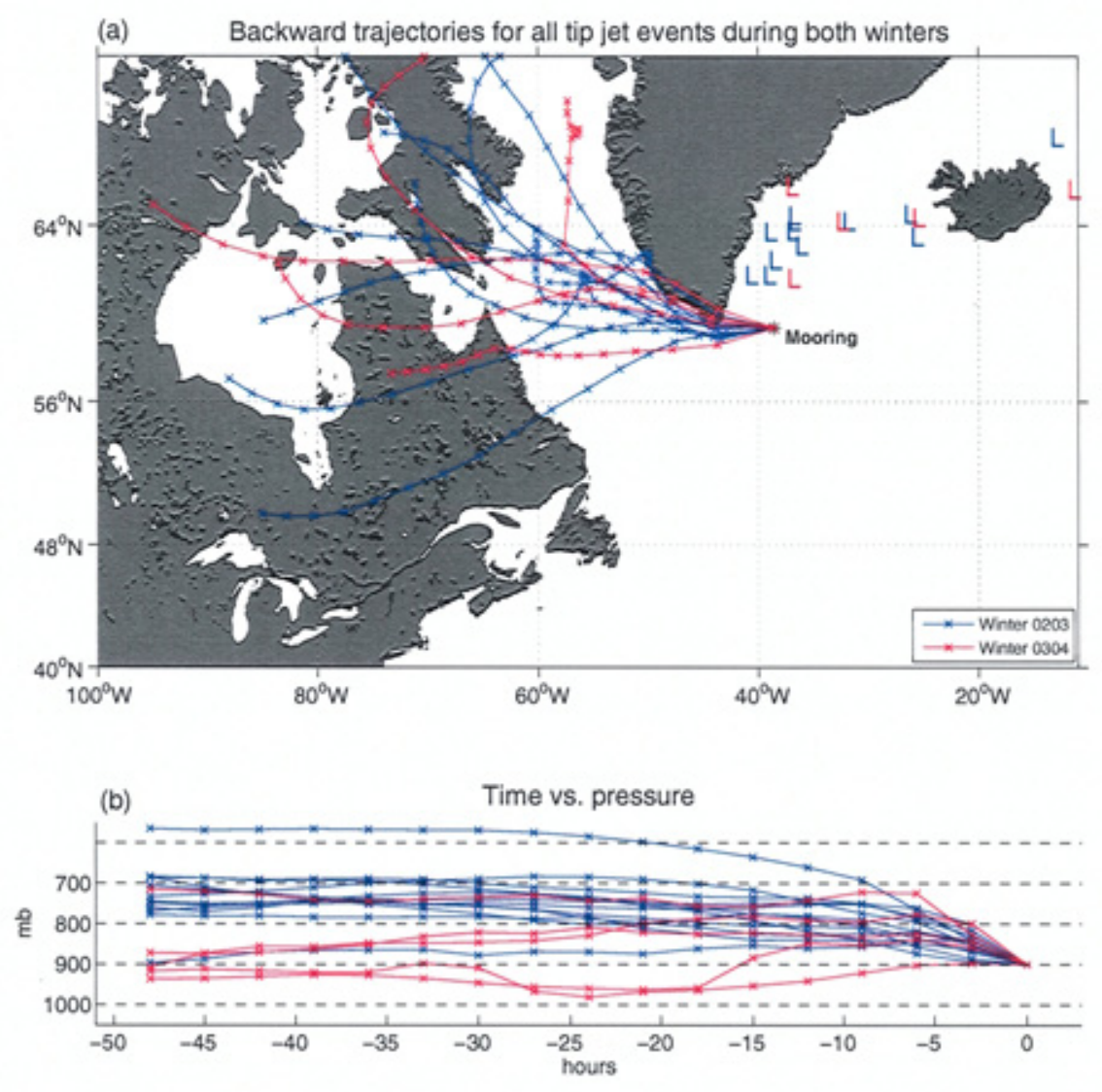

Figure 4-10: Backward trajectory model results at the time of the peak for all of the robust tip jet events directly affecting the mooring during winter 0203 (blue) and winter 0304 (red). The trajectories and the positions of the parent low-pressure systems (marked with L's) during the peak (a) and the along-track pressures (b) are displayed.

Moore and Renfrew (2005) that an acceleration of the wind through the deflection of air parcels is a robust feature of tip jets. The main difference between the trajectories of the two winters' tip jet events is that most of the air parcels originated higher in the atmosphere during the winter 0203 than during the winter 0304 (Fig. 4-10 (b)). The lower origin and the resulting modification of the air as it transited the Labrador Sea during the second winter may in part explain why the tip jets of the second winter were observed to contain warmer air (Fig. 4-5).

To further highlight the impact of Greenland on the formation of tip jets, the change in pressure and velocity along each trajectory for the 0203 events were computed and linearly interpolated onto a $0.5^{\circ}$ grid. Due to the limited number of tip 
jet trajectories, several grid points were omitted. The contour plots show clearly the descent (Fig. 4-11 (a)) and acceleration (Fig. 4-11 (b)) of the air parcels in the vicinity of southern Greenland prior to arrival at the mooring site. Inclusion of the 0304 trajectories resulted in slightly weaker pressure changes near Greenland (not shown), but did not change the overall impression of descending and accelerating flow near southern Greenland.
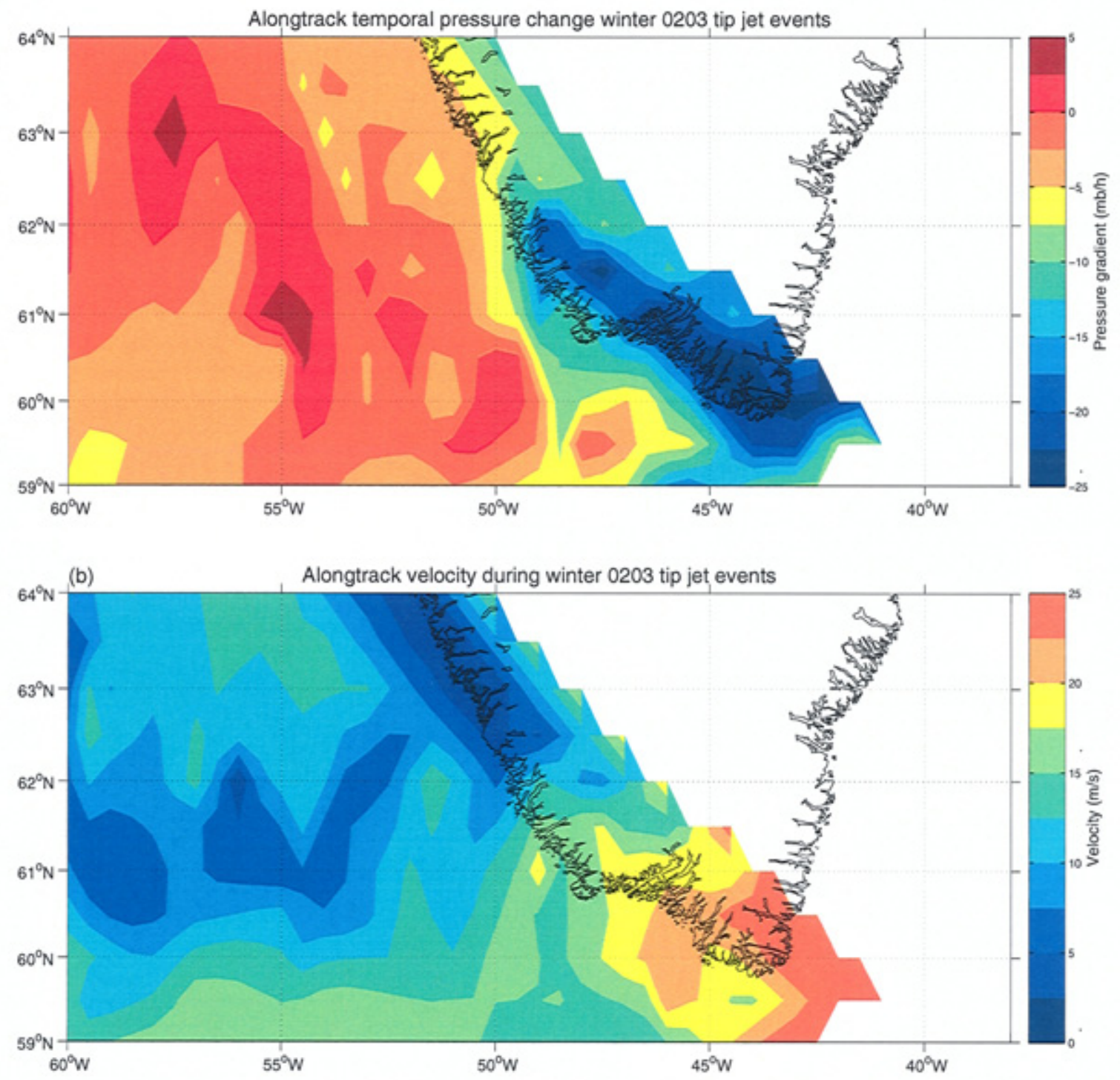

Figure 4-11: Temporal pressure change (a) and velocity (b) along the backward trajectories of the winter 0203 tip jet events. 


\subsection{Objective detection of tip jets}

Using data from the Prins Christian Sund meteorological station (labeled PCS in Fig. 1-1), Pickart et al. (2003b) determined that tip jet events were characterized by strong westerly winds, anomalously low air temperatures and low sea level pressure. They used empirical orthogonal functions (EOFs) with the PCS data to objectively identify the occurrence of tip jet events over a period of approximately 30 years. EOF analysis is a decomposition of a data set into orthogonal basis functions determined from the data using the covariance or correlation matrix. The method is ideally suited to find dominant modes of variability in a data set and provides a measure of the importance of each mode (the amount of variance explained), but cannot say anything about the physical cause of the variability (Björnsson and Venegas, 1997). The storm tracks (Fig. 4-1) and the composite images (Figures 4-2 to 4-5) indicate that the occurrence of a tip jet event is dependent on more than a storm's central pressure, and suggest that the gradient of pressure should be considered as well. As described above, intensified pressure gradients along the east coast of Greenland turning sharply eastwards over the Irminger Sea near Cape Farewell were observed during each tip jet event, regardless of the position and strength of the parent cyclone. The varying path of the tip jet and the suspected influence of the high topography of Greenland make the suitability of the zonal winds from the PCS meteorological station, as used by Pickart et al. (2003b), less than ideal.

A new EOF approach has therefore been devised in which zonal winds, pressure gradients and air temperature were employed. For the wind timeseries, QuikSCAT data were used. In particular, at each point in time the maximum zonal wind within the red box on Figure 4-6, was computed, thereby taking into account the shifting path of the tip jets. Although the temporal resolution of QuikSCAT is lower than PCS (12 hours versus 3 hours), the QuikSCAT winds at the mooring site are not influenced by any fjord effects as coastal met station data may be. Pressure gradients were computed along the lines labeled $\mathrm{a}, \mathrm{b}$ and $\mathrm{c}$ in Figure 4-6 using the NCEP sea level pressure field, and the mean of these three values was used. Although a temperature 
signal was evident in the NCEP reanalysis (Fig. 4-5), its coarse resolution makes it unsuitable to accurately capture the small scale signature of the Greenland tip jet. ${ }^{1}$ Ideally an equivalent roving air temperature timeseries, tied to the position of the maximum QuikSCAT zonal wind, should be used. Unfortunately no product with the desired resolution and accuracy is presently available, and the PCS temperature data were deemed the best available choice. This introduces the possibility of tip jets evading the meteorological station and thus leaving no temperature signature. Inspection of the zonal wind and temperature PCS timeseries at the times of the observed tip jet events implied that two of the observed tip jet events in the first winter and four in the second were undetectable at the meteorological station. These were, however, among the weakest events that occurred, and the signatures of all of the more robust events were clearly detectable in the PCS data.

The EOF calculation was done for the months of November through April, and the dominant mode of variability for both years was that due to tip jet occurrences. The strength of the events varied throughout the winter, and those in which the reconstructed zonal wind speed exceeded $25 \mathrm{~m} / \mathrm{s}$ were designated as robust tip jet events. In the winter of 020316 of the 17 events passed this criterion, and $65 \%$ of the variance was explained. The winter 0304 contained overall weaker tip jet events; only 11 of the 17 tip jets that occurred were robust, and $58 \%$ of the variance was explained. As a check on the EOF calculation, the data were inspected manually for the signature of tip jet events, and no robust events were found that were not detected by the EOF approach. Conversely no tip jet events were detected by the EOF that escaped manual detection. All of the events that did not pass the $25 \mathrm{~m} / \mathrm{s}$ criterion had either below average zonal winds or distorted pressure gradients preventing formation of robust tip jets. Comparison of the EOF method employed here with the method of Pickart et al. (2003b) indicate that the new method is more sensitive. Using data from the PCS meteorological station alone (as Pickart et al. (2003b) did), only 6 tip jets were identified and $52 \%$ of the variance was explained for the winter of 0203 , and 7 events were detected and $45 \%$ of the variance was explained for the winter of 0304 .

\footnotetext{
${ }^{1}$ The NCEP sea level pressure gradient field has a much larger tip jet signature.
} 
This indicates that the meteorological weather station data are influenced by other phenomena, such as fjord effects, and that the EOF approach devised here is better suited for identifying tip jet occurrences.

In order to determine the number of tip jet events directly affecting the mooring site, the QuikSCAT wind at this location, obtained through spatial interpolation, was used in the EOF computation instead of the wind at the roving point. The pressure gradient and temperature timeseries remained unchanged, while the reconstructed zonal wind speed criterion for designation as a robust tip jet event was lowered to 20 $\mathrm{m} / \mathrm{s}$. The resulting number of robust tip jet events was 12 and 5 for the winters of 0203 and 0304 respectively. Meridional shifts in the path of the tip jets was the reason for the reduced number of tip jet events. The occurrences of the tip jet events impacting the mooring site and the development of the depth of the deepest mixed-layer are plotted in Figure 4-12. Considering the differences in the mixed-layer depths for the two years, the discrepancy seems to be largely attributable to the differences between the two winters' tip jet events. The considerable deepening of the mixed-layer that took place throughout February 2003 happened during a concentrated set of tip jet events (7) that occurred just before and during that month. By contrast, the 5 robust storms that directly affected the mooring site during the winter of 0304 were more scattered in time (and two of them occurred after the moored profiler failed). The integrated effect of the heat loss through the winter governs deep convection, which is more likely to occur when concentrated in intense storms rather than distributed evenly but more weakly throughout the winter (Marshall and Schott, 1999). It is shown below that the heat fluxes resulting from tip jet events do indeed largely govern the depth of the mixed-layer in the southwest Irminger Sea. 

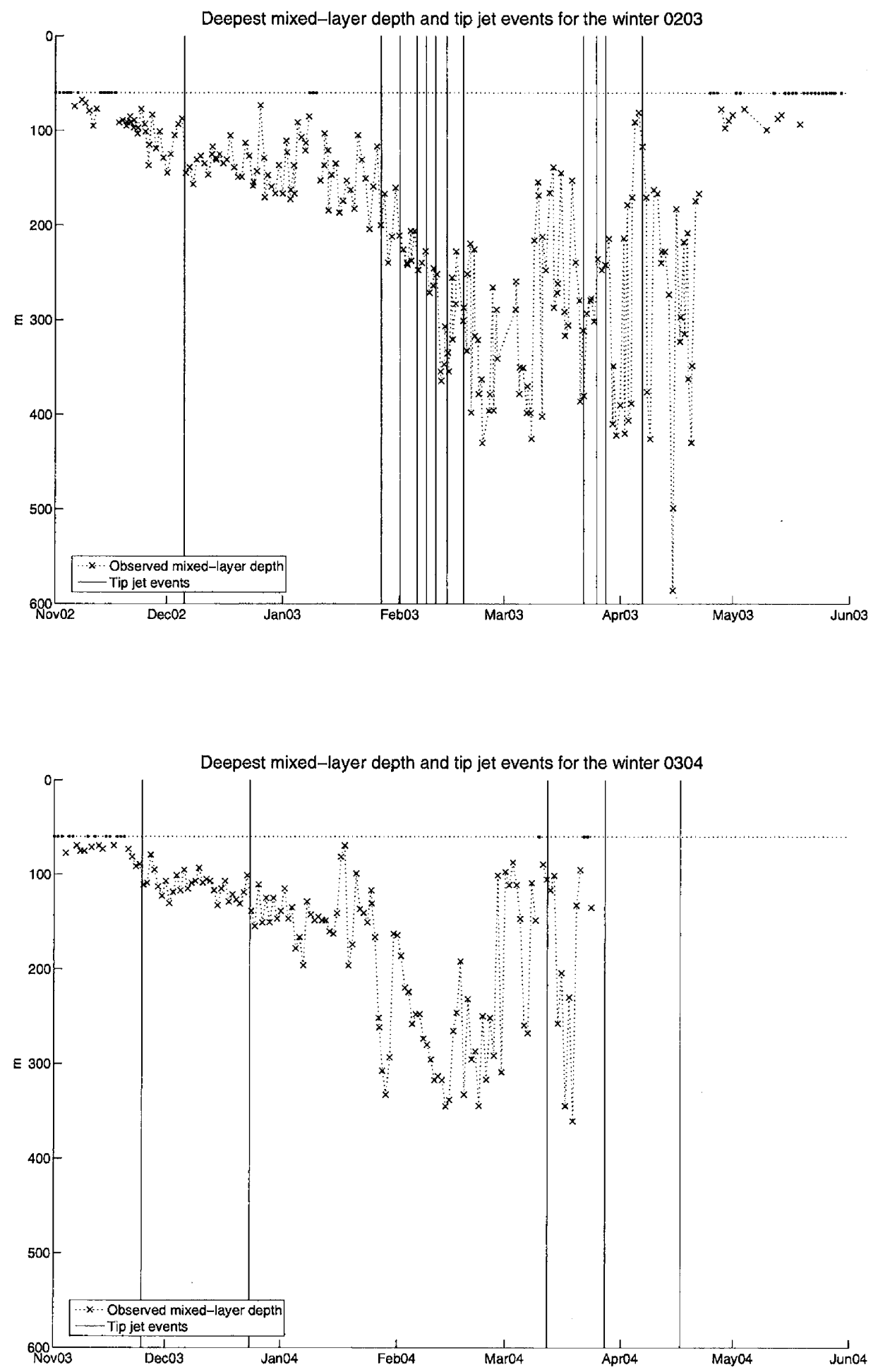

Figure 4-12: Depth of the deepest mixed-layer (black x's) for the winters of 0203 (top) and 0304 (bottom). The black dots identify profiles for which no mixed-layer was observed below $60 \mathrm{~m}$. Tip jet events are indicated by the vertical lines. 


\section{Chapter 5}

\section{Heat fluxes}

Figure 5-1 shows that the concerns raised about NCEP's ability to capture small scale phenomena in the vicinity of Greenland (Pickart et al., 2003b; Moore, 2003) were warranted. While the NCEP and QuikSCAT zonal winds at the mooring site agree quite well overall (correlation coefficient of 0.85), during the tip jet events of the winter of 0203 the QuikSCAT zonal winds were almost twice the strength of the NCEP zonal winds. The scatterometer data is less accurate in rain, and rain-flagged data points were interpolated over. This affected about $10 \%$ of the data, but not during any of the tip jet events.

Renfrew et al. (2002) examined the representation of the ocean-atmosphere interaction in the NCEP model reanalysis using wintertime in-situ data from the Labrador Sea. They found that the surface flux fields in the NCEP reanalysis were systematically overestimated in moderate to high wind conditions due to inappropriate formulation of the heat and moisture roughness length formulations, particularly during events characterized by large air-sea temperature differences. Consequently they used bulk formulae to compute adjusted heat fluxes. We use their flux corrected product in this study, which are referred to simply as NCEP heat fluxes. However, since the NCEP wind field has already been shown to insufficiently capture tip jet events, even the adjusted NCEP heat fluxes during these events will be underestimates. Furthermore, Renfrew et al. (2002) found that neither the NCEP humidity nor the sea surface temperature fields agreed particularly well with in-situ observations, and both 


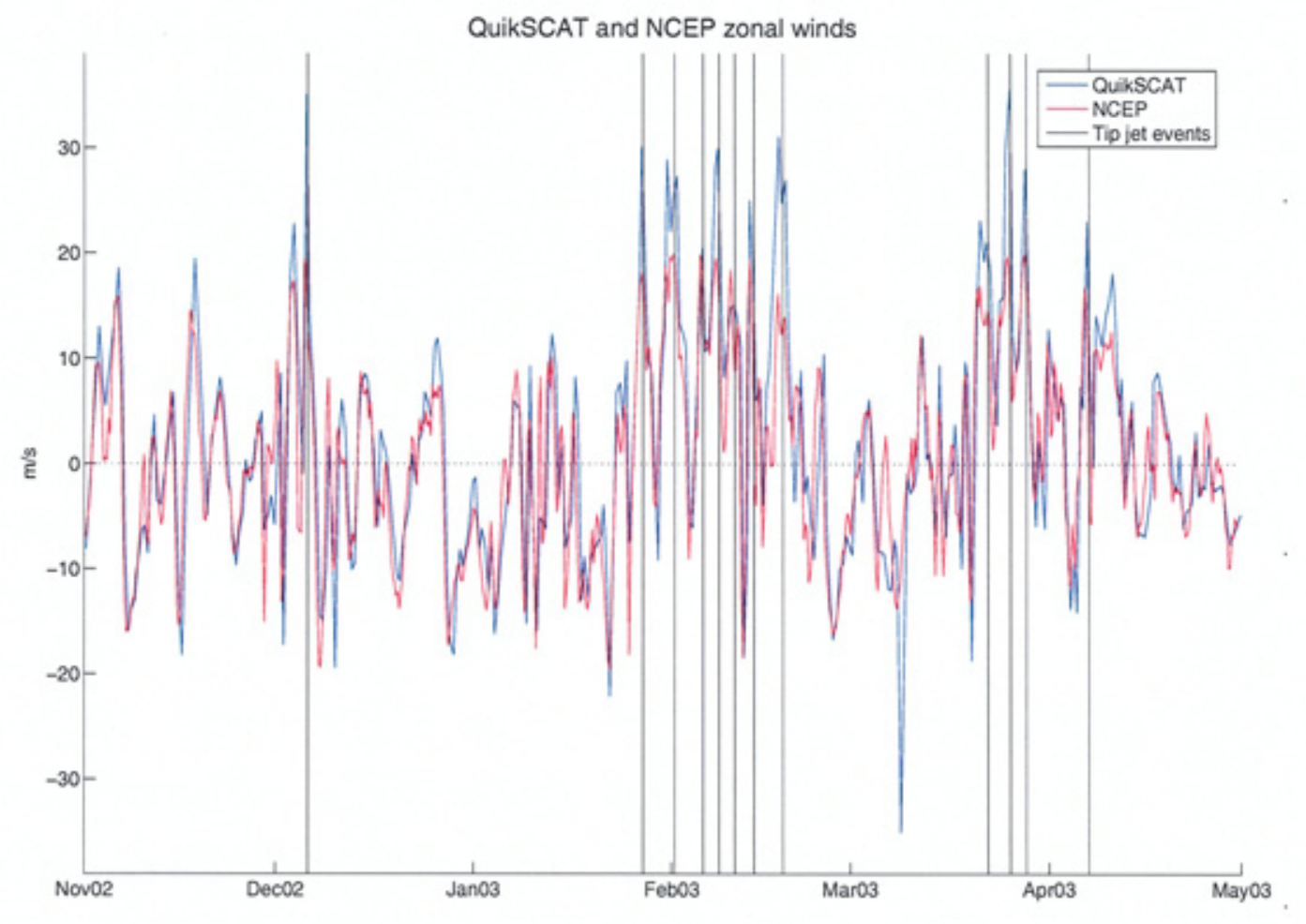

Figure 5-1: Comparison of QuikSCAT (blue) and NCEP (red) zonal winds for winter 0203. Rain-flagged QuikSCAT data points have been interpolated over. Tip jets are indicated by the vertical, black lines.

air temperature and humidity are expected to be strongly influenced by tip jet events. For these reasons we have constructed an alternate method of computing heat fluxes at the mooring site using bulk formulae.

The sources of in-situ data available to us for this purpose were the QuikSCAT scatterometer winds and the PCS meteorological station wind and air temperature data. In addition, a meteorological buoy was deployed at the mooring site during the final year of the field program in August 2004, and returned wind vectors, air temperature and relative humidity until it broke loose early in December the same year. There are two types of turbulent heat fluxes; latent and sensible. The latent heat flux is associated with phase changes, and is primarily influenced by wind speed and relative humidity. The sensible heat flux is associated with measurable temperatures, and is determined by wind speed and air-sea temperature difference. It may be considered the ocean's wind chill factor. The methodology we adopt for both the 
latent and sensible heat fluxes are now outlined. The radiative heat flux terms have smaller magnitudes and are to a much lesser extent influenced by the tip jet events, and the NCEP radiative flux fields were accepted as is. It should be noted that the fresh water flux can also be significant for the development of the mixed-layer, but as for the Labrador Sea, the buoyancy contribution of the evaporation-precipitation difference for the Irminger Sea is small compared with the heat fluxes (Marshall and Schott, 1999).

\section{$5.1 \quad$ Latent heat flux}

The QuikSCAT wind timeseries interpolated to the mooring site agreed well with the buoy wind measurements (correlations better than 0.93 for both components). Unfortunately, there was no source of in-situ humidity data for the winters 0203 and 0304, so the NCEP humidity field must be used. However, the data from the meteorological buoy presented a valuable timeseries for calibration. Ideally we would have liked to compare the NCEP humidity to the buoy data over an entire winter, but since the buoy malfunctioned in early December, we have only used the short segment of data after 1 November (when conditions became more winter-like at the mooring site). The correlation between the buoy and NCEP relative humidities over this period was 0.74 . On average the NCEP relative humidity exceeded the measured humidity by $6 \%$, which was significantly less than the discrepancy between NCEP and in-situ relative humidities found by Renfrew et al. (2002) for the Labrador Sea in the middle of the winter. The NCEP relative humidity was adjusted to match both the mean and the standard deviation of the buoy relative humidity. The NCEP field was first de-meaned and normalized by its standard deviation, before multiplication by the standard deviation of the buoy relative humidity. Finally the mean buoy relative humidity was added to the NCEP field. The standard deviation quotient (1.4) and the

difference between the means $(-6 \%)$ for that period were subsequently used to calibrate the NCEP relative humidities for the winters 0203 and 0304 . Using the QuikSCAT wind data and the calibrated humidity, the latent heat flux was computed using the 

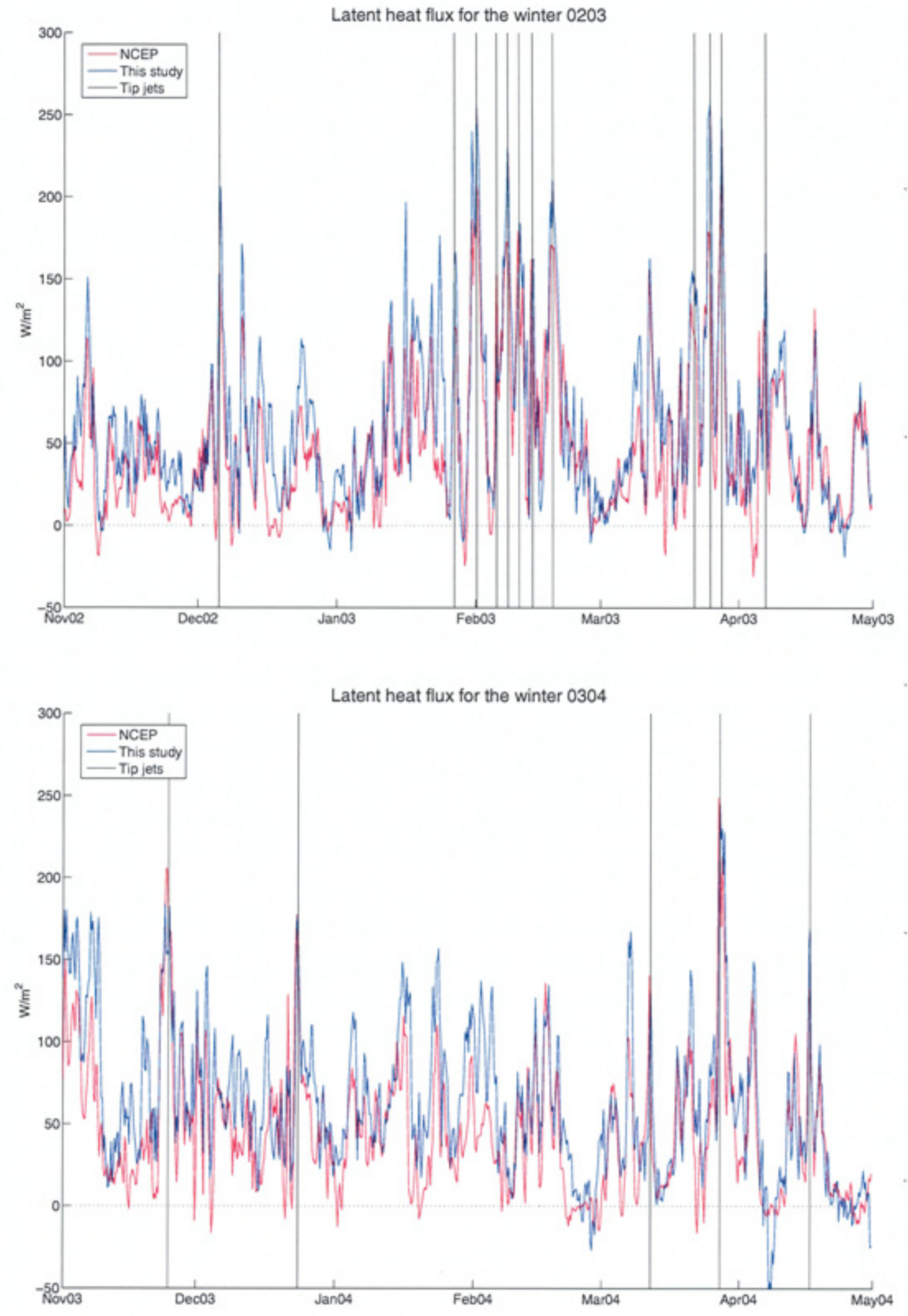

Figure 5-2: Comparison of NCEP (red) latent heat fluxes with those computed in this study (blue) during winters 0203 (top) and 0304 (bottom). Positive heat fluxes are directed out of the ocean. Occurrence of tip jet events are marked by the vertical, black lines. 
bulk formulae of Fairall et al. (1996). The NCEP latent heat fluxes (computed using the procedure of Renfrew et al. (2002)) and our timeseries are compared in Figure 52. Our latent heat fluxes were on average $14 \mathrm{~W} / \mathrm{m}^{2}$ and $18 \mathrm{~W} / \mathrm{m}^{2}$ greater than the NCEP latent heat fluxes during the winters 0203 and 0304 respectively.

Unfortunately no robust tip jets occurred during the period that the buoy was present at the mooring site, and the NCEP fields could not be compared with in-situ data during such events. No tip jet specific corrections could thus be made to the humidity, and the calibrated NCEP relative humidities for the winters 0203 and 0304 are likely still overestimates resulting in weaker tip jet latent heat fluxes.

\subsection{Sensible heat flux}

In addition to wind data, air and sea surface temperatures (SST) are required to compute the sensible heat flux. As for the latent heat fluxes, we used the QuikSCAT wind timeseries. Air temperature measurements from the PCS meteorological station were obtained and calibrated using the buoy temperature timeseries in the analogous manner of the relative humidity calibration. Even though the PCS measurements were made at a coastal location, and thus recorded colder temperatures with a higher variance than the buoy, this approach was chosen because of NCEP's inability to properly resolve tip jets. The temperature data from PCS showed a stronger response during the tip jet events of the winters 0203 and 0304 than the NCEP temperatures (not shown). The correlation between the buoy and PCS temperatures was 0.70, and the standard deviation quotient and difference between the means used to adjust the PCS temperatures during the winters 0203 and 0304 were 0.65 and $4.0^{\circ} \mathrm{C}$ respectively. The sea surface temperature record was obtained from an extrapolation to the surface of the MP mixed-layer values using the linear fit described above. The resulting mean SSTs for the winters 0203 and 0304 were $0.8{ }^{\circ} \mathrm{C}$ and $0.5^{\circ} \mathrm{C}$ colder than the NCEP sea surface temperatures, but agreed very well with satellite SST observations (which are sparse due to cloud cover). Our sensible heat flux timeseries are compared to the NCEP values in Figure 5-3, and were $4 \mathrm{~W} / \mathrm{m}^{2}$ and $10 \mathrm{~W} / \mathrm{m}^{2}$ greater than the NCEP 

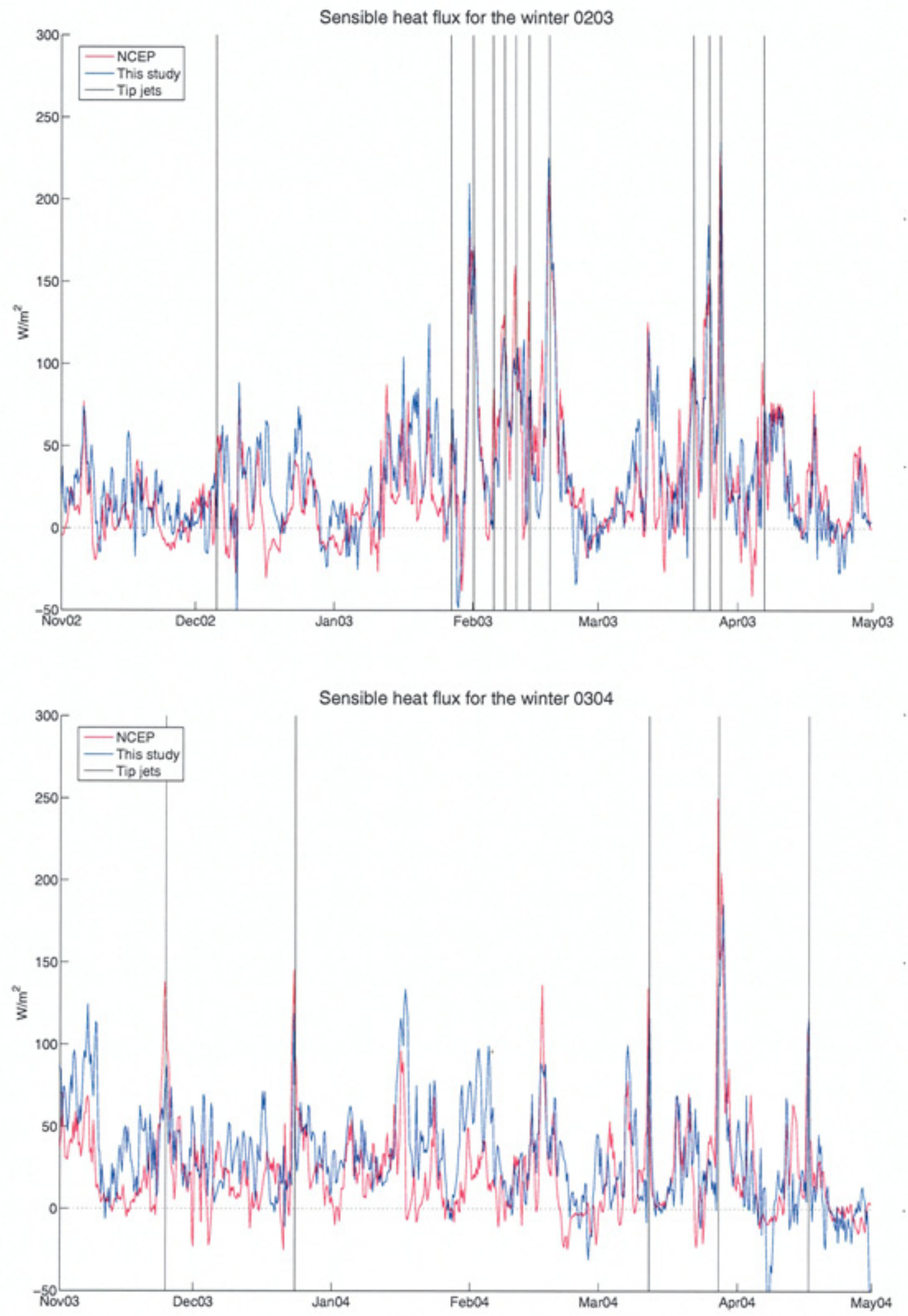

Figure 5-3: Comparison of NCEP (red) sensible heat fluxes with those computed in this study (blue) during winters 0203 (top) and 0304 (bottom). Positive heat fluxes are directed out of the ocean. Occurrence of tip jet events are marked by the vertical, black lines. 
sensible heat fluxes on the average during the winters 0203 and 0304 respectively.

\subsection{Total heat flux}

The total turbulent (sum of latent and sensible) heat fluxes are plotted in Figure 5-4. The winter mean heat flux computed using our method was larger by $18 \mathrm{~W} / \mathrm{m}^{2}$ in 0203 (93 vs. $75 \mathrm{~W} / \mathrm{m}^{2}$ ) and $27 \mathrm{~W} / \mathrm{m}^{2}$ in 0304 (95 vs. $68 \mathrm{~W} / \mathrm{m}^{2}$ ). Hence our procedure increased the heat fluxes by $24 \%$ and $40 \%$ respectively for the two winters. Although the mean total heat flux for the first winter from NCEP alone exceeded that for the second winter, the second winter had a slightly higher mean heat flux than the first according to our timeseries. This may indicate that the period during which the meteorological buoy was present at the mooring site was not representative for one or both of the winters or that the effect of the tip jet events still was not fully accounted for. Despite the uncertainties associated with our computed heat fluxes, they are considered more accurate than the NCEP heat fluxes given NCEP's coarse resolution and the resulting difficulty in capturing the small-scale tip jet phenomenon, as well as the known discrepancies between NCEP and in-situ humidity and sea surface temperature (Renfrew et al., 2002).

The maximum total turbulent heat fluxes from our procedure (hereafter referred to as the "best estimate" fluxes) were $490 \mathrm{~W} / \mathrm{m}^{2}$ and $410 \mathrm{~W} / \mathrm{m}^{2}$ for the first and second winters. These values are lower than the typical winter heat fluxes at the convection sites in the Labrador Sea, the Greenland Sea and the Mediterranean (Marshall and Schott, 1999), but this is likely a reflection of the overall mild nature of the winters of 0203 and 0304. During past high-NAO winters, the mean NCEP total turbulent heat flux from the Irminger Sea was more than twice as large as the mean NCEP fluxes from winters 0203 and 0304 (Pickart et al., 2003a). Without exception, all of the high heat flux events in 0203 and 0304 (those exceeding $300 \mathrm{~W} / \mathrm{m}^{2}$ ) occurred during tip jet events. During a high-NAO winter, a greater number of large heat flux events would be expected, and the heat loss concentrated in those storms can be very effective in driving deep convection (Marshall and Schott, 1999). 

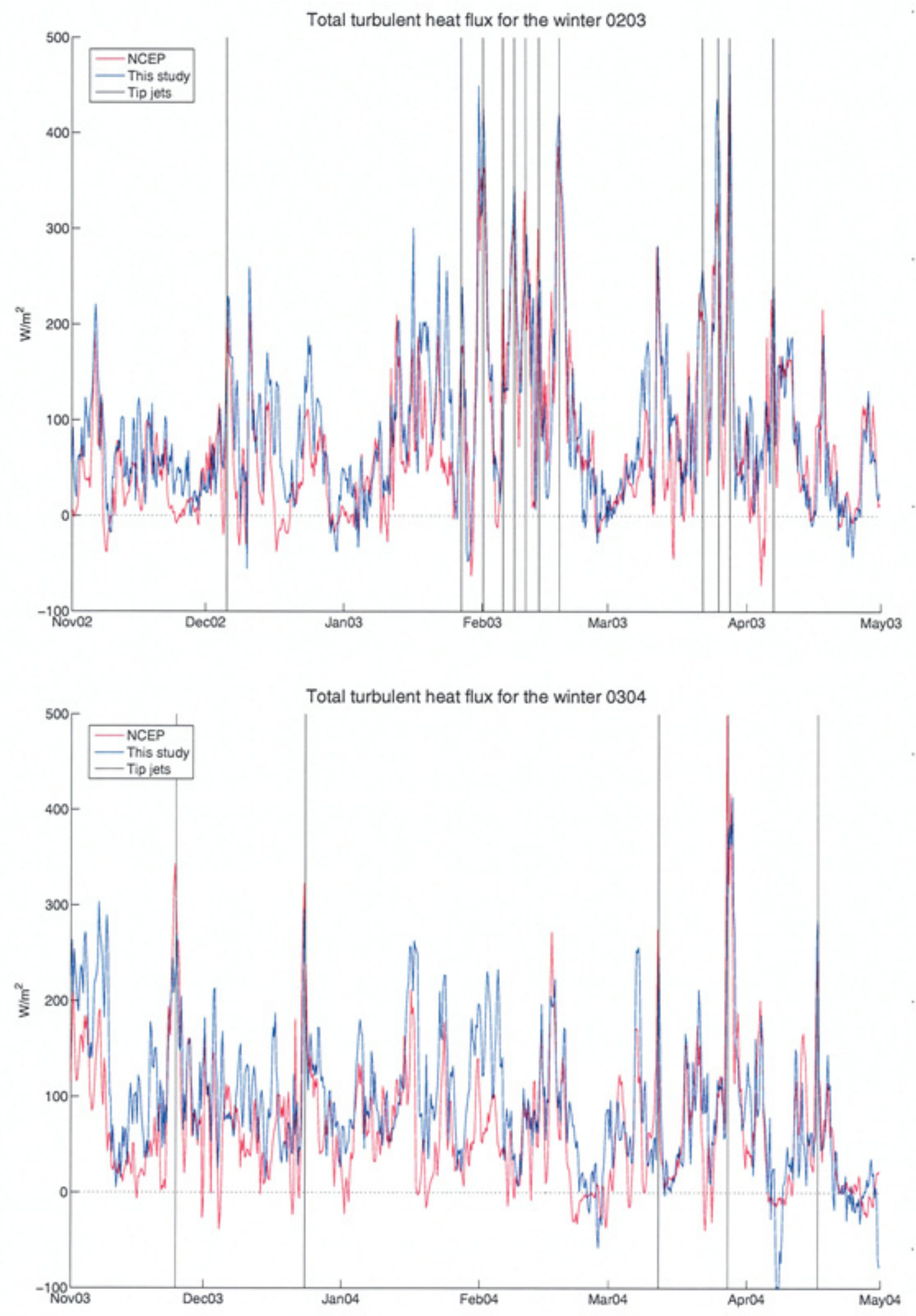

Figure 5-4: Comparison of NCEP (red) latent plus sensible heat fluxes with those computed in this study (blue) during winters 0203 (top) and 0304 (bottom). Positive heat fluxes are directed out of the ocean. Occurrence of tip jet events are marked by the vertical, black lines. 


\section{Chapter 6}

\section{D mixed-layer model}

To further investigate the cause of the wintertime mixed-layer development in the Irminger Sea as observed by the MP mooring, a one-dimensional mixed-layer model (Price et al., 1986; hereafter PWP) was employed. Within the Irminger Sea gyre the mean currents are relatively weak (on the order of a few $\mathrm{cm} / \mathrm{s}$ from the MP ACM data and from Lavender et al., 2005), and it is an area of relatively low eddy kinetic energy (Fratantoni, 2001). The cyclonic circulation traps the water within the gyre, and a 1D mixed-layer model predicted with skill the evolution of the mixed-layer under similar conditions in the Labrador Sea (Bramson, 1997). For these reasons a 1D approach is assumed reasonable to first order in this setting, and the good agreement below supports this assertion.

The heart of the PWP model lies in the parameterization of vertical mixing due to turbulent fluxes. The fluxes of heat, freshwater and momentum were imposed at the surface at each time step, and mixing was carried out until the following three stability criteria were satisfied:

$$
\begin{gathered}
\frac{\partial \rho}{\partial z} \geq 0 \\
R_{b}=\frac{g \Delta \rho h}{\rho_{0}(\Delta \mathbf{u})^{2}} \geq 0.65 \\
R_{g}=\frac{N^{2}}{(\partial \mathbf{u} / \partial z)^{2}} \geq 0.25
\end{gathered}
$$


Here $\rho$ is density, $z$ is depth, $g$ is the gravitational acceleration, $h$ is the mixed-layer depth, $\Delta$ refers to the difference between the mixed-layer and the level immediately below, $\rho_{0}$ is a constant reference value of the density, $\mathbf{u}$ is the vector velocity, $N$ is the buoyancy frequency, $R_{b}$ is the bulk Richardson number and $R_{g}$ is the gradient Richardson number. Density was computed at each time step from the new temperature and salinity profiles after the surface fluxes had been applied. The first criterion is for static stability and simulates free convection, which occurs during heat loss from the sea surface. It is violated when dense water is situated above lighter water. The bulk Richardson number criterion is a condition for mixed-layer stability, and regulates mixed-layer entrainment. The last criterion simulates the effects of shear flow instability, and creates a smooth transition layer between the mixed-layer and the oceanic interior. The last two conditions describe wind mixing processes, as the velocity appearing in the Richardson numbers is entirely wind driven, and both processes would be inactive without wind.

The model was run on a vertical grid with $2 m$ resolution from the surface to $1000 \mathrm{~m}$. We forced the model with both NCEP heat fluxes (the corrected product of Renfrew et al., 2002) and our best estimate fluxes, with a time step of 6 hours. Such a time step is marginal in terms of resolving the inertial period, which at the latitude of the mooring is about 14 hours. However, comparison of model results using PCS wind stress with a time step of 3 hours and subsampled PCS winds with a time step of 6 hours showed no significant difference in terms of mixed-layer depth, which indicates that resolution of the inertial period is not critical to this study. Furthermore, sensitivity studies presented below indicate that the direct effect of wind stress is secondary compared to the effect of the total turbulent heat flux.

\subsection{Winter 0203}

Figure 6-1 shows a comparison of the observed and modeled mixed-layers for the winter of 0203 . The model was initialized with the low-pass filtered average MP profile for the first half of November 2002, and each run started on 8 November and lasted 
until the end of April. The model mixed-layer depths were determined automatically using the method of Lorbacher et al.(2006), which identifies the shallowest extremum of curvature of the potential density profile with the base of the mixed-layer. For less than $4 \%$ of the profiles, a shallow mixed-layer was found instead of the deeper primary mixed-layer. These appeared as spikes in the mixed-layer depth timeseries, and were interpolated over. The final mixed-layer depths were examined manually for each profile.

For the first run, the model was forced with NCEP surface fluxes only, and the depth of the deepest mixed-layer is indicated by the red curve in Figure 6-1. The second run was forced with the best estimate heat fluxes computed in the previous chapter and with momentum fluxes (wind stress) computed from the QuikSCAT data set, and the results are plotted in blue. To assess the importance of tip jet events on convection, a third run was carried out in which the tip jet signature was removed from the best estimate heat fluxes and QuikSCAT momentum fluxes. This was done simply by finding the two minima of the latent heat flux (which provided the dominant contribution) in the 1.5 days before and after the peak of each event, and then linearly interpolating between the points. This procedure took the variable duration of each event into account, and assumed in agreement with observations that none lasted longer than 3 days. When the tip jets were removed as such, the mean total turbulent best estimate heat flux over the entire winter was reduced by 13 $\mathrm{W} / \mathrm{m}^{2}$, from $93 \mathrm{~W} / \mathrm{m}^{2}$ to $80 \mathrm{~W} / \mathrm{m}^{2}$. The modeled mixed-layer depths for the no tip jet case are indicated by the green curve in Figure 6-1. The sensitivity studies below indicate that the effect of the heat fluxes dominates the effect of the momentum fluxes by an order of magnitude, and that the effect of the fresh water flux is minimal. For all of the model runs, the fresh water flux was provided by NCEP.

Both the NCEP and best estimate heat fluxes generate timeseries of model mixedlayer depths that have the general appearance of the observed mixed-layer depths, with gentle deepening early in the winter, a more rapid deepening during late January and February and restratification in late April. However, Figure 6-1 indicates that the NCEP heat fluxes are too weak to produce the extent of mixed-layer deepening 


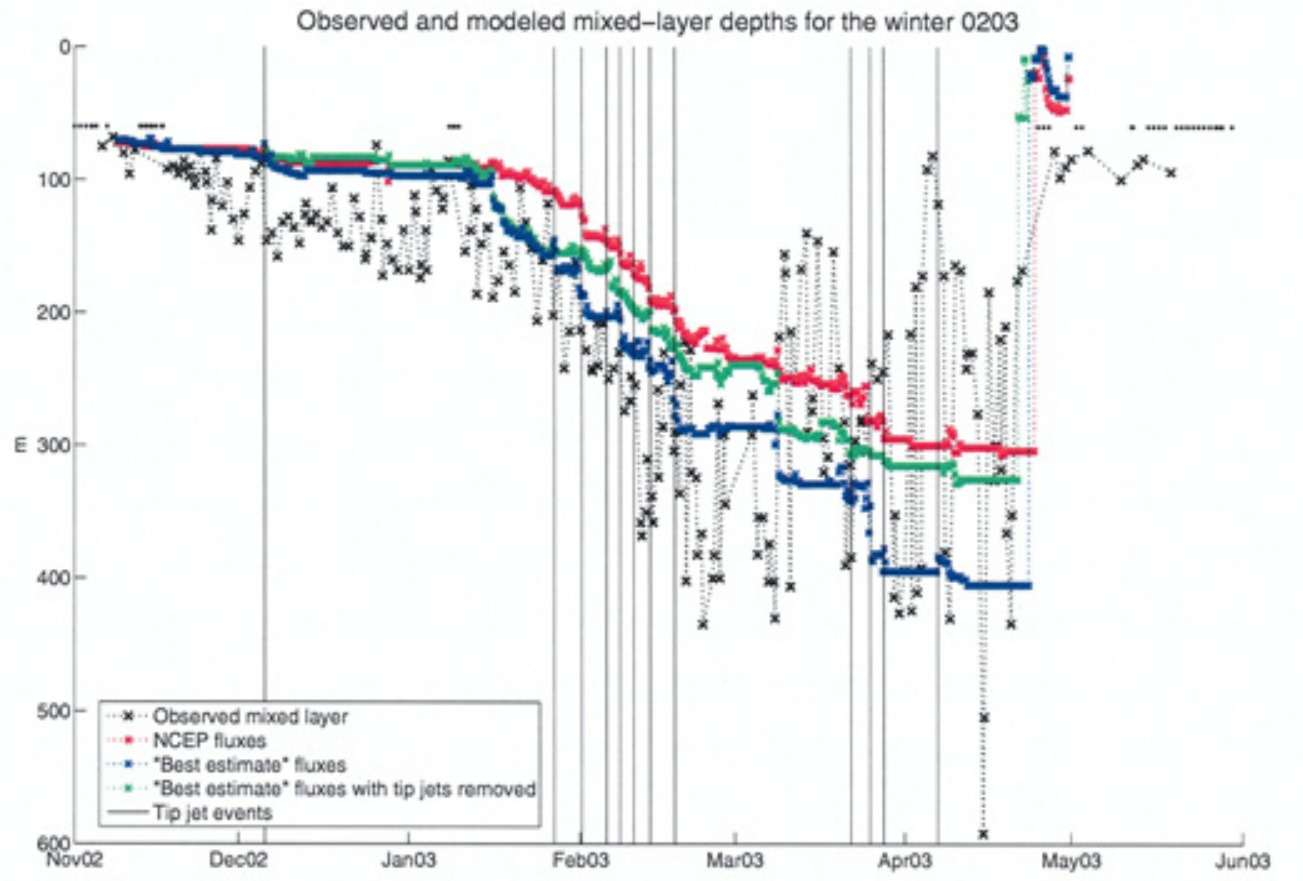

Figure 6-1: Comparison of observed mixed-layer depth and modeled mixed-layer depth for winter 0203 using the 1D PWP model. The separate model runs were forced with NCEP surface fluxes (red), the best estimate fluxes described in the previous chapter (blue) and the best estimate fluxes with the tip jet events removed (green).

observed by the MP. Using the best estimate heat fluxes, however, the resulting mixed-layer depth timeseries is $\sim 100 \mathrm{~m}$ deeper and agrees well with the observations. Due to NCEP's inability to properly resolve tip jet events, one would expect that this discrepancy is due to the enhanced heat loss caused by these high wind speed events. The final model run in Figure 6-1 shows that this is indeed the case and that the tip jets had a significant effect on the evolution of the mixed-layer in the winter of 0203 . The removal of the tip jets caused a difference of $80 \mathrm{~m}$ in final predicted depth of convection, and the difference between the model results with and without tip jets became particularly large during the periods of frequent tip jet events in early February and late March. The integrated effect of the intense heat fluxes associated with the tip jet events, and in particular when several tip jets strike in short succession, plays an important role in the development of the mixed-layer. 
Although the general envelope of mixed-layer depth is fairly well captured by the PWP model with the best estimate fluxes, there are discrepancies between the model and the observations, especially regarding the high frequency variability that is not represented by the model. This is likely due in part to the missing effect of advection. The mixed-layers predicted by the PWP model can only be changed by surface fluxes, and without sufficient forcing, the deep mixed-layer will remain unaffected. In the real ocean, this is not the case. Small-scale variability is ubiquitous during active convection (Pickart et al., 2002), and the effects of advection and mesoscale events distort the mixed-layer, which is evident by the range of mixed-layer depths observed during the second half of each winter in our records.

\subsection{Winter 0304}

Figure 6-2 compares the observed and modeled mixed-layers for the winter of 0304 . As before the initial profile was the low-pass filtered average MP profile from the first half of November, and the model was run from 8 November until the end of April with the same three sets of surface fluxes as the previous winter. Again it was found that the NCEP heat fluxes resulted in too shallow mixed-layers, while the best estimate heat fluxes generated a model mixed-layer depth timeseries that reached 100 $m$ deeper in fair agreement with the observations. Due to the low number of robust tip jet events during this winter, the difference between the results produced by the best estimate heat fluxes with and without tip jets was minor. The general evolution of the mixed-layer was similar for the observed and modeled mixed-layer depths, but the MP failed before restratification occurred, which prevented comparison between observations and model regarding the timing of the restratification.

Considering both the data and the model results, the depth of convection during the second winter was about 50 to $80 \mathrm{~m}$ shallower than for the first winter. In addition to the atmospheric conditions, the initial stratification of the ocean plays an important role in determining the final depth of the mixed-layer. At the start of the winter 0203 , the water column at the mooring site was better preconditioned, 


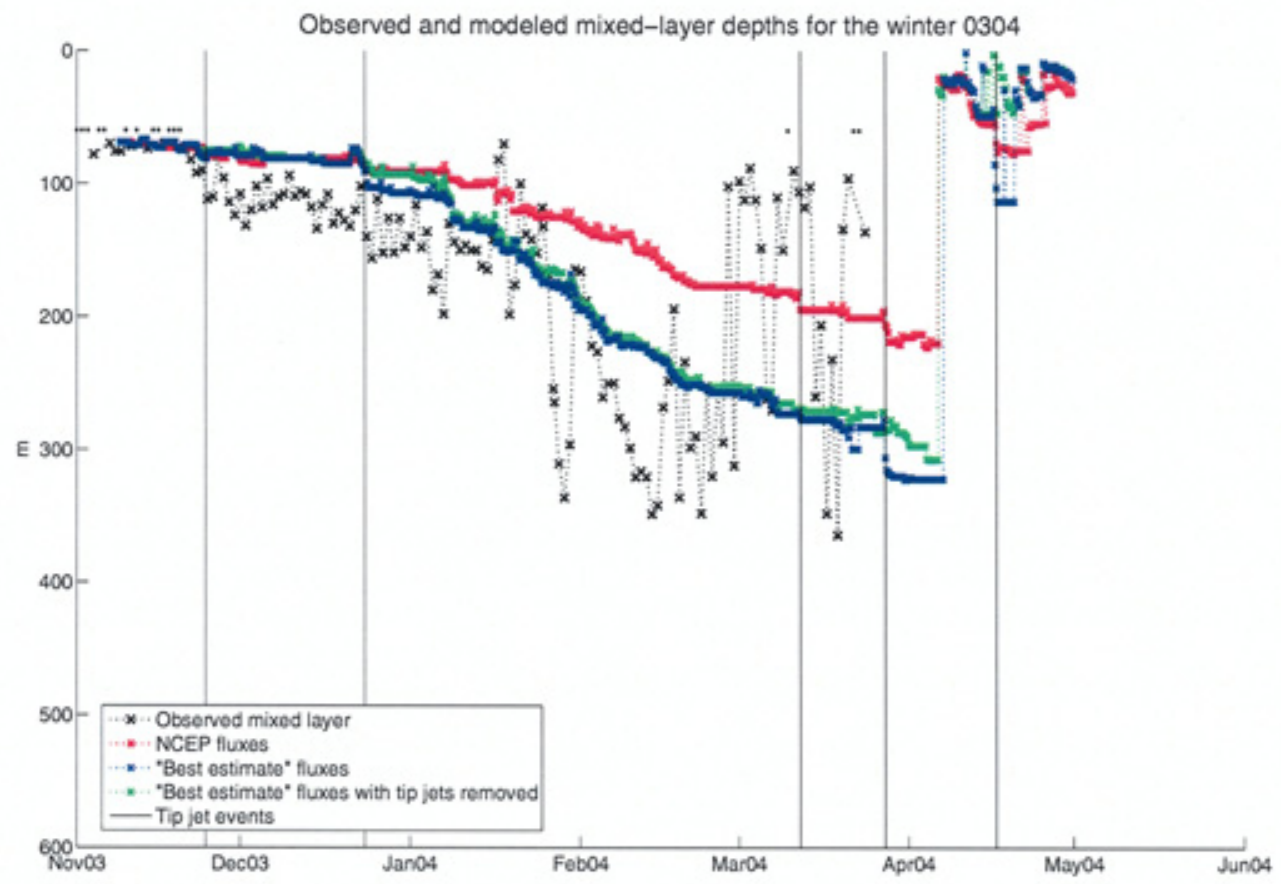

Figure 6-2: As Fig. 6-1, but for the winter 0304.

i.e. more weakly stratified, than at the start of the winter 0304, and thus weaker surface fluxes were required to deepen the mixed-layer to an equivalent depth for the first winter compared with the second. However, the difference in initial stratification between the two winters under consideration was not very significant. When the NCEP heat fluxes from the winter of 0304 were used to force the PWP model with the November 0203 initial profile, the mixed-layer reached about $10 \mathrm{~m}$ (230 $\mathrm{m}$ versus $220 \mathrm{~m}$ ) deeper than when the November 0304 initial profile was used.

\subsection{Winter 9495}

The good agreement between the observed and the modeled mixed-layer depths over the two winters when forced by the best estimate heat fluxes encouraged application of the model to a more robust winter, particularly one during the high NAO period of the early 1990s when convection reached great depth in the Labrador Sea. The 
idea is that convection might have reached similar depths in the Irminger Sea due to repeated robust tip jet events. Unfortunately there were no mooring timeseries for verification of the results, but the World Ocean Circulation Experiment (WOCE) A1E CTD line passes over the mooring site and there were quasi-annual occupations of the line during this period. One of the A1E CTD casts near the mooring site taken in late November 1994 provided an initial profile for the model, and the model grid was extended to $2000 \mathrm{~m}$ with the same vertical resolution. The winter 9495 was near the end of the high-NAO period of the early 1990s, and presented a well preconditioned ocean and above average heat fluxes associated with the high NAO index.

Obtaining heat fluxes to force the model presented another challenge, however, as scatterometer data were not yet available at that time. Comparison between NCEP, PCS and QuikSCAT winter wind measurements for the period during which the scatterometer was in operation (July 1999 to present) showed good agreement between NCEP and QuikSCAT, except during the high zonal wind tip jet events. The PCS zonal winds, however, captured the tip jets better (see Pickart et al., 2003b). Thus for the winter of 9495, an adjusted version of the PCS zonal winds and the NCEP meridional winds were used to compute the adjusted heat fluxes. ${ }^{1}$ The correlation between the zonal PCS and QuikSCAT winds was 0.75, and the correlation between the meridional NCEP and QuikSCAT winds was 0.85. The ratios of means and standard deviations for the absolute values of the QuikSCAT and PCS zonal winds for the five winters of overlap (9900 to 0405) were computed and used to adjust the winter 9495 PCS zonal winds. Before scaling with the ratio of the standard deviations, the mean was removed from the PCS winds. Finally the mean PCS wind multiplied by the ratio of the mean QuikSCAT and PCS winds was added to the scaled product to make the absolute values of the adjusted PCS have the same mean and standard deviation as the absolute QuikSCAT zonal winds for the five winters.

Without an MP, observations of sea surface temperature were not available. In-

\footnotetext{
${ }^{1}$ The PCS meridional winds were inappropriate because the meteorological station is situated adjacent to a zonally oriented sound and is thus partially shielded from meridional winds.
} 
stead, the mean difference between the NCEP sea surface temperature field and the extrapolated mixed-layer temperatures of the winters 0203 and 0304 of $0.73{ }^{\circ} \mathrm{C}$ was subtracted from the NCEP sea surface temperature field for the winter 9495. The PCS air temperature was adjusted to have the same standard deviation as the air temperature recorded by the meteorological buoy in November and December 2004, and the same mean as the NCEP temperature for the winter 9495 lowered by the difference between the mean buoy and NCEP air temperatures for the period that they overlapped. The reason for the different adjustment procedure compared to the 0203 and 0304 winters was that the mean winter air temperature was more than $3{ }^{\circ} \mathrm{C}$ colder during the winter 9495 than it was during the winter 0304, which would have resulted in unrealistically low temperatures at the mooring site. Finally the relative humidity was computed using the meteorological buoy data to calibrate the NCEP data as described in the previous chapter.

As a check on this approach, the corresponding heat flux timeseries for the winter of 0203 was computed. The mean total turbulent heat flux was. $5 \%$ smaller compared to the best estimate heat fluxes, and according to the PWP model, the final mixedlayer depths differed by less than $10 \mathrm{~m}$ when forced by the two heat flux timeseries. This gives us confidence that the procedure used to compute the 9495 heat fluxes is sound.

The resulting bulk total turbulent heat fluxes for the winter of 9495 are plotted in Figure 6-3. The mean best estimate total heat flux for this winter was $116 \mathrm{~W} / \mathrm{m}^{2}, 35$ $W / m^{2}$ or $30 \%$ greater than the original NCEP heat flux. The increase is comparable to that of the best estimate heat fluxes from winters 0203 and 0304 relative to the NCEP heat fluxes. The mean total heat flux (including radiative fluxes) for the period December 1994 through February 1995 was $196 \mathrm{~W} / \mathrm{m}^{2}$, which is about 30 $W / m^{2}$ greater than the value found by Pickart et al. (2003a) during all high-NAO (NAO index greater than one) December through February periods in the NCEP data set. The maximum of the total turbulent best estimate heat flux was found during the tip jet event in the beginning of March 1995, and exceeded $580 \mathrm{~W} / \mathrm{m}^{2}$. The times of occurrence of the tip jet events for this winter were determined using the EOF 

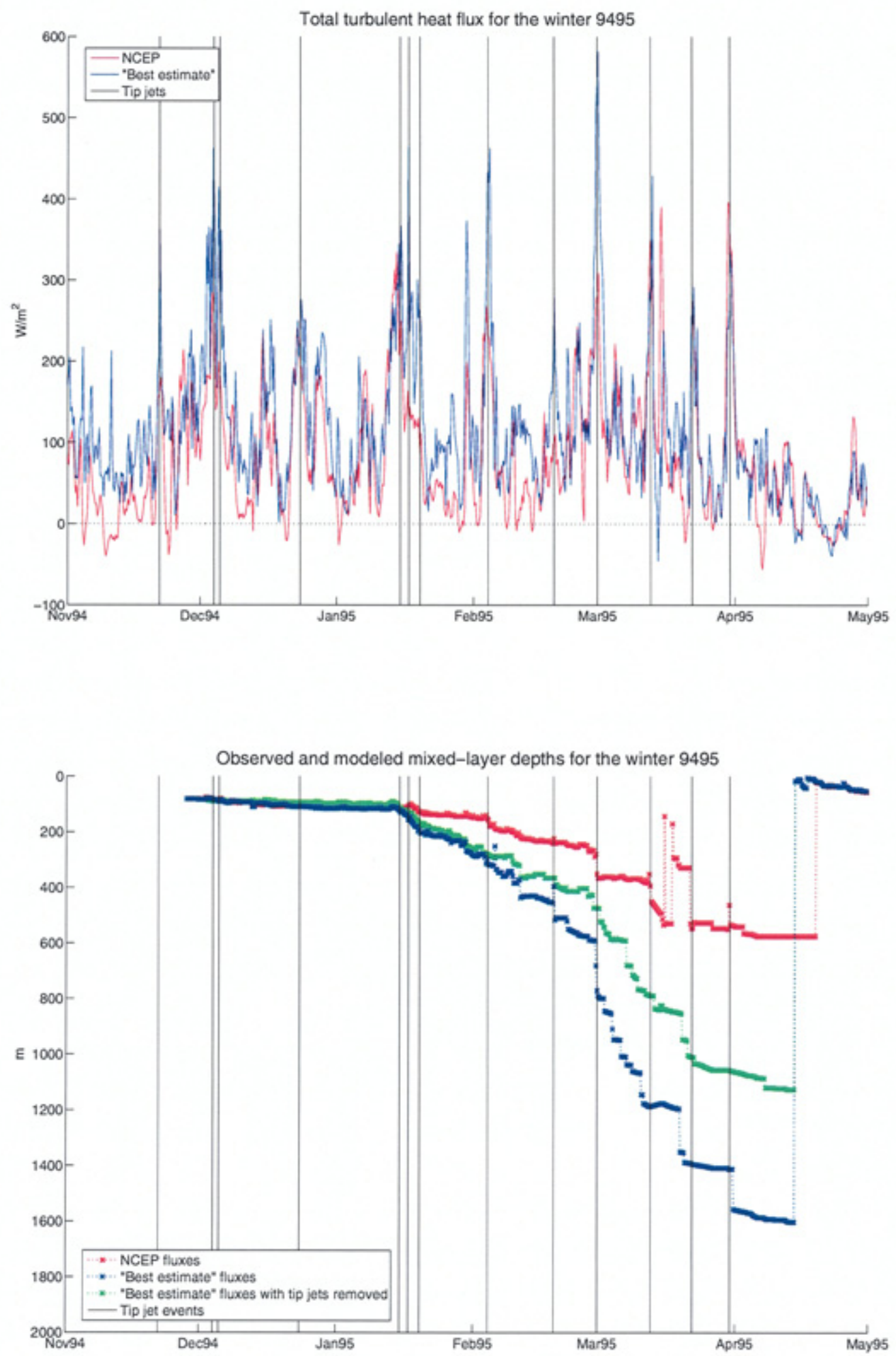

Figure 6-3: As Fig. 5-4 (top) and as Fig. 6-1 (bottom), but for the winter 9495 and without MP data. 
approach of Pickart et al. (2003b).

At the end of the convective season, the mixed-layer depth for the model run forced with the best estimate heat fluxes reached a depth of $1600 \mathrm{~m}$. This is consistent with the summer 1995 WOCE A1E CTD data indicating that convection reached $1700 \mathrm{~m}$ that winter (Pickart et al., 2003a). This is slightly less than the convective depth observed in the Labrador Sea during the same winter (Lilly et al., 1999). By comparison, the model run with NCEP heat fluxes alone resulted in a $1000 \mathrm{~m}$ shallower mixed-layer, and the best estimate heat fluxes without tip jets resulted in a $500 \mathrm{~m}$ shallower mixed-layer (Fig. 6-3). As the NCEP heat fluxes for the winters of 0203 and 0304 led to an underprediction of the final mixed-layer depth, it is most likely also the case for the winter of 9495 . The reduction in convection caused by removal of the tip jet events is consistent with the results from the winter of 0203 . These results add to the growing body of work supporting the hypothesis that deep convection in the central Irminger Sea may indeed occur during high-NAO winters.

\subsection{Sensitivity studies}

In order to assess the importance of the various surface fluxes on the evolution of the mixed-layer, sensitivity studies were made by running the model twice with a \pm $100 \%$ change in the given parameter for the winter 0203, comparing the case of double contribution and no contribution to the total forcing, with the remaining parameters held constant. The sensitivity runs were all forced by NCEP fields alone, with one exception for the heat fluxes.

\subsubsection{Momentum flux}

The final depths of the two mixed-layers differed by less than $40 \mathrm{~m}$ or $12 \%$ in the cases of double and no wind stress. There were, however, differences in the evolution of the mixed-layer depth. With double wind stress, the mixed-layer abruptly deepened to about $100 \mathrm{~m}$ in the beginning of the run before steadily deepening to the final depth of $350 \mathrm{~m}$. Without wind stress, the mixed-layer remained near the initial depth of 
about $70 \mathrm{~m}$ until the end of January, when the period of strong forcing and high tip jet activity began and an abrupt deepening occurred, which eventually brought the mixed-layer to a final depth of $310 \mathrm{~m}$. The direct effect of the wind stress in this study appeared to diminish rapidly below about $100 \mathrm{~m}$. The no wind stress results were more similar to both the baseline NCEP model results and the observed mixed-layer than the double wind stress results.

\subsubsection{Heat flux}

Forced by a double turbulent heat flux, the mixed-layer reached a final depth of 830 $m$, more than 6 times deeper than the final depth of the mixed-layer in the zero turbulent heat flux run. Accurate representation of the winds is important, but more in terms of their influence on the latent and sensible heat fluxes than for their direct effect of wind-driven mixing. Thus free convection dictates to first order the evolution of the mixed-layer, and the total turbulent heat flux is the most critical parameter in the model.

The error associated with the adjusted heat fluxes is unknown, in particular. for the winter 9495 for which there were no scatterometer wind data. In order to obtain a rough estimate of the uncertainty of the mixed-layer depths reached by the PWP model, a sensitivity test using $10 \%$ stronger and weaker adjusted heat fluxes for the winter 9495 was made, which is a conservative guess at the error of the adjusted heat fluxes. A $10 \%$ reduction of the heat fluxes resulted in a final mixed-layer depth of $1200 \mathrm{~m}$, while a $10 \%$ increase of the heat fluxes caused convection to $1800 \mathrm{~m}$.

\subsubsection{Fresh water flux}

The final depths of the two mixed-layers differed by less than $1 \mathrm{~m}$ or $0.5 \%$ in the cases of double and no fresh water flux. The result confirms that the buoyancy contribution of the precipitation-evaporation difference is small, as in the case of the Labrador Sea (Marshall and Schott, 1999). 


\section{Chapter 7}

\section{Discussion and conclusions}

Pickart et al. (2003a) cast doubt on the "Labrador Sea centric" view that the Labrador Basin is the sole location of LSW formation. They showed that with the exception of atmospheric forcing, all of the conditions required for deep convection are satisfied also in the Irminger Sea, and presented indirect evidence of deep convection occurring east of Greenland. Pickart et al. (2003b) identified a mechanism capable

of enhancing the atmospheric forcing over the southern Irminger Sea, in the form of strong, intermittent wind events called Greenland tip jets, which regularly form when low-pressure systems occupy the area between Greenland and Iceland.

Direct observations of the winter mixed-layer development in the southwest Irminger Sea were made possible during a recent field program with the deployment of a moored profiler, a motorized vehicle equipped with oceanographic instrumentation that is able to obtain daily hydrographic profiles of the water column. The two MP deployments returned by the field program presents an unprecedented data set. Unfortunately, the experiment took place during a period of low NAO index, with below-average atmospheric forcing and a well-stratified water column. Nonetheless, the observed mixed-layers reached depths of $400 \mathrm{~m}$ and $350 \mathrm{~m}$ for the winters 0203 and 0304 respectively, with a maximum of almost $600 \mathrm{~m}$ in 0203 .

All of the storms that entered a domain centered on the Irminger Sea during the winters of the deployment periods were tracked using the NCEP re-analysis data, and the tip jet events that occurred throughout the two winters were identified. Composite 
images of the tip jet events elucidated the conditions during which tip jets were likely to occur, i.e. a parent low situated east of Greenland causing enhanced pressure gradients along the eastern coast of Greenland that curve sharply to the east near Cape Farewell over the Irminger Sea. A greater sensitivity to the large scale pressure gradient configuration than to absolute pressure alone was demonstrated, which led to the development of an EOF method of tip jet detection, relying on timeseries of zonal wind speed, spatially averaged pressure gradient and air temperature.

Trajectory studies were undertaken to investigate the origin of the air masses constituting the tip jets. The results indicate that acceleration and descent of air parcels deflecting around the southern tip of Greenland more aptly describes the flow patterns of the tip jets than direct orographic descent from the Greenland plateau, which confirms the observation of Moore and Renfrew (2005). However, such trajectory studies should be expanded to other winters and preferably with the use of higher resolution model and data, in order to obtain more accurate and statistically significant data from which to draw more robust conclusions.

The two winters under consideration differed significantly in terms of atmospheric forcing and the character of their tip jet events. Because of different configurations of the upper level steering currents, the tracks of the tip jet producing storms of winter 0203 followed a "highway" from Newfoundland past Cape Farewell through the Denmark Strait compared to the much greater spread of tip jet producing storm tracks for winter 0304. As a result, a greater number of storms were focused next to Greenland causing overall lower pressures and stronger pressure gradients during the first winter, which led to more robust tip jet events. The trajectory studies show that the air contained in the tip jets generally came from higher altitudes during winter 0203, which meant less modification over the Labrador Sea. The overall higher wind speed and lower air temperature of the winter 0203 tip jets resulted in stronger heat fluxes.

The effect of the tip jets on the evolution of the mixed-layer was investigated with a 1D mixed-layer model (Price et al., 1986). Comparison of the model output and the MP timeseries showed that the forcing supplied by the reanalyzed NCEP surface 
flux fields of Renfrew et al. (2002) was insufficient to account for the observed deepening of the mixed-layer. This is mainly because the coarse grid of the NCEP fields is unable to resolve the small-scale tip jets. It was also found that the humidity and air and sea surface temperatures provided by NCEP significantly differed from the in-situ observations. In-situ and model reanalysis data calibrated with observations from a meteorological buoy at the mooring site were used to compute new turbulent heat fluxes, which are the dominant forcing terms in this region. Using these "best estimate" fluxes, the model results agreed well with the observations for both winters, indicating that our heat fluxes more accurately represent the conditions in the southwest Irminger Sea for the winters 0203 and 0304 than the NCEP heat fluxes.

The direct effect of the tip jets on the mixed-layer development was estimated by forcing the 1D model with heat flux timeseries from which the tip jet events were removed, leaving only the background heat fluxes. For the first winter, during which 11 robust tip jet events influenced the mooring site, the depth of the mixed-layer was reduced by $80 \mathrm{~m}$ ( $20 \%$ shallower) without the presence of tip jets. For about a month, from late January to late February 2003, 7 tip jets occurred in quick succession, and the integrated effect of these storms contributed significantly to the rapid deepening of the mixed-layer that took place during that period. This is not surprising, as all of the high turbulent heat flux events (exceeding $300 \mathrm{~W} / \mathrm{m}^{2}$ ) occurred during tip jets. For the second winter, during which there were only 3 robust tip jets during the period of the mooring, their removal naturally had less of an effect.

The good agreement achieved between the 1D model and the observations encouraged application of the model to a high-NAO winter. Bulk heat fluxes from the winter 9495 were computed, but without the aid of in-situ data. At the end of the winter, the mixed-layer had reached a depth of $1600 \mathrm{~m}$, which is consistent with hydrographic measurements in the summer of 1995 (Pickart et al., 2003a), and is a little less than observed convection in the Labrador Sea for the same winter (Lilly et al., 1999). This suggests that deep convection does indeed take place in the southwest Irminger Sea under more favorable conditions. With a $10 \%$ margin of error, the model provided a range of convection from 1200 to $1800 \mathrm{~m}$. More accurate atmospheric data are 
required to obtain better estimates of the heat fluxes. Winters prior to the advent of satellite scatterometer data suffer particularly from this, since wind speed is an important parameter for computation of both latent and sensible heat fluxes (which are more important than momentum fluxes directly in driving deep convection).

Possible avenues of future work include an expansion from the 1D mixed-layer model to a 3D regional model, both to take into account the effect of advection on the development of the mixed-layer, even though 1D mixed-layer models have been used with skill under similar conditions (Bramson, 1997), and to investigate the effect of the strong wind stress curl associated with the tip jet events (Spall and Pickart, 2002; Chelton et al., 2004) on the regional circulation and convection. There is, however, no substitute for in-situ hydrographic observations in the Irminger Sea obtained during a high-NAO winter for confirmation of deep convection taking place there. 


\section{Bibliography}

[1] S. Bacon, W.J. Gould, and Y.L. Jia. Open-ocean convection in the Irminger Sea. Geophysical Research Letters, 30:1246, doi:10.1029/2002GL016271, 2003.

[2] F. Bakalian, S. Hameed, and R.S. Pickart. The influence of the Icelandic low latitude on the frequency of Greenland tip jet events and deep convection in the Irminger Sea. Unpublished manuscript, 2006.

[3] H. Björnsson and S.A. Venegas. A manual for EOF and SVD analyses of climatic data. Unpublished manuscript, 1997.

[4] L.S. Bramson. Air-sea interactions and deep convection in the Labrador Sea. Master's thesis, Naval Postgraduate School, Monterey, CA, 1997.

[5] L.R. Centurioni and W.J. Gould. Winter conditions in the Irminger Sea observed with profiling floats. Journal of Marine Science, 62:313-336, 2004.

[6] D.B. Chelton, M.G. Schlax, M.H. Freilich, and R.F. Milliff. Satellite measurements reveal persistent small-scale features in ocean winds. Science, 303:978-983, 2004.

[7] R.A. Clarke and J.C. Gascard. The formation of Labrador Sea water. Part 1: Large-scale processes. Journal of Physical Oceanography, 13:1764-1778, 1983.

[8] A. Defant. Bericht über die ozeanographischen Untersuchungen des Vermessungsschiffes "Meteor" in der Dänemarkstrasse und in der Irmingersee. Sitzungsberichte der Preussischen Akademie der Wissenschaften, PhysikalischMathematische Klasse XIX:232-242, 1936. 
[9] R.R. Dickson and J. Brown. The production of North Atlantic deep water: Sources, rates and pathways. Journal of Geophysical Research, 99:12319-12341, 1994.

[10] R.R. Dickson, J.R.N. Lazier, J. Meincke, P.B. Rhines, and J. Swift. Long-term coordinated changes in the convective activity of the North Atlantic. Progress in Oceanography, 38:241-295, 1996.

[11] K.W. Doherty, D.E. Frye, S.P. Liberatore, and J.M. Toole. A moored profiling instrument. Journal of Atmospheric and Oceanic Technology, 16:1816-1829, 1999.

[12] J.D. Doyle and M.A. Shapiro. Flow response to large-scale topography: the Greenland tip jet. Tellus, 51:728-748, 1999.

[13] C.W. Fairall, E.F. Bradley, D.P. Rogers, J.B. Edson, and G.S. Young. Bulk parameterization of air-sea fluxes for Tropical Ocean-Global Atmosphere CoupledOcean Atmosphere Response Experiment. Journal of Geophysical Research, 101:3747-3764, 1996.

[14] D.M. Fratantoni. North Atlantic surface circulation during the 1990's observed with satellite-tracked drifters. Journal of Geophysical Research, 106:2206722093, 2001.

[15] P.S. Fratantoni, R.S. Pickart, S. Zimmermann, and M. Swartz. Western Arctic Shelf-Basin Interactions Experiment: Processing of moored profiler data from the Beaufort Shelf Edge mooring array. Technical report, WHOI, in preparation.

[16] B.J. Hoskins and K.I. Hodges. New perspectives on the Northern Hemisphere winter storm tracks. Journal of the Atmospheric Sciences, 59:1041-1061, 2002.

[17] E. Kalnay and Coauthors. The NCEP/NCAR 40-year reanalysis project. Bulletin of the American Meteorological Society, 77:437-471, 1996. 
[18] LabSea-Group. The Labrador Sea Deep Convection Experiment. Bulletin of the American Meteorological Society, 79:2033-2058, 1998.

[19] K.L. Lavender, R.E. Davis, and W.B. Owens. Mid-depth recirculation observed in the interior Labrador and Irminger seas by direct velocity measurements. Nature, 407:66-69, 2000.

[20] K.L. Lavender, R.E. Davis, and W.B. Owens. Observations of open-ocean deep convection in the Labrador Sea from subsurface floats. Journal of Physical Oceanography, 32:511-526, 2002.

[21] K.L. Lavender, W.B. Owens, and R.E. Davis. The mid-depth circulation of the subpolar North Atlantic Ocean as measured by subsurface floats. Deep Sea Research I, 52:767-785, 2005.

[22] J.R.N. Lazier, R. Hendry, R.A. Clarke, I.M. Yashayaev, and P.B. Rhines. Convection and restratification in the Labrador Sea, 1990-2000. Deep Sea Research I, 49:1819-1835, 2002.

[23] J.M. Lilly, P.B. Rhines, M. Visbeck, R.E. Davis, J.R.N. Lazier, F. Schott, and D. Farmer. Observing deep convection in the Labrador Sea during winter 1994/95. Journal of Physical Oceanography, 29:2065-2098, 1999.

[24] K. Lorbacher, D. Dommenget, P.P. Niiler, and A. Köhl. Ocean mixed layer depth: A subsurface proxy of ocean-atmosphere variability. Journal of Geophysical Research, accepted for publication.

[25] J. Marshall and F. Schott. Open-ocean convection: Observations, theory, and models. Reviews of Geophysics, 37:1-64, 1999.

[26] R. Martin and G.W.K. Moore. Transition of a synoptic system to a polar low via interaction with the orography of Greenland. Tellus, 58:236-253, 2006.

[27] G.W.K. Moore. Gale force winds over the Irminger Sea to the east of Cape Farewell, Greenland. Geophysical Research Letters, 30:1894, doi:10.1029/2003GLO18012, 2003. 
[28] G.W.K. Moore and I.A. Renfrew. Tip jets and barrier winds: A QuikSCAT climatology of high wind speed events around Greenland. Journal of Climate, 18:3713-3725, 2005.

[29] F. Nansen. Das Bodenwasser und die Abkühlung des Meeres. Internationale Revue der gesamten Hydrobiologie and Hydrographie, Band V:1-42, 1912.

[30] J. Pedlosky. Geophsyical Fluid Dynmaics. Springer-Verlag, New York, NY, Second edition, 1987.

[31] G.N. Petersen, H. Ólafsson, and J.E. Kristjánsson. Flow in the lee of idealized mountains and Greenland. Journal of the Atmospheric Sciences, 60:2183-2195, 2003.

[32] R.S. Pickart, M.A. Spall, M.H. Ribergaard, G.W.K. Moore, and R.F. Milliff. Deep convection in the Irminger Sea forced by the Greenland tip jet. Nature, 424:152-156, 2003b.

[33] R.S. Pickart, F. Straneo, and G.W.K. Moore. Is Labrador Sea water formed in the Irminger Basin? Deep Sea Research I, 50:23-52, 2003a.

[34] R.S. Pickart, D.J. Torres, and R.A. Clarke. Hydrography of the Labrador Sea during active convection. Journal of Physical Oceanography, 32:428-457, 2002.

[35] J.F. Price, R.A. Weller, and R. Pinkel. Diurnal cycling: Observations and models of the upper ocean response to diurnal heating, cooling, and wind mixing. Journal of Geophysical Research, 91:8411-8427, 1986.

[36] I.A. Renfrew, G.W.K. Moore, P.S. Guest, and K. Bumke. A comparison of surface layer and surface turbulent flux observations over the Labrador Sea with ECMWF analyses and NCEP reanalyses. Journal of Physical Oceanography, 32:383-400, 2002.

[37] J.C. Rogers. Patterns of low-frequency monthly sea level pressure variability (1899-1986) and associated wave cyclone frequencies. Journal of Climate, 3:13641379, 1990. 
[38] W.J. Schmitz and M.S. McCartney. On the North Atlantic circulation. Reviews of Geophysics, 31:29-49, 1993.

[39] M.C. Serreze, F. Carse, R.G. Barry, and J.C. Rogers. Icelandic low cyclone activity: Climatological features, linkages with the NAO, and relationships with recent changes in the Northern Hemisphere circulation. Journal of Climate, 10:453-464, 1997.

[40] M.A. Spall and R.S. Pickart. Wind-driven recirculations and exchange in the Labrador and Irminger seas. Journal of Physical Oceanography, 33:1829-1845, 2003.

[41] F. Straneo, R.S. Pickart, and K.L. Lavender. Spreading of Labrador sea water: an advective-diffusive study based on Lagrangian data. Deep Sea Research I, 50:701-719, 2003.

[42] H.U. Sverdrup, M.W. Johnson, and R.H. Fleming. The Oceans: Their Physics, Chemistry and General Biology. Prentice-Hall, New York, NY, 1942.

[43] A. Sy, M. Rhein, J.R.N. Lazier, K.P. Koltermann, J. Meincke, A. Putzka, and M. Bersch. Surprisingly rapid spreading of newly formed intermediate water across the North Atlantic Ocean. Nature, 386:675-679, 1997.

[44] L.D. Talley. Shallow, intermediate, and deep overturning components of the global heat budget. Journal of Physical Oceanography, 33:530-560, 2003.

[45] L.D. Talley and M.S. McCartney. Distribution and circulation of Labrador Sea water. Journal of Physical Oceanography, 12:1189-1205, 1982.

[46] J.M. Toole, K.W. Doherty, D.E. Frye, and S.P. Liberatore. Velocity measurements from a moored profiling instrument. In IEEE Sixth Working Conference on Current Measurement, 1999.

[47] M. Tsukernik, D. Kindig, and M.C. Serreze. Characteristics of winter cyclone activity in the northern North Atlantic: Insights from observations and regional modeling. Journal of Geophysical Research, submitted for publication. 
[48] R. Vautard. Multiple weather regimes over the North Atlantic: Analysis of precursors and successors. Monthly Weather Review, 118:2056-2081, 1990.

[49] H. Wattenberg. Die Verteilung des Sauerstoffs im Atlantischen Ozean. Verlag von Walter de Gruyter \& Co., Berlin, 1938.

[50] F.J. Wentz, D.K. Smith, C.A. Mears, and C.L. Gentemann. Advanced algorithms for QuikScat and SeaWinds/AMSR. In IGARSS'01 Proceedings, 2001.

[51] G. Wüst. Der subarktische Bodenstrom in der westatlantischen Mulde. Annalen der Hydrographie und Maritimen Meteorologie, Heft IV/VI:249-256, 1943. 